\title{
WELLHEAD PROTECTION AREA DELINEATION UNDER UNCERTAINTY
}

\author{
by
}

Elizabeth Jacobson

Roko Andricevic

Thomas Hultin

\section{DISCLAIMER}

\begin{abstract}
This report was prepared as an account of work sponsored by an agency of the United States Government. Neither the United States Government nor any agency thereof, nor any of their employees, makes any warranty, express or implied, or assumes any legal liability or responsibility for the accuracy, completeness, or usefulness of any information, apparatus, product, or process disclosed, or represents that its use would not infringe privately owned rights. Reference herein to any specific commercial product, process, or service by trade name, trademark, manufacturer, or otherwise does not necessarily constitute or imply its endorsement, recommendation, or favoring by the United States Government or any agency thereof. The views and opinions of authors expressed herein do not necessarily state or reflect those of the United States Government or any agency thereof.
\end{abstract}




\section{DISCLAIMER}

Portions of this document may be illegible in electronic image products. Images are produced from the best available original document. 
This report was prepared as an account of work sponsored by the United States Government. Neither the United States nor the United States Department of Energy, nor any of their employees, makes any warranty, express or implied, or assumes any legal liability or responsibility for the accuracy, completeness or usefulness of any information, apparatus, product or process disclosed, or represents that its use would not infringe privately owned rights. Reference herein to any specific commercial product, process, or service by trade name, mark, manufacturer, or otherwise, does not necessarily constitute or imply its endorsement, recommendation, or favoring by the United States Government or any agency thereof. The views and opinions of authors expressed herein do not necessarily state or reflect those of the United States Government or any agency thereof.

This report has been reproduced directly from the best available copy.

Available to DOE and DOE contractors from the Office of Scientific and Technical Information, P.O. Box 62, Oak Ridge, TN 37831; prices available from (615) 576-8401.

Available to the public from the National Technical Information Service, U.S. Department of Commerce, 5285 Port Royal Rd., Springfield, VA 22161. 


\title{
WELLHEAD PROTECTION AREA DELINEATION UNDER UNCERTAINTY
}

\author{
by \\ Elizabeth Jacobson \\ Roko Andricevic \\ Thomas Hultin \\ Water Resources Center \\ Desert Research Institute \\ University and Community College System of Nevada
}

Publication No. 45118

prepared for

Nevada Operations Office

U.S. Department of Energy

Las Vegas, Nevada

September 1994

The work upon which this report is based was supported by the U.S. Department of Energy under Contract \#DE-AC08-90NV10845. 


\section{CONTENTS}

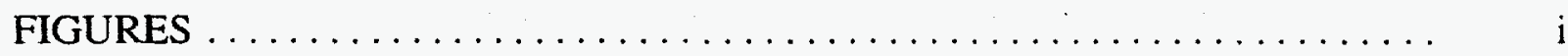

TABLES $\ldots \ldots \ldots \ldots \ldots \ldots \ldots \ldots \ldots \ldots \ldots \ldots \ldots \ldots \ldots \ldots \ldots \ldots \ldots \ldots \ldots \ldots \ldots$, iii

EXECUTIVE SUMMARY $\ldots \ldots \ldots \ldots \ldots \ldots \ldots \ldots \ldots \ldots \ldots \ldots \ldots \ldots \ldots \ldots \ldots$ iv

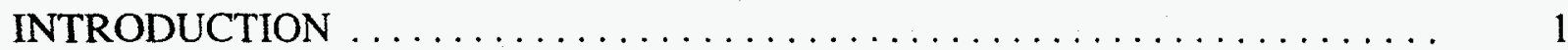

METHODOLOGY FOR WELLHEAD PROTECTION AREA
DELINEATION UNDER UNCERTAINTY $\ldots \ldots \ldots \ldots \ldots \ldots \ldots \ldots \ldots \ldots \ldots$.

WELLHEAD PROTECTION DELINEATION FOR THE

WATER-SUPPLY WELLS AT THE NEVADA TEST SITE $\ldots \ldots \ldots \ldots \ldots \ldots .6$

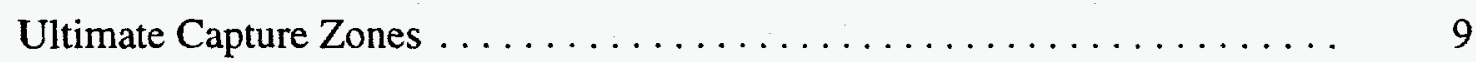

Time-Dependent Capture Zones $\ldots \ldots \ldots \ldots \ldots \ldots \ldots \ldots \ldots \ldots \ldots \ldots$

SUMMARY ............................................ 11

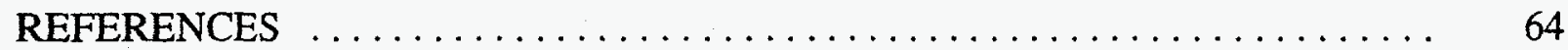

APPENDIX A: MATHEMATICAL DEVELOPMENT OF METHODOLOGY

FOR WELLHEAD PROTECTION AREA DELINEATION

UNDER UNCERTAINTY $\ldots \ldots \ldots \ldots \ldots \ldots \ldots \ldots \ldots \ldots \ldots \ldots \ldots \ldots \ldots$

\section{FIGURES}

1. Schematic of pumping well in a regional flow system; shown in (a) vertical profile

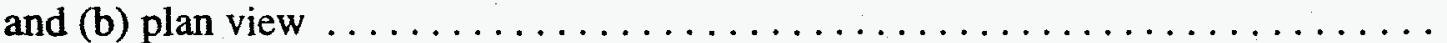

2. Capture zones corresponding to the deterministic (i.e., 0.50 value) curve and two bounding curves corresponding to the reliability levels shown on the curves.

3. Schematic of two capture zones for a specified reliability level $\ldots \ldots \ldots \ldots \ldots \ldots$

4. Map of the NTS showing the location of 14 water-supply wells $\ldots \ldots \ldots \ldots \ldots$

5. NTS water table map $\ldots \ldots \ldots \ldots \ldots \ldots \ldots \ldots \ldots \ldots \ldots \ldots \ldots \ldots \ldots \ldots$

6a. Ultimate capture zone for the $50 \%$ reliability level for Well Army \#1 ........ 13

6b. Ultimate capture zones for the $95 \%$ reliability level for Well Army $\# 1 \ldots \ldots \ldots \ldots \quad 14$

7a. Ultimate capture zone for the $50 \%$ reliability level for Well J-12 $\ldots \ldots \ldots \ldots \ldots$

7b. Ultimate capture zones for the $95 \%$ reliability level for Well $\mathrm{J}-12 \ldots \ldots \ldots \ldots \ldots$

8a. Ultimate capture zone for the $50 \%$ reliability level for Well J-13 $\ldots \ldots \ldots \ldots \ldots$

8b. Ultimate capture zones for the $95 \%$ reliability level for Well J-13 . . . . . . . 18

9a. Ultimate capture zone for the $50 \%$ reliability level for Well 5B $\ldots \ldots \ldots \ldots \ldots .10$

9b. Ultimate capture zones for the $95 \%$ reliability level for Well 5B $\ldots \ldots \ldots \ldots \ldots 20$ 
10a. Ultimate capture zone for the $50 \%$ reliability level for Well $5 \mathrm{C} \ldots \ldots \ldots \ldots \ldots 21$

10b. Ultimate capture zones for the $95 \%$ reliability level for Well $5 \mathrm{C} \ldots \ldots \ldots \ldots \ldots 22$

11a. Ultimate capture zone for the $50 \%$ reliability level for Well UE-5C $\ldots \ldots \ldots \ldots .23$

11b. Ultimate capture zones for the $95 \%$ reliability level for Well UE-5C $\ldots \ldots \ldots \ldots 24$

12a. Ultimate capture zone for the $50 \%$ reliability level for Wells 4 and $4 \mathrm{~A} \ldots \ldots \ldots 25$

12b. Ultimate capture zones for the $95 \%$ reliability level for Wells 4 and $4 \mathrm{~A} \ldots \ldots \ldots 26$

13a. Ultimate capture zone for the $50 \%$ reliability level for Wells $\mathrm{C}$ and $\mathrm{C}-1 \ldots \ldots \ldots \ldots 27$

13b. Ultimate capture zones for the $95 \%$ reliability level for Wells $\mathrm{C}$ and $\mathrm{C}-1 \ldots \ldots \ldots 28$

14a. Ultimate capture zone for the $50 \%$ reliability level for Well UE-16d . . . . . . . . 29

14b. Ultimate capture zones for the $95 \%$ reliability level for Well UE-16d ......... 30

15a. Ultimate capture zone for the $50 \%$ reliability level for Well $8 \ldots \ldots \ldots \ldots \ldots .31$

15b. Ultimate capture zones for the $95 \%$ reliability level for Well $8 \ldots \ldots \ldots \ldots \ldots, 32$

16a. Ultimate capture zone for the $50 \%$ reliability level for Well UE-19c ......... 33

16b. Ultimate capture zones for the $95 \%$ reliability level for Well UE-19c ........ 34

17a. Ultimate capture zone for the $50 \%$ reliability level for Well $U-20 \ldots \ldots \ldots \ldots \ldots$

17b. Ultimate capture zones for the $95 \%$ reliability level for Well $\mathrm{U}-20 \ldots \ldots \ldots \ldots . \ldots 36$

18. Time-dependent capture zones for the $50 \%$ reliability level for Well J-13 $\ldots \ldots \ldots \quad 37$

18b. Time-dependent capture zones for the $67 \%$ reliability level for Well J-13 . . . . . 38

18c. Time-dependent capture zones for the $95 \%$ reliability level for Well $\mathrm{J}-13 \ldots \ldots \ldots 39$

19a. Time-dependent capture zones for the $50 \%$ reliability level for Well $5 B \ldots \ldots \ldots .40$

19b. Time-dependent capture zones for the $67 \%$ reliability level for Well 5B $\ldots \ldots \ldots \ldots 41$

19c. Time-dependent capture zones for the $95 \%$ reliability level for Well $5 \mathrm{~B} \ldots \ldots \ldots \quad 42$

20a. Time-dependent capture zones for the $50 \%$ reliability level for Well $5 \mathrm{C} \ldots \ldots \ldots \quad 43$

20b. Time-dependent capture zones for the $67 \%$ reliability level for Well $5 \mathrm{C} \ldots \ldots \ldots \ldots \quad 44$

20c. Time-dependent capture zones for the $95 \%$ reliability level for Well $5 \mathrm{C} \ldots \ldots \ldots \quad 45$

21a. Time-dependent capture zones for the 50\% reliability level for Well UE-5C $\ldots \ldots .46$

21b. Time-dependent capture zones for the $67 \%$ reliability level for Well UE-5C $\ldots \ldots .47$

21c. Time-dependent capture zones for the $95 \%$ reliability level for Well UE-5C . . . . 48 
22a. Time-dependent capture zones for the $50 \%$ reliability level for Wells 4 and $4 \mathrm{~A} \ldots \ldots$

22b. Time-dependent capture zones for the $67 \%$ reliability level for Wells 4 and $4 \mathrm{~A} \ldots \ldots$

22c. Time-dependent capture zones for the $95 \%$ reliability level for Wells 4 and $4 \mathrm{~A} \ldots \ldots 1$

23a. Time-dependent capture zones for the $50 \%$ reliability level for Well UE-16d . . . . 52

23b. Time-dependent capture zones for the $67 \%$ reliability level for Well UE-16d . . . . 53

23c. Time-dependent capture zones for the $95 \%$ reliability level for Well UE-16d . . . . . 54

24a. Time-dependent capture zones for the $50 \%$ reliability level for Well $8 \ldots \ldots 5$

24b. Time-dependent capture zones for the $67 \%$ reliability level for Well $8 \ldots \ldots 6$

24c. Time-dependent capture zones for the $95 \%$ reliability level for Well $8 \ldots \ldots 7$

25a. Time-dependent capture zones for the $50 \%$ reliability level for Well UE-19c . . . . 58

25b. Time-dependent capture zones for the $67 \%$ reliability level for Well UE-19c . . . . . 59

25c. Time-dependent capture zones for the $95 \%$ reliability level for Well UE-19c . . . . 60

26a. Time-dependent capture zones for the $50 \%$ reliability level for Well U-20 . . . . 61

26b. Time-dependent capture zones for the $67 \%$ reliability level for Well U-20 . . . . . 62

26c. Time-dependent capture zones for the $95 \%$ reliability level for Well U-20 . . . . . 63

\section{LIST OF TABLES}

1. Hydraulic Properties and their Statistics for Each Water-Supply Well at the NTS. . .

2. Maximum Upgradient Width of Ultimate Capture Zone for Each

Water-Supply Well at the NTS. 


\section{EXECUTIVE SUMMARY}

A program to protect groundwater resources used for water supply from all potential threats due to contamination was established in the Amendments to the Safe Drinking Water Act (SDWA). The goal of the State Wellhead Protection (WHP) Program is to "protect wellhead areas within their jurisdiction from contaminants which may have any adverse effect on the health of persons." A major component of WHP is the determination of zones around water-supply wells called Wellhead Protection Areas (WHPAs) within which contaminant source assessment and management should be addressed. WHPAs are defined in the SDWA as "the surface and subsurface area surrounding a water well or wellfield, supplying a public water system, through which contaminants are reasonably likely to move toward and reach such water well or wellfield." A total of 14 water-supply wells are currently being used at the Nevada Test Site (NTS). Eleven of the wells are used for potable water supplies and the remaining three wells are used for construction purposes only. The purpose of this study as conducted by the Desert Research Institute (DRI) for the Department of Energy, Nevada Operations Office (DOE/NV), is to estimate WHPAs for each water-supply well at the NTS. Due to the limited information about the hydraulic properties needed for estimating the WHPAs, an approach that considered the uncertainty in the estimates of the hydraulic properties was developed and implemented.

The delineation of WHPAs as suggested by the U.S. Environmental Protection Agency is based on a steady-state analytic solution of a groundwater flow system that consists of a pumping well in a homogeneous aquifer with a regional gradient. The zone of influence (ZOI) corresponds to the drawdown curve and is related to the hydraulics of the system, not necessarily actual contaminant movement. The zone of capture represents the WHPA for the flow system and varies depending on the time period of desired well protection. The ultimate capture zone, also called the zone of contribution (ZOC), assumes infinite time available for travel of a contaminant and is terminated upgradient at the groundwater divide for the flow system. The time-dependent capture zone, also called the zone of transport (ZOT), is determined based on the distance a contaminant can travel in the selected time period. Both ultimate and time-dependent capture zones that considered uncertainties in the estimates of the hydraulic properties were developed for the water-supply wells at the NTS.

In this report, the focus is on the parameter uncertainty, the uncertainty in the modeling of capture zones coming primarily from the uncertainty in the magnitude and direction of the regional flow. At this stage, the spatial variability of the regional flow is not considered, only the uncertainty of the parameters used to form the analytical model of the capture zone. In general, the magnitude of the mean regional flow is not measured, but rather estimated indirectly using a form of Darcy's law, $q=T J$, where $T$ is the aquifer transmissivity and $J$ is the hydraulic head gradient. Since these parameters are estimated from the scarce field data, they are subject to an estimation error which produces the total uncertainty in the regional flow estimate. The approach uses the uncertainties in $T$ and $J$ to estimate the corresponding uncertainty in the $q$ which, in turn, produces the uncertainty in the capture zone. The magnitude of the regional flow and its direction are treated separately. Ultimate capture zones are generated for the 50 percent and 95 percent reliability levels where the reliability level corresponds to a level of confidence. The meaning of the 95 percent capture zone corresponds to the statement that there is a 95 percent level of confidence that the size of that specific 
capture zone is large enough to encompass the entire capture zone for that well. The capture zone for the 50 percent reliability level corresponds to the deterministic capture zone based on the mean values of the hydraulic properties. The width of the capture zone is influenced by the uncertainty in the magnitude of the regional flow. The uncertainty in the flow direction produces two capture zones for each reliability level. For example, the two capture zones for the 67 percent reliability level are generated by calculating the $q$ value that represents one standard deviation from its mean value, using this $q$ value to determine the shape of the capture zone and then rotating that capture zone from the mean regional flow direction to the two angles that represent the plus and minus one standard deviation from the mean angle. The outer envelope of these two capture zones is the 67 percent reliability level capture zone. This envelope represents the total capture zone given the uncertainties in $q$ and angle $\alpha$ at a certain reliability level. Time-dependent capture zones were generated for the 50 percent, 67 percent and 95 percent reliability level for the width of the capture zone.

Ultimate and time-dependent capture zones were generated based on the best available information on the hydraulic properties, pumping rates, and well construction. Information on the hydraulic properties needed for calculating the capture zones was obtained from reports. The hydraulic head gradient, both magnitude and direction, for each well is based on the water table map generated by Boughton (1986).

Ultimate capture zones were estimated for the water-supply wells. The ultimate capture zones were not extended to the groundwater divide because information on the location of a divide is unavailable. Only a finite length of the ultimate capture zone was shown to demonstrate the general shape of the capture zones. For water-supply wells J-12, J-13,UE-5C, combined 4 and $4 \mathrm{~A}$, combined $\mathrm{C}$ and $\mathrm{C}-1$, and 8 , the ultimate capture zones are very narrow. These narrow ultimate capture zones are produced primarily by the comparatively larger estimated value for regional flow relative to a low pumping rate.

Time-dependent capture zones were estimated for the water-supply wells. The time-dependent capture zones are long and narrow for wells J-12, J-13, UE-5C, combined 4 and 4A, combined C and $\mathrm{C}-1$, and 8 . This shape for these capture zones is again due to the comparatively larger regional flow relative to a low pumping rate, as was seen for the ultimate capture zones. Wells 5B, UE-16d, and U-20 have time-dependent capture zones similar to the expected shapes. The time-dependent capture zones for wells 5C and UE-19c are close to circular in shape. The circular shape for a time-dependent zone is due to very low regional flow compared to the pumping rate of the well.

Due to the lack of studies conducted at the NTS regarding the quantification of subsurface heterogeneity of the basic aquifer properties (e.g., hydraulic conductivity, porosity) and the resulting transport characteristics for mobile radionuclides, several simplifying assumptions are employed. These are:

1. homogeneity and isotropy of hydraulic properties (e.g., hydraulic conductivity, porosity);

2. conservative and advective transport only;

3. uniform hydraulic head gradient and pumping rates; and

4. steady-state flow conditions.

While assumptions 3 and 4 are less likely to significantly alter the estimated capture zones, assumptions 1 and 2 are known to be violated for the complex hydrogeological settings at the NTS. 
At the present time, no information is available such that conditions 1 and 2 do not have to be assumed; therefore, this study employed the uncertainty in the mean flow magnitude and direction to indirectly account for the present lack of knowledge regarding the subsurface heterogeneity structure and other important transport properties. Information from additional studies aimed at quantifying the subsurface heterogeneity (at various scales) at the NTS is necessary to describe the groundwater flow and radionuclide transport processes with some confidence. 


\section{INTRODUCTION}

A program to protect groundwater resources used for water supply from all potential threats due to contamination was established in the 1986 Amendments to the Safe Drinking Water Act (SDWA). The goal of the State Wellhead Protection (WHP) Program is to "protect wellhead areas within their jurisdiction from contaminants which may have any adverse effect on the health of persons." A major component of WHP is the determination of zones around water-supply wells called Wellhead Protection Areas (WHPAs) within which contaminant source assessment and management should be addressed. WHPAs are defined in the SDWA as "the surface and subsurface area surrounding a water well or wellfield, supplying a public water system, through which contaminants are reasonably likely to move toward and reach such water well or wellfield." A total of 14 water-supply wells are currently being used at the Nevada Test Site (NTS). Eleven of the wells are used for potable water supplies and the remaining three wells are used for construction purposes only. The purpose of this study as conducted by the Desert Research Institute (DRI) for the Department of Energy, Nevada Operations Office (DOE/NV), is to estimate WHPAs for each water-supply well at the NTS. Due to the limited information about the hydraulic properties needed for estimating the WHPAs, an approach that considered the uncertainty in the estimates of the hydraulic properties was developed and implemented.

The delineation of WHPAs as suggested by the U.S. Environmental Protection Agency (EPA) is based on a steady-state analytic solution of a groundwater flow system that consists of a pumping well in a homogeneous aquifer with a regional gradient, schematically shown in Figure 1 . The zone of influence (ZOI) corresponds to the drawdown curve shown in Figure la and is related to the hydraulics of the system, not necessarily actual contaminant movement. The zone of capture represents the WHPA for the flow system and varies depending on the time period of desired well protection. The ultimate capture zone, also called the zone of contribution (ZOC), assumes infinite time available for travel of a contaminant and is terminated upgradient at the groundwater divide for the flow system. The time-dependent capture zone, also called the zone of transport (ZOT), is determined based on the distance a contaminant can travel in the selected time period. Both ultimate and time-dependent capture zones that considered uncertainties in the estimates of the hydraulic properties were developed for the water-supply wells at the NTS.

The ultimate capture zone, as shown in Figure 1b, is obtained by solution of the following equations:

$$
\left(\frac{y}{x}\right)=\tan \left[\frac{+2 \pi q \theta}{Q}\right] y>0 ;\left(\frac{y}{x}\right)=-\tan \left[\frac{+2 \pi q \theta}{Q}\right] y<0
$$

where $Q$ is the well pumping rate, $q=T J, T$ is transmissivity of the aquifer, $J$ is the regional hydraulic head gradient, $\theta=(-x \sin \alpha+y \cos \alpha)$ and $\alpha$ is the angle between the $\mathrm{x}$-axis and the direction of uniform regional flow. The derivation of equation (1) is found in Appendix A. As $x$ becomes large, the width of the ultimate capture zone approaches the finite limits 

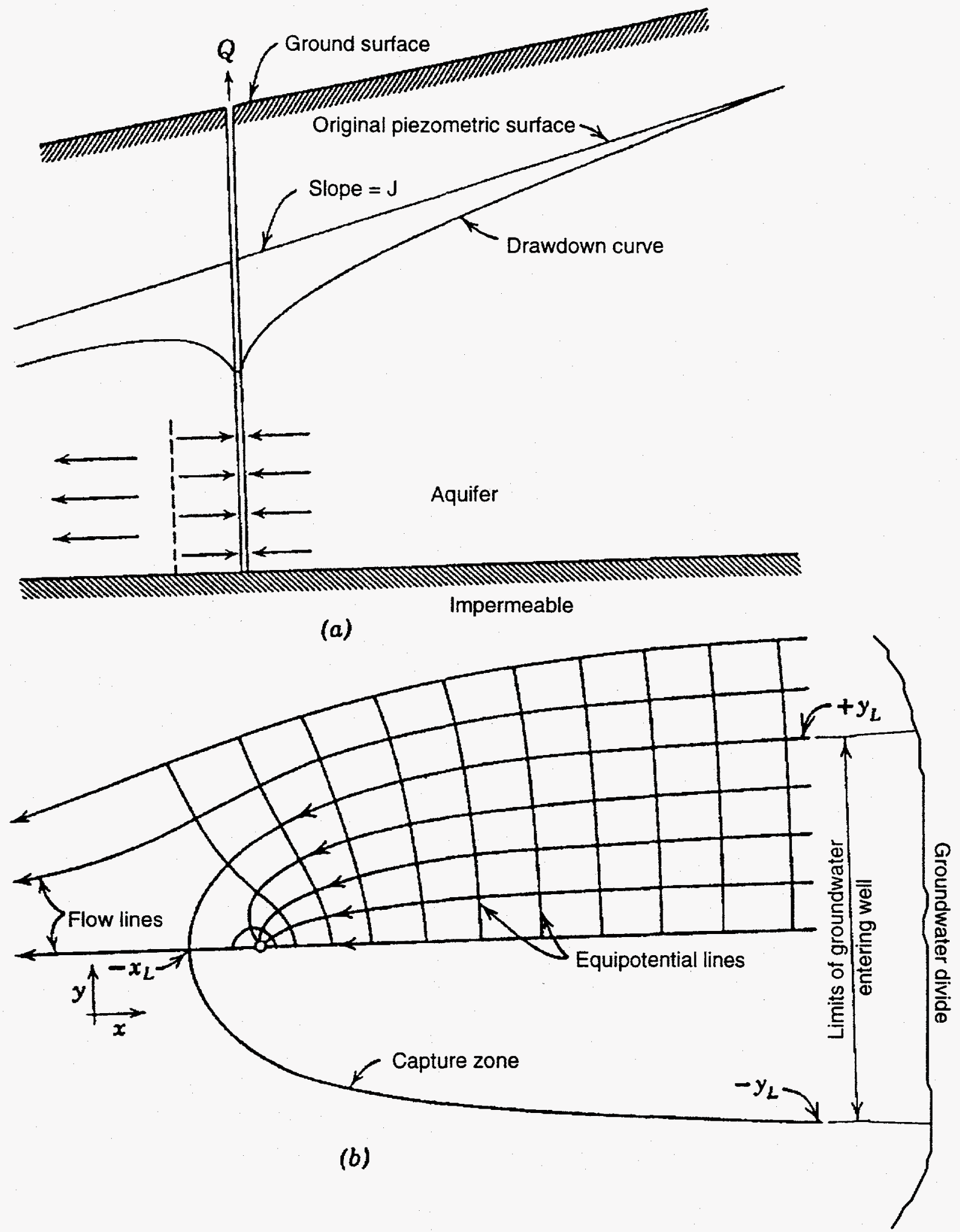

Figure 1. Schematic of pumping well in a regional flow system; shown in (a) vertical profile and (b) plan view (after Todd, 1980). 


$$
y_{L}= \pm \frac{Q}{2 T J}
$$

as shown in Figure $\mathrm{lb}$. The boundary of the capture zone extends downstream to a stagnation point, $\mathrm{x}_{\mathrm{L}}$, where

$$
x_{L}=-\frac{Q}{2 \pi T J}
$$

as indicated in Figure $1 \mathrm{~b}$.

The ultimate capture zone can be obtained from equation (1) given information on the well pumping rate, transmissivity of the aquifer, regional hydraulic head gradient and direction of the uniform regional flow. However, calculation of the time-dependent capture zone also requires information on the porosity of the aquifer, $n$, and the aquifer thickness, $b$, which is usually assumed to be the thickness of the screened interval of the well if the actual aquifer thickness is unknown. To calculate a time-dependent capture zone, the flow pattern shown in Figure $1 \mathrm{~b}$ is used and particles are moved along the flowlines a distance determined from the time of travel and the velocity. The velocity components in the $\mathrm{x}$ and $\mathrm{y}$ direction are

$$
v_{x}=-\frac{T}{b n} \frac{\partial H}{\partial x} \text { and } \quad v_{y}=-\frac{T}{b n} \frac{\partial H}{\partial y}
$$

where $H$ is the hydraulic head for the flow system. Both the ultimate and time-dependent capture zones are based on the set of parameters that are assumed to be perfectly known. A deterministic solution is based on these representative values for the various model parameters. They usually represent a mean or average value of the system. Since perfect knowledge in model parameters is seldom the case, the influence of the uncertainty becomes a major factor.

There are numerous sources of uncertainty which can influence the formation of capture zones around a pumping well. These uncertainties can range from the conceptual modeling uncertainty, uncertainty in the selected form of a mathematical model, and parameter uncertainty. It is important to identify what is the most important source of uncertainty for a particular case. In this report, the focus is on parameter uncertainty, the uncertainty in the modeling of capture zones coming primarily from the uncertainty in the magnitude and direction of the regional flow. At this stage, the spatial variability of the regional flow is not considered, only the uncertainty of the parameters used to form the analytical model of the capture zone. In addition, the model uncertainty in representing the complex groundwater flow patterns found at the NTS by the simplified analytical model is not addressed and may be a significant component in the total uncertainty in the capture zones.

\section{METHODOLOGY FOR WELLHEAD PROTECTION AREA DELINEATION UNDER UNCERTAINTY}

The ability to determine the capture zones conditioned on the uncertainty in the mean regional flow is a first step in delineating the WHPA. In general, the mean flow is not measured, but rather 
estimated indirectly using a form of Darcy's law, $q=T J$, where $T$ is the aquifer transmissivity and $J$ is the hydraulic head gradient. These parameters are estimated from the scarce field data, thus they are subject to an estimation error which produces the total uncertainty in the regional flow estimate, $q$. If both $T$ and $J$ are lognormally distributed, then so is $q$ (Benjamin and Cornell, 1970). The mean and variance of $q$ is estimated based on the means and variances of $T$ and $J$. The uncertainty in $q$ causes variations in the capture zone as shown in Figure 2. The mean capture zone as indicated by the 0.50 curve in Figure 2 is the deterministic capture zone based on the mean $q$ value. Capture zones that represent various reliability levels can be determined based on the appropriate uncertainty in the $q$ value for the given reliability level. For example, the 0.67 and the 0.33 percent reliability level capture zones shown in Figure 2 represent the curves generated by the $q$ values obtained from subtracting and adding, respectively, one standard deviation to the mean $q$ value. The larger $q$ value yields a narrower capture zone upgradient (the 0.33 reliability level curve), whereas the smaller $q$ value produces a wider capture zone upgradient (the 0.67 reliability level curve). The 67 percent reliability level capture zone means there is a 67 percent reliability that the capture zone is large enough to include the true capture zone given the uncertainty in the mean flow $q$.

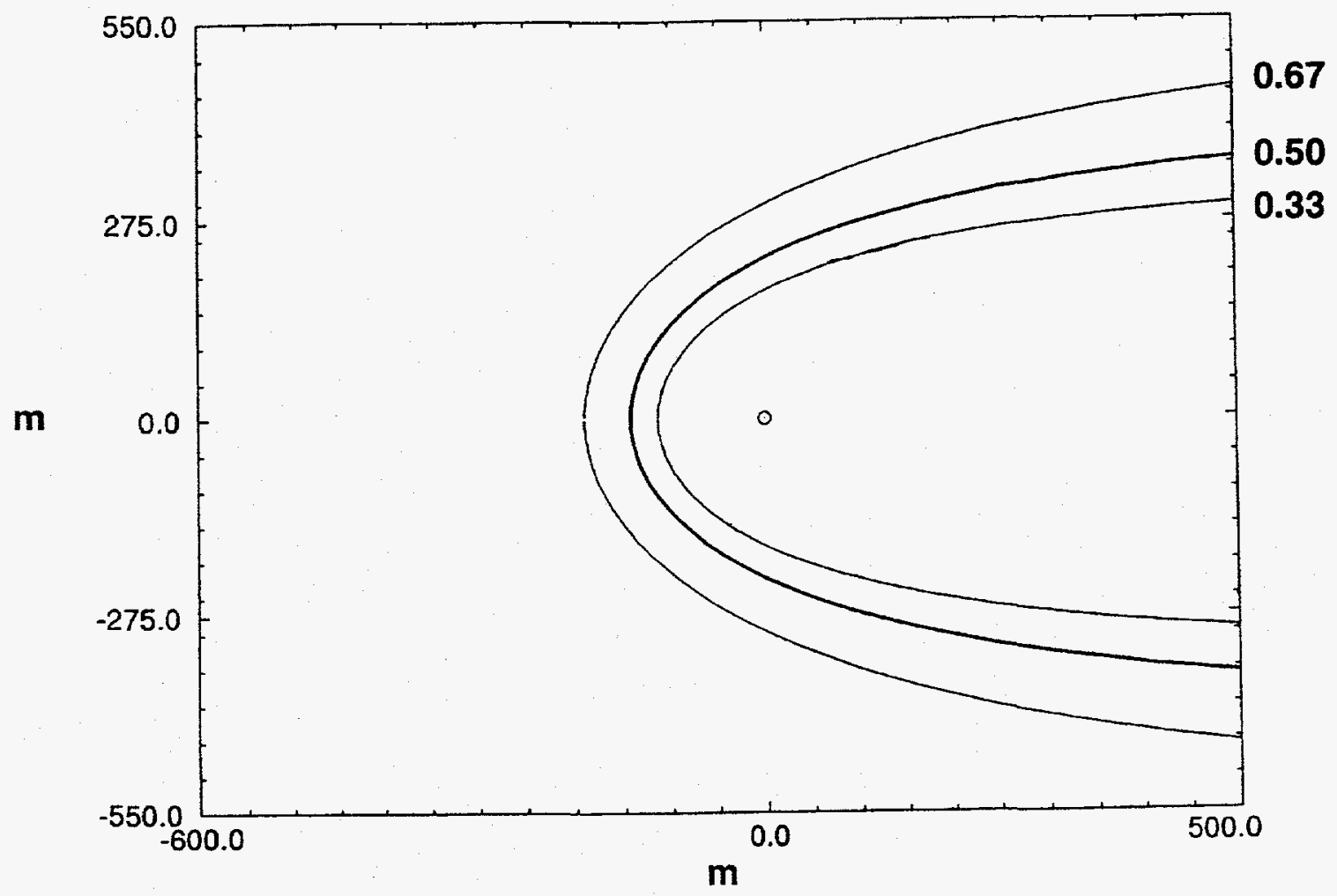

Figure 2. Capture zones corresponding to the deterministic (i.e., 0.50 value) curve and two bounding curves corresponding to the reliability levels shown on the curves. 
The uncertainty in the capture zone caused by the uncertainty in the angle $\alpha$ can be estimated in the same manner based on the reliability level. Assuming $a$ is normally distributed, the 67 percent reliability level will correspond to two angles that are equal to the mean $a$ plus and minus one standard deviation of the angle. The two capture zones for the 67 percent reliability level are generated by calculating the $q$ value that represents one standard deviation from its mean value, using this $q$ value to determine the shape of the capture zone and then rotating that capture zone from the mean regional flow direction to the two angles that represent the plus and minus one standard deviation from the mean angle. The outer envelope of these two capture zones is the 67 percent reliability level capture zone. This envelope represents the total capture zone given the uncertainties in $q$ and angle $a$ at a certain reliability level. A schematic of two capture zones and the outer envelope is shown in Figure 3. The 95 percent reliability level corresponds to two standard deviations in uncertainty of $q$ and $a$, whereas the 67 percent reliability level corresponds to one standard deviation in uncertainty.

A detailed mathematical derivation of the methodology for wellhead protection area delineation under uncertainty is given in Appendix A.

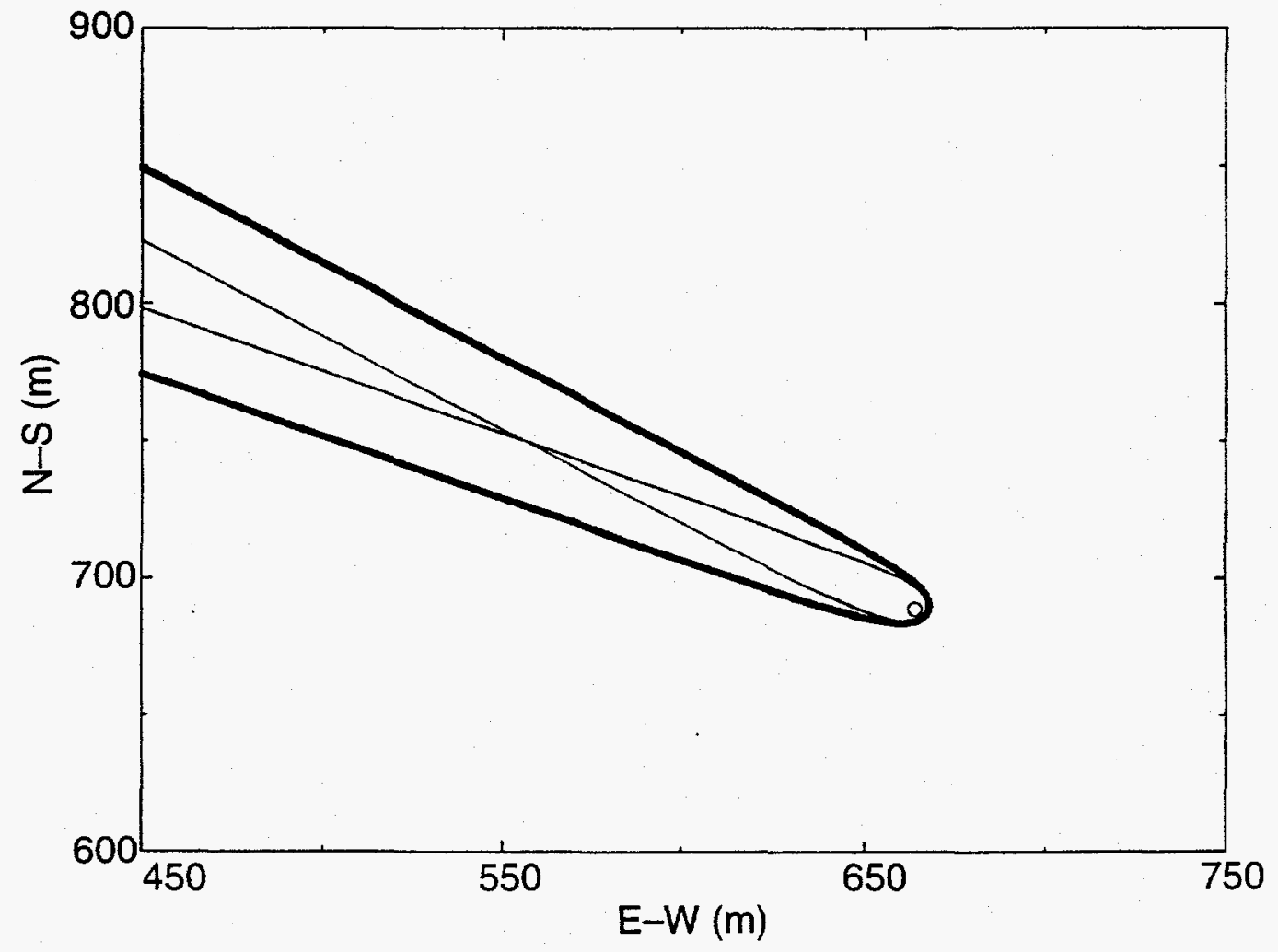

Figure 3. Schematic of two capture zones for a specified reliability level. Heavy line indicates outer envelope for the two curves. 


\section{WELLHEAD PROTECTION DELINEATION UNDER UNCERTAINTY FOR THE WATER-SUPPLY WELLS AT THE NEVADA TEST SITE}

A total of 14 water-supply wells are currently being used at the NTS and their locations are shown in Figure 4. Coordinates for these wells, along with well construction details, were taken from the Raytheon Services Nevada (1991) "Red Book." The gradients and direction of groundwater flow for all 14 wells were determined by using the NTS water table map prepared by Boughton (1986), as shown in Figure 5. This water table map is based on computer-generated contours of hydraulic heads and is only one possible representation of the hydraulic heads because of the sparse head data available for use in the contouring. As additional hydraulic head data from new wells are collected, the hydraulic head map for the NTS can be modified and any changes to head gradients and directions of groundwater flow can be used to generate new capture zones where appropriate. Pumping rates for all of the wells, with the exception of water well 4A for which there are no data yet, were obtained from David Wood (U.S. Geological Survey, personal communication).

Wells $\mathrm{C}$ and $\mathrm{C}-1$ were combined and treated as one well since they are only 30 meters apart, as were wells 4 and $4 \mathrm{~A}$, which are 360 meters apart and each pair has identical means and standard deviations in $T, J$ and $\alpha$. In these two cases, the total pumping rate for the combined well was the sum of the pumping rates for the two wells and the total thickness was the sum of the thicknesses for the two wells.

Capture zones were generated for each of the supply wells using equation (1) with the appropriate statistics on regional flow. Estimates of the mean and variance for transmissivity and the magnitude of the regional gradient were needed to obtain the mean and variance for the $q$ parameter. In general, limited information about the hydraulic properties is available for the various wells at the NTS and statistical information is unavailable. Thus, the statistical information for transmissivity was based on the best judgement of the authors concerning the possible ranges in values of transmissivity for a given area. In general, the range in transmissivity was assumed to be one order of magnitude and the statistics were developed to reproduce this range. The statistical information for the regional gradient was obtained from the NTS water table map prepared by Boughton (1986). The estimates of the means and variances for the regional gradient at each well were obtained by having several individuals estimate the regional gradient using the water table map. The range in their results was used to estimate the mean of variance of the regional gradient for each well. The mean angle of the regional gradient was estimated based on a similar procedure with the variance in the angle taken as 15 degrees at each well to allow for the larger uncertainty in the flow direction expected because of the limited hydraulic head data used to obtain the NTS water table map. Once mean values and standard deviations were derived for the log of transmissivity and the $\log$ of hydraulic head gradient, the mean of $\log q$ and its associated variance $\sigma^{2} \ln q$ are calculated from the equations presented in Appendix A. The correlation coefficient between the $\ln T$ and $\ln J$ terms for the regional flow was assumed to be -0.8 because for a given regional flow, $T$ is inversely proportional to $J$.

The information on hydraulic properties and their statistics, pumping rates and well construction used to generate the capture zones for each well is given in Table 1 . The transmissivity 


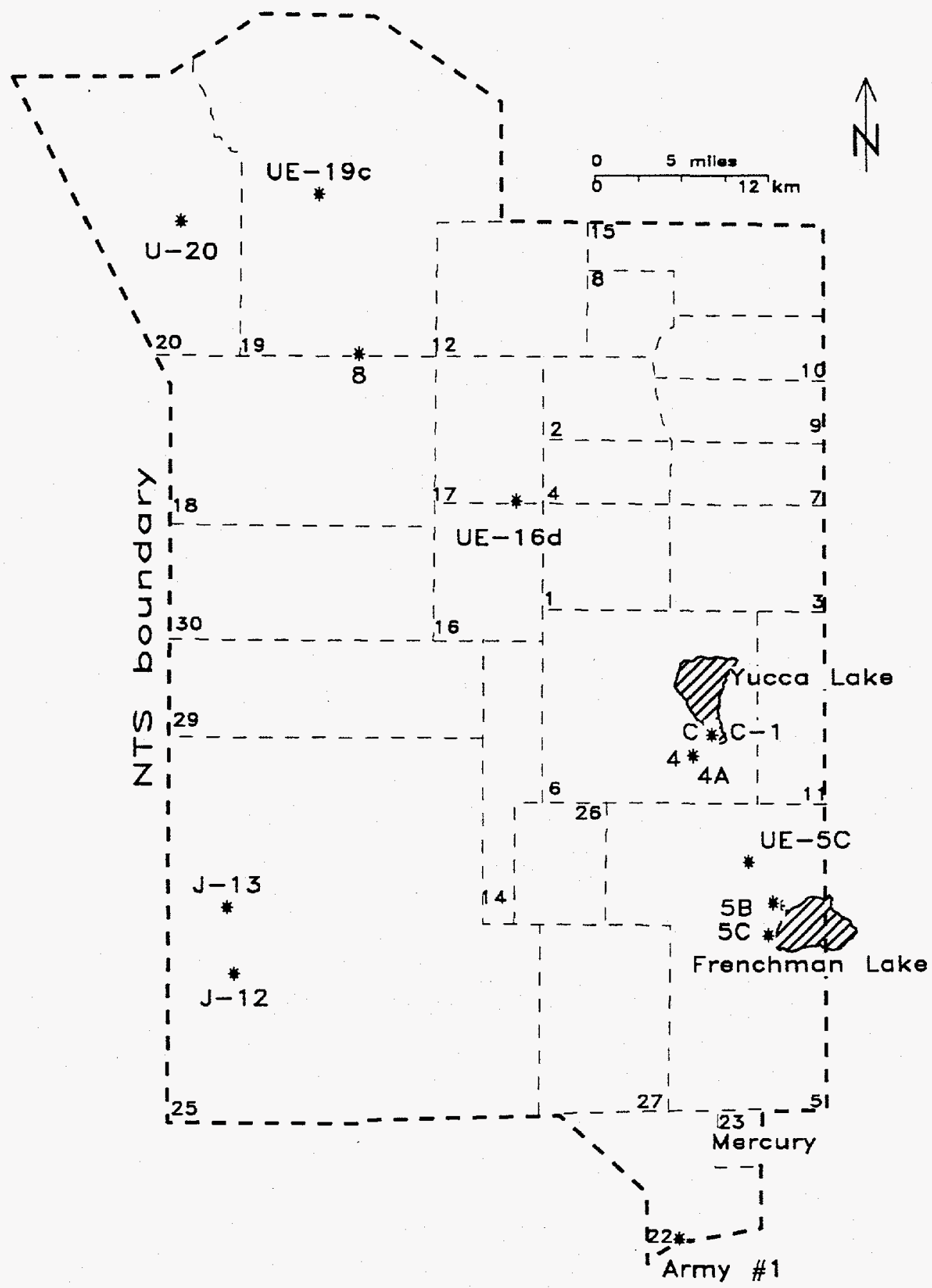

Figure 4. Map of the NTS showing the location of 14 water-supply wells. 


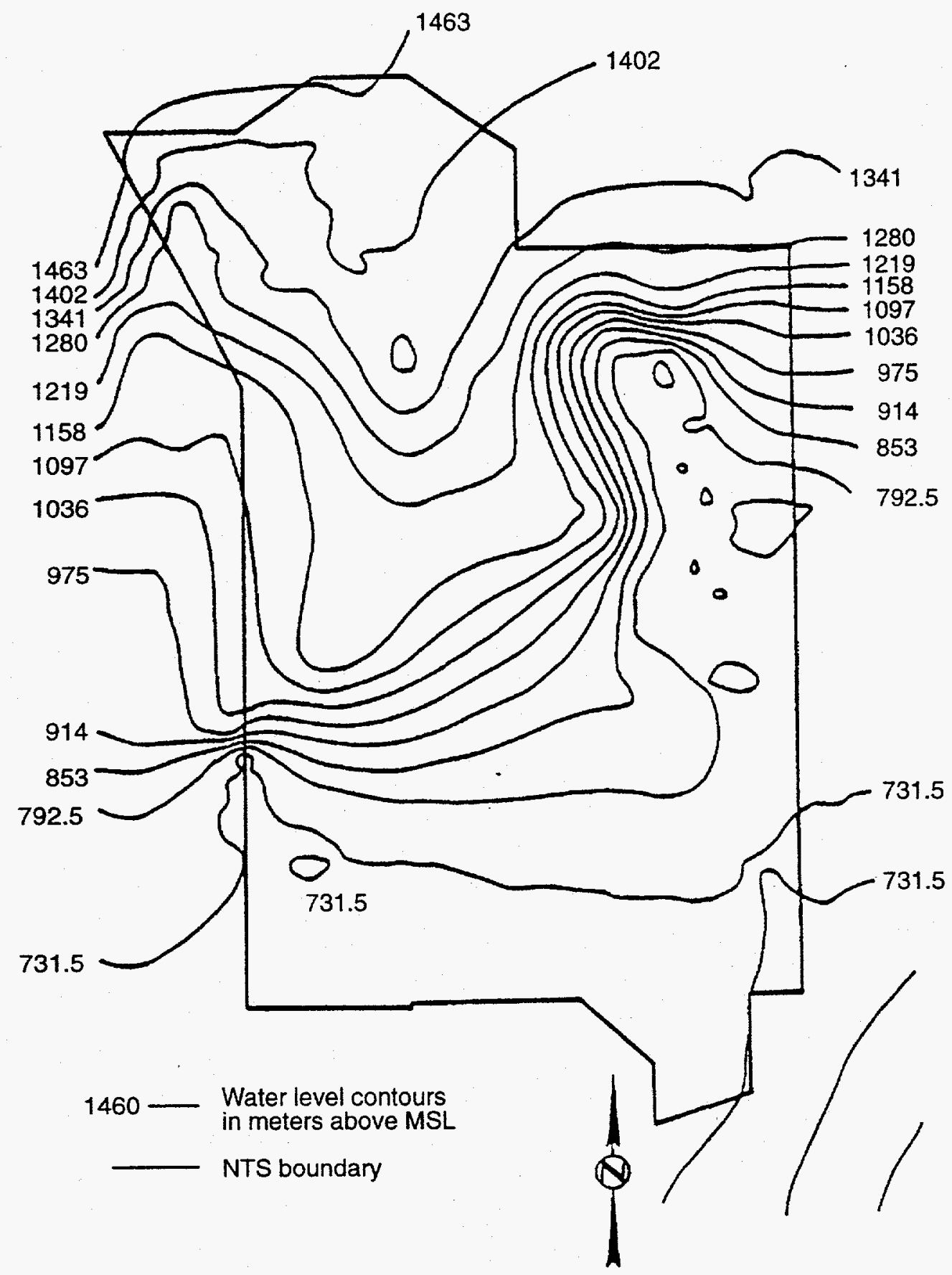

Figure 5. NTS water table map (after Boughton, 1986). 
estimates were obtained from Winograd and Thordarson (1975), Raytheon Services Nevada (1990), and Blankennagel and Weir (1973). The well location and construction information was compiled from Raytheon Services Nevada (1991) and Arteaga et al. (1991). The thicknesses were based on the open or screened interval of the wells because no information was available about the actual intervals supplying the water to the wells. The porosity values for each well were estimated based on interval of completion. A porosity of 0.02 was assumed for the carbonate units, 0.05 for the tuff units, and 0.15 for the alluvium units (Sadler, 1990; Blankennagel and Weir, 1973).

\section{Ultimate Capture Zones}

Ultimate capture zones for 50 percent and 95 percent reliability levels were estimated for the water-supply wells and presented on individual maps. The figure number for each water-supply well map is listed in Table 1. The ultimate capture zones shown in the figures have not been extended to the groundwater divide because information on the location of a divide is unavailable. Only a finite length of the ultimate capture zone has been shown in the figures to demonstrate the general shape of the capture zones. For water-supply wells J-12, J-13, UE-5C, combined 4 and 4A, combined $\mathrm{C}$ and $\mathrm{C}-1$, and 8 , the ultimate capture zones are very narrow, as plotted on the figures. The maximum width of the ultimate capture zone for the 50 percent reliability level as calculated from equation (2) is given in Table 2 for each well. The maximum width for the wells listed above is $57 \mathrm{~m}$ or less. These narrow ultimate capture zones are produced primarily by the relatively larger regional flow $(q)$ caused by larger $T$ values together with the $J$ values, but at times combined with a low pumping rate.

The uncertainty on the angle of the regional flow was, in general, smaller for the ultimate capture zone than the values listed in Table 1. The standard deviation of the angle used to generate the 95 percent reliability level capture zone is included in the corresponding figure caption for each well. The smaller uncertainty in angle is based on error in estimating the angle from the water table map of Boughton (1986). The objective in estimating the ultimate capture zone for each well is to observe the effect of the large-scale regional flow as represented by the water table map. The time-dependent capture zones are influenced more by the local-scale flow and may have higher uncertainties in flow direction.

\section{Time-Dependent Capture Zones}

Time-dependent capture zones for 50 percent, 67 percent and 95 percent reliability levels were estimated for the water-supply wells. The figure number for each well is listed in Table 1 with the time periods used to generate the curves. Time-dependent capture zones for water-supply wells Army \#1, J-12, and combined C and C-1 are not presented because they are very similar to the ultimate capture zones. To represent possible variations in the local-scale flow patterns over time, a larger uncertainty in the flow direction of $\sigma_{\alpha}$ equal to 15 degrees was used. This leads to more conservative estimates in the width or spread of the capture zone perpendicular to the mean flow direction. Thus, the time-dependent capture zones represent a certain reliability level, such as 67 percent or 95 percent, in the width of the capture zone. The upgradient length of the time-dependent capture zone is best represented by the deterministic (or 50 percent) capture zone because as the 
Table 1. Hydraulic Properties and their Statistics for Each Water-Supply Well at the NTS.

\begin{tabular}{|c|c|c|c|c|c|c|c|c|c|c|c|c|c|c|}
\hline Well & $\begin{array}{c}X \\
\text { (east) } \\
(\mathrm{m})\end{array}$ & $\begin{array}{c}\mathrm{Y} \\
\text { (north) } \\
(\mathrm{m})\end{array}$ & $\begin{array}{c}\mathrm{Q} \\
\left(\mathrm{m}^{3} / \mathrm{day}\right)\end{array}$ & $\begin{array}{c}\mathrm{T} \\
\left(\mathrm{m}^{2} / \text { day }\right)\end{array}$ & $\left(\begin{array}{c}\mathrm{sT} \\
\left(\mathrm{m}^{2} / \text { day }\right)\end{array}\right.$ & J & $s_{\mathbf{J}}$ & a & $s_{\alpha}$ & $\mathrm{n}$ & $\begin{array}{c}\mathrm{b} \\
(\mathrm{m})\end{array}$ & $\begin{array}{l}\text { Ultimate } \\
\text { Capture } \\
\text { Zone Figs. }\end{array}$ & $\begin{array}{c}\text { Time- } \\
\text { Dependent } \\
\text { Capture Zone Figs. }\end{array}$ & $\begin{array}{l}\text { Time } \\
\text { (yrs) }\end{array}$ \\
\hline Army 1 & 208719 & 204491 & 1446 & 1190 & 585 & 0.0054 & .0009 & 124 & 15 & .02 & 76 & $6 a, b$ & $6 a, b$ & 10 \\
\hline $\mathrm{J}-12$ & 177092 & 223573 & 130 & 1323 & 486 & 0.0056 & .0005 & 22.5 & 15 & .05 & 23 & $7 a, b$ & $7 a, b$ & 10 \\
\hline$J-13$ & 176678 & 228359 & 274 & 934 & 442 & 0.0133 & .0013 & 27 & 15 & .05 & 309 & $8 a, b$ & $18 \mathrm{a}, \mathrm{b}, \mathrm{c}$ & $5,10,15$ \\
\hline $5 B$ & 214659 & 227795 & 596 & 149 & 63.8 & 0.0084 & .0008 & 303.5 & 15 & .15 & 65 & $9 a, b$ & $19 \mathrm{a}, \mathrm{b}, \mathrm{c}$ & $30,40,50$ \\
\hline $5 \mathrm{C}$ & 215155 & 226424 & 634 & 33.6 & 14 & 0.0087 & .0009 & 310.5 & 15 & .15 & 91 & $10 \mathrm{a}, \mathrm{b}$ & $20 \mathrm{a}, \mathrm{b}, \mathrm{c}$ & $40,50,60$ \\
\hline $\mathrm{UE}-5 \mathrm{C}^{*}$ & 213664 & 231689 & 55 & 1020 & 489 & 0.0088 & .0013 & 299.5 & 15 & .15 & 365 & $11 \mathrm{a}, \mathrm{b}$ & $21 a, b, c$ & $30,40,50$ \\
\hline 4 & 209672 & 239268 & 876 & 1821 & 702 & 0.0182 & .0017 & 237 & 15 & .05 & 151 & $12 a, b$ & $22 a, b, c$ & $3,4,5$ \\
\hline $4 A$ & 209367 & 239070 & 876 & 1821 & 702 & 0.0182 & .0017 & 237 & 15 & .05 & 94 & $12 a, b$ & $22 a, b, c$ & $3,4,5$ \\
\hline C & 210940 & 240817 & 154 & 6175 & 2797 & 0.0175 & .0025 & 241.5 & 15 & .02 & 22 & $13 a, b$ & $13 a, b$ & 1 \\
\hline$C-1$ & 210962 & 240795 & 314 & 6175 & 2797 & 0.0175 & .0025 & 241.5 & 15 & .02 & 34 & $13 a, b$ & $13 a, b$ & 1 \\
\hline$U E-16 d$ & 197074 & 257519 & 341 & 47 & 18.5 & 0.0097 & .0005 & 301 & 15 & .02 & 50 & $14 a, b$ & $23 \mathrm{a}, \mathrm{b}, \mathrm{c}$ & $5,10,15$ \\
\hline 8 & 185928 & 268062 & 587 & 2477 & 996 & 0.0145 & .0025 & 355 & 15 & .05 & 293 & $15 \mathrm{a}, \mathrm{b}$ & $24 a, b, c$ & $5,10,15$ \\
\hline UE-19c* & 183193 & 279502 & 505 & 162.5 & 70.8 & 0.0031 & .0012 & 357 & 15 & .05 & 1849 & $16 a, b$ & $25 a, b, c$ & $40,50,60$ \\
\hline U-20* & 173459 & 277545 & 858 & 207 & 74.9 & 0.011 & .001 & 60 & 15 & .05 & 233 & $17 a, b$ & $26 a, b, c$ & $5,10,15$ \\
\hline
\end{tabular}

* Water-supply wells used for construction purposes only. 
reliability levels increase, the corresponding time-dependent capture zone gets wider and shorter, as can be seen for Well 5B in Figure 19a, b, c. This trade-off between width and length of the capture zone is caused by requiring the same volume of water to enter the well for a given time period.

Table 2. Maximum Upgradient Width of Ultimate Capture Zone for Each Water-Supply Well at the NTS.

\begin{tabular}{lccc}
\hline \hline \multicolumn{1}{c}{ Well } & $\begin{array}{c}\mathrm{Q} \\
\left(\mathrm{m}^{3 / \text { day }}\right)\end{array}$ & $\begin{array}{c}\mathrm{q}_{50} \\
\left(\mathrm{~m}^{2} / \text { day }\right)\end{array}$ & $\begin{array}{c}\text { Maximum width }\left(2 \mathrm{y}_{\mathrm{L}}\right) \\
(\mathrm{m})\end{array}$ \\
\hline Army \#1 & 1446 & 5.692 & 254 \\
$\mathrm{~J}-12$ & 130 & 6.869 & 18.9 \\
$\mathrm{~J}-13$ & 274 & 11.179 & 24.6 \\
5B & 596 & 1.153 & 517 \\
5C & 634 & 0.267 & 2374 \\
UE-5C & 55 & 7.965 & 6.9 \\
4 \& 4A & 1752 & 30.723 & 57 \\
C \& C-1 & 468 & 97.417 & 4.8 \\
UE-16d & 341 & 0.428 & 796 \\
8 & 587 & 32.819 & 17.8 \\
UE-19c & 505 & 0.432 & 1168 \\
U-20 & 858 & 2.132 & 402 \\
\hline \hline
\end{tabular}

The time-dependent capture zones are long and narrow for wells J-12, J-13, UE-5C, combined 4 and $4 \mathrm{~A}$, combined $\mathrm{C}$ and $\mathrm{C}-1$, and 8 . This shape for these capture zones is again due to the relatively larger regional flow at times combined with lower pumping rates, as was seen for the ultimate capture zones. Wells 5B, UE-16d, and U-20 have time-dependent capture zones similar to the expected shapes (as shown in Figure $1 \mathrm{~b}$ ). The time-dependent capture zones for wells $5 \mathrm{C}$ and UE-19c are close to circular in shape. The circular shape for a time-dependent zone is due to very low regional flow compared to the pumping rate of the well.

\section{SUMMARY}

Ultimate and time-dependent capture zones were generated based on the best available information on the hydraulic properties, pumping rates, and well construction. Information on the hydraulic properties needed for calculating the capture zones was obtained from reports. The hydraulic head gradient, both magnitude and direction, for each well is based on the water table map generated by Boughton (1986).

Ultimate capture zones were estimated for the water-supply wells. The ultimate capture zones were not extended to the groundwater divide because that information is unavailable. Only a finite length of the ultimate capture zone was shown to demonstrate the general shape of the capture zones. 
For water-supply wells J-12,J-13,UE-5C, combined 4 and $4 \mathrm{~A}$, combined $\mathrm{C}$ and $\mathrm{C}-1$, and 8 , the ultimate capture zones are very narrow. These narrow ultimate capture zones are produced primarily by the large estimated value for regional flow relative to a low pumping rate.

Time-dependent capture zones were estimated for the water-supply wells. The time-dependent capture zones are long and narrow for wells J-12, J-13, UE-5C, combined 4 and 4A, combined C and $\mathrm{C}-1$, and 8 . This shape for these capture zones is again due to the large regional flow as was seen for the ultimate capture zones. Wells 5B, UE-16d, and U-20 have time-dependent capture zones similar to the expected shapes. The time-dependent capture zones for wells $5 \mathrm{C}$ and $\mathrm{UE}-19 \mathrm{c}$ are close to circular in shape. The circular shape for a time-dependent zone is due to very low regional flow compared to the pumping rate of the well.

Due to the lack of studies conducted at the NTS regarding the quantification of subsurface heterogeneity of the basic aquifer properties (e.g., hydraulic conductivity, porosity) and the resulting transport characteristics for mobile radionuclides, several simplifying assumptions are employed. These are:

1. homogeneity and isotropy of hydraulic properties (e.g., hydraulic conductivity, porosity);

2. conservative and advective transport only;

3. uniform hydraulic head gradient and pumping rates; and

4. steady-state flow conditions.

While assumptions 3 and 4 are less likely to significantly alter the estimated capture zones, assumptions 1 and 2 are known to be violated for the complex hydrogeological settings at the NTS. At the present time, no information is available such that conditions 1 and 2 do not have to be assumed; therefore, this study employed the uncertainty in the mean flow magnitude and direction to indirectly account for the present lack of knowledge regarding the subsurface heterogeneity structure and other important transport properties. Information from additional studies aimed at quantifying the subsurface heterogeneity (at various scales) at the NTS is necessary to describe the groundwater flow and radionuclide transport processes with some confidence. 


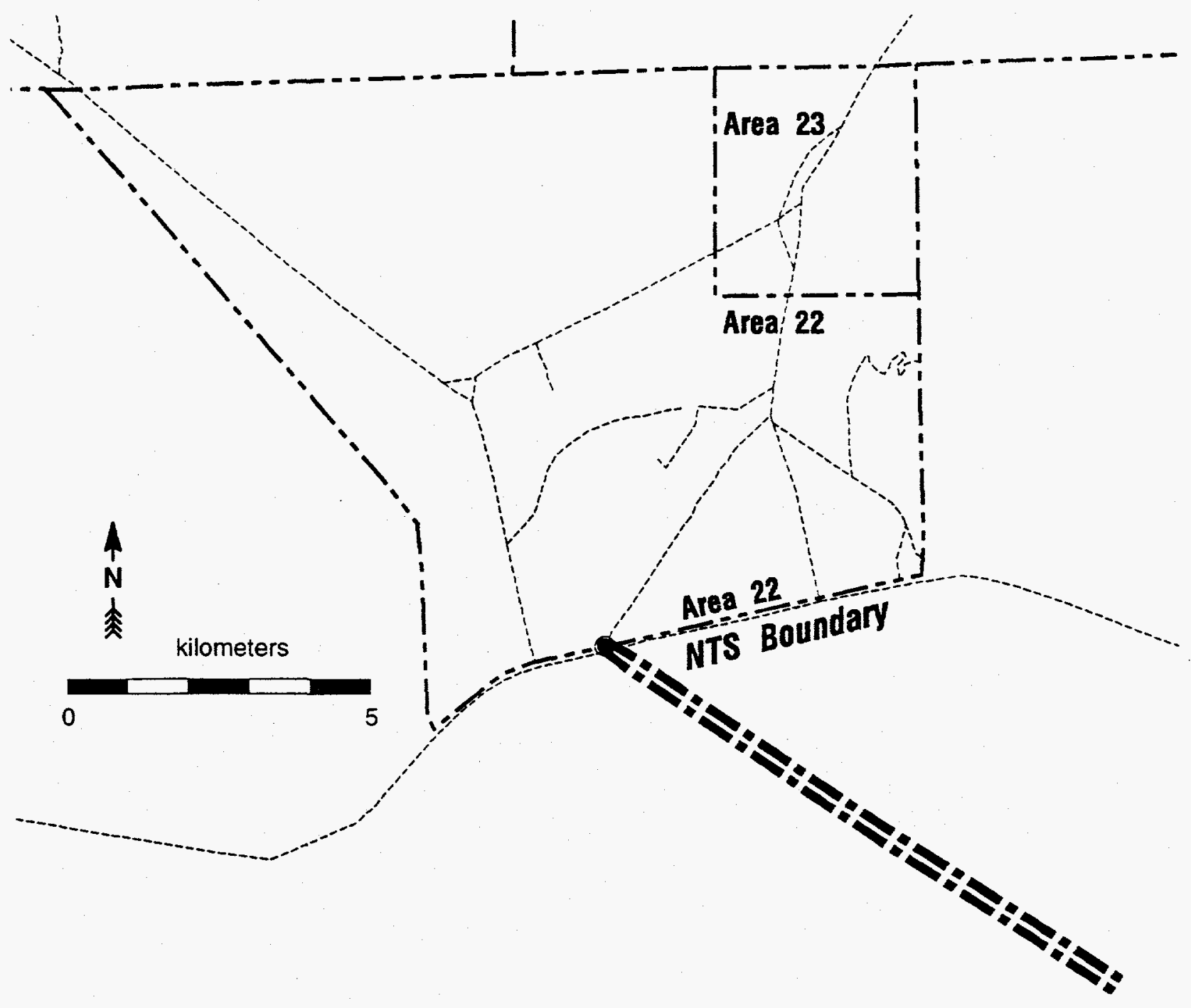

Figure 6a. Ultimate capture zone for the 50\% reliability level for Well Army \#1. Filled circle indicates a well. 


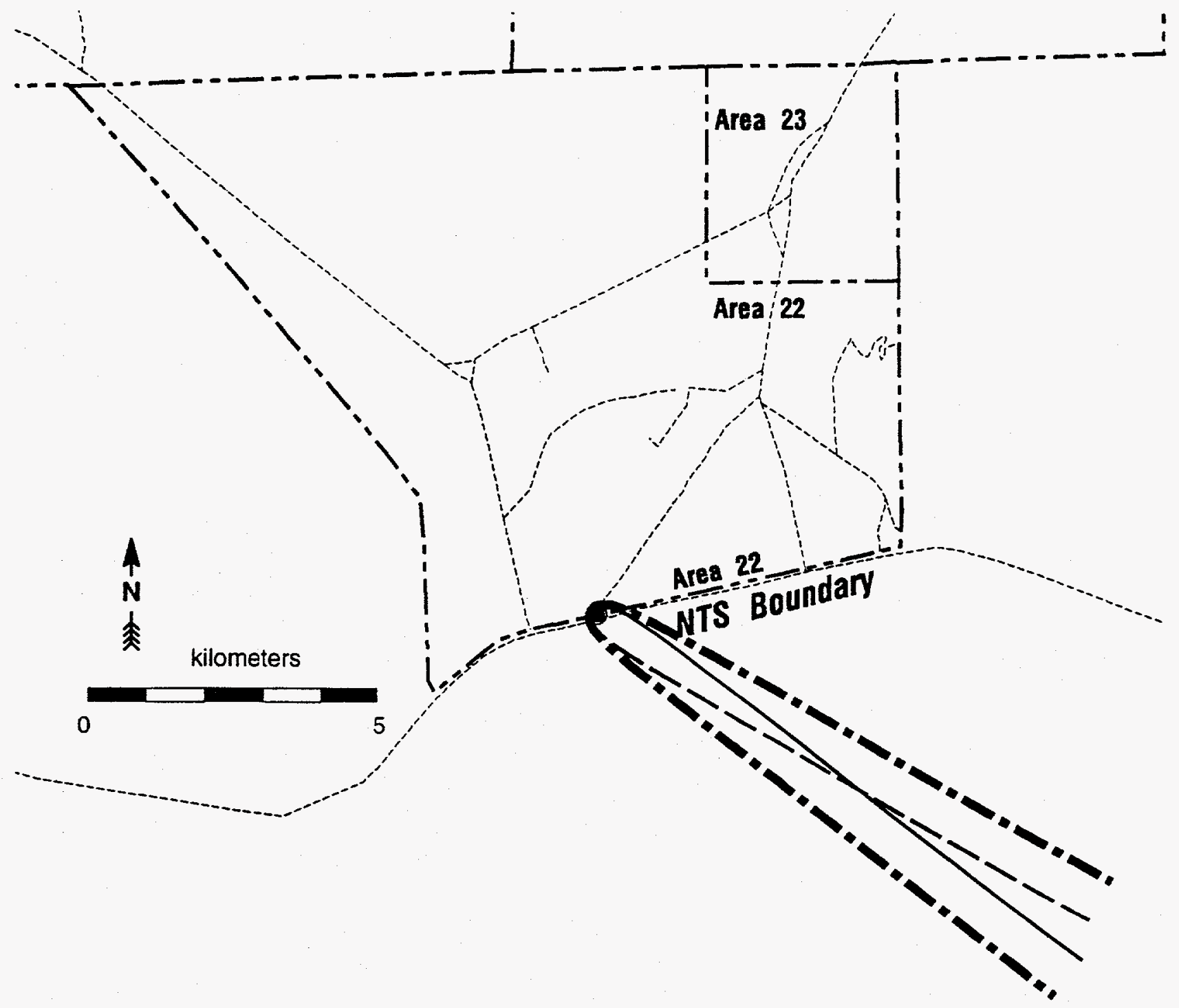

Figure 6b. Ultimate capture zones for the 95\% reliability level for Well Army \#1. Heavy dashed line is outer envelope for the two curves. Filled circle indicates a well. Standard deviation on the angle is $2^{\circ}$. 


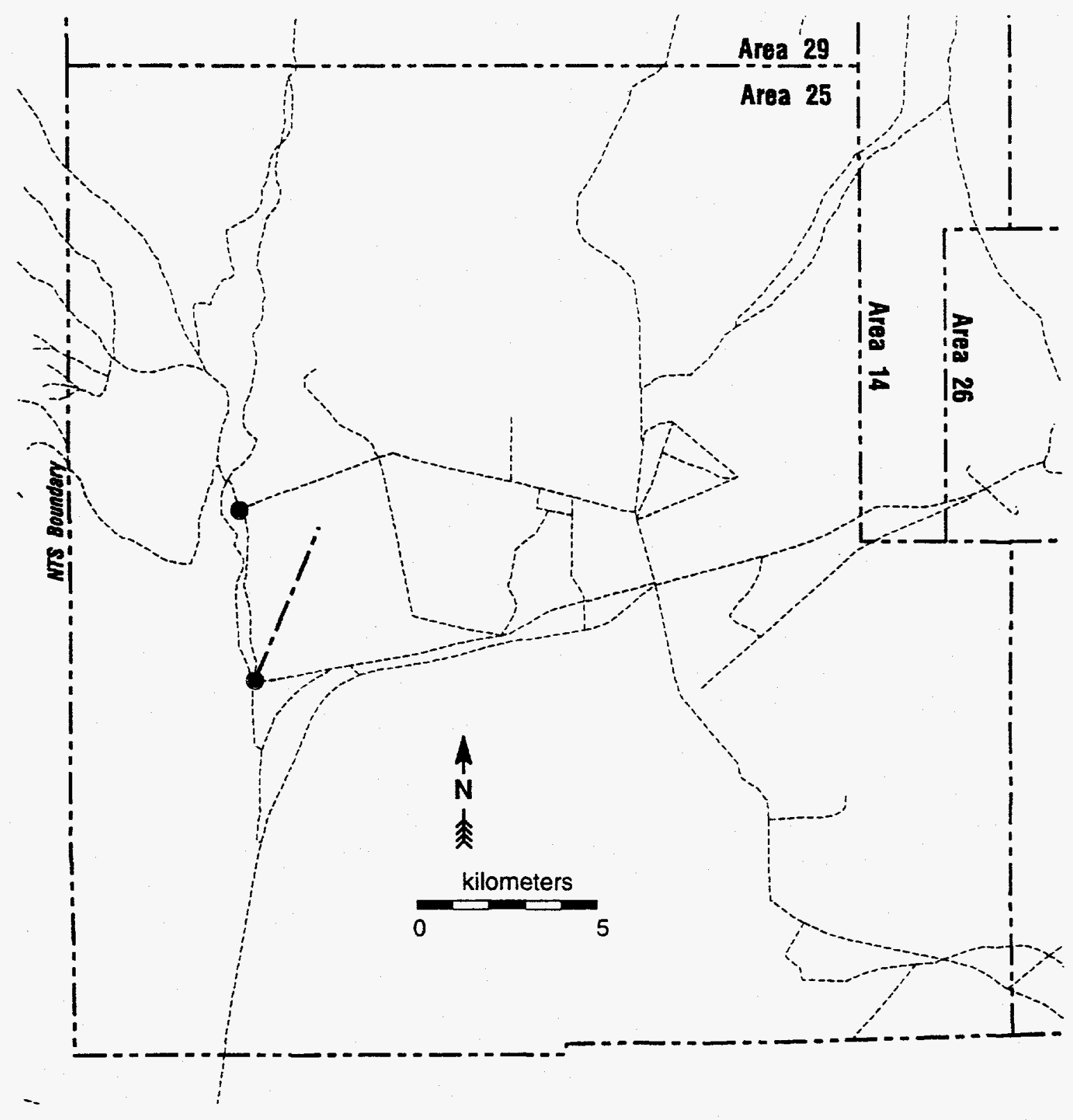

Figure 7a. Ulitmate capture zone for the $50 \%$ reliability level for Well $\mathbf{J}-12$. Filled circle indicates a well. 


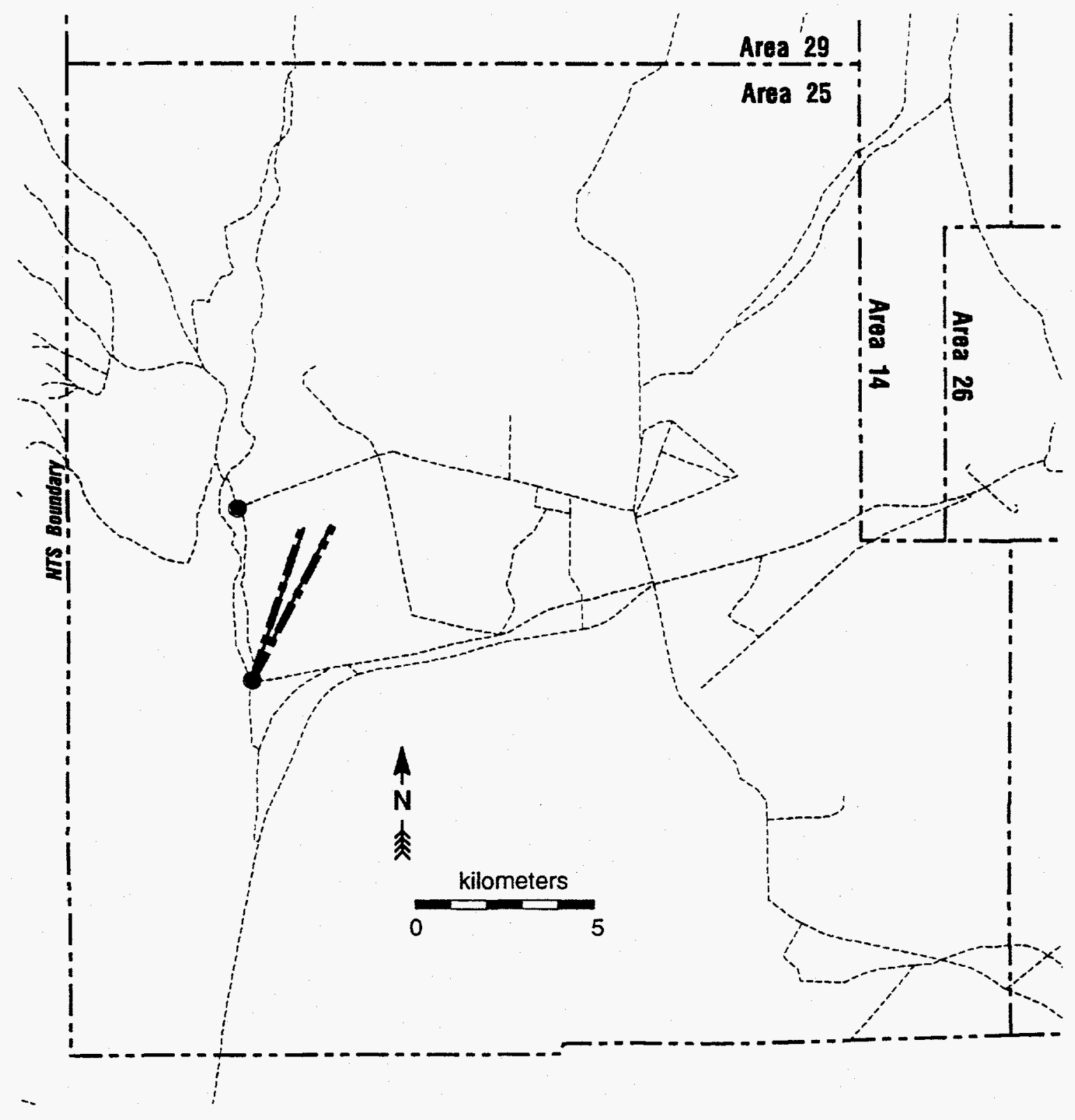

Figure $7 \mathrm{~b}$. Ultimate capture zones for the $95 \%$ reliability level for Well J-12. Heavy dashed line is outer envelope for the two curves. Filled circle indicates a well. Standard deviation on the angle is $2.2^{\circ}$. 


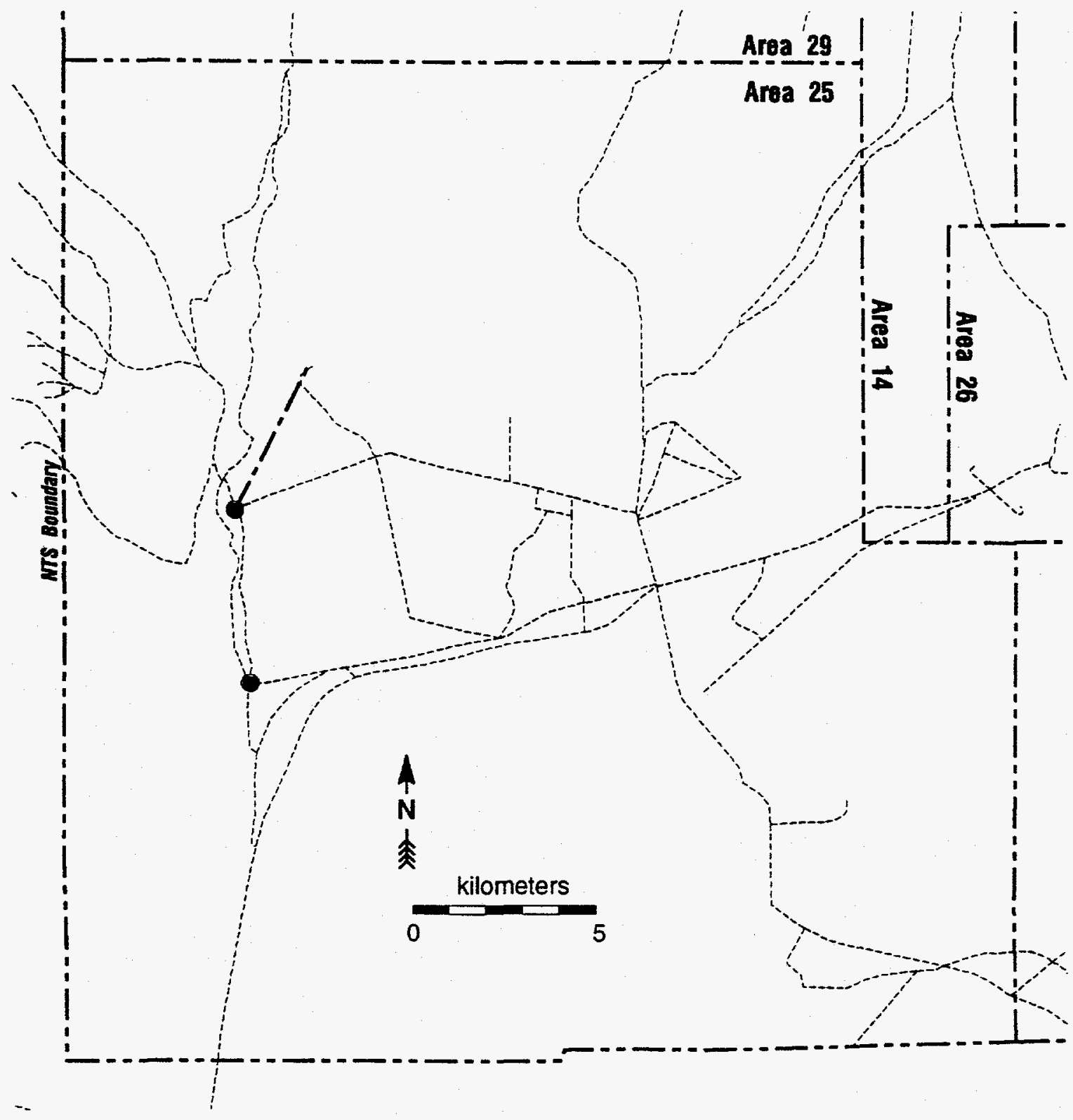

Figure 8a. Ultimate capture zone for the $50 \%$ reliability level for Well $\mathrm{J}-13$. Filled circle indicates a well. 


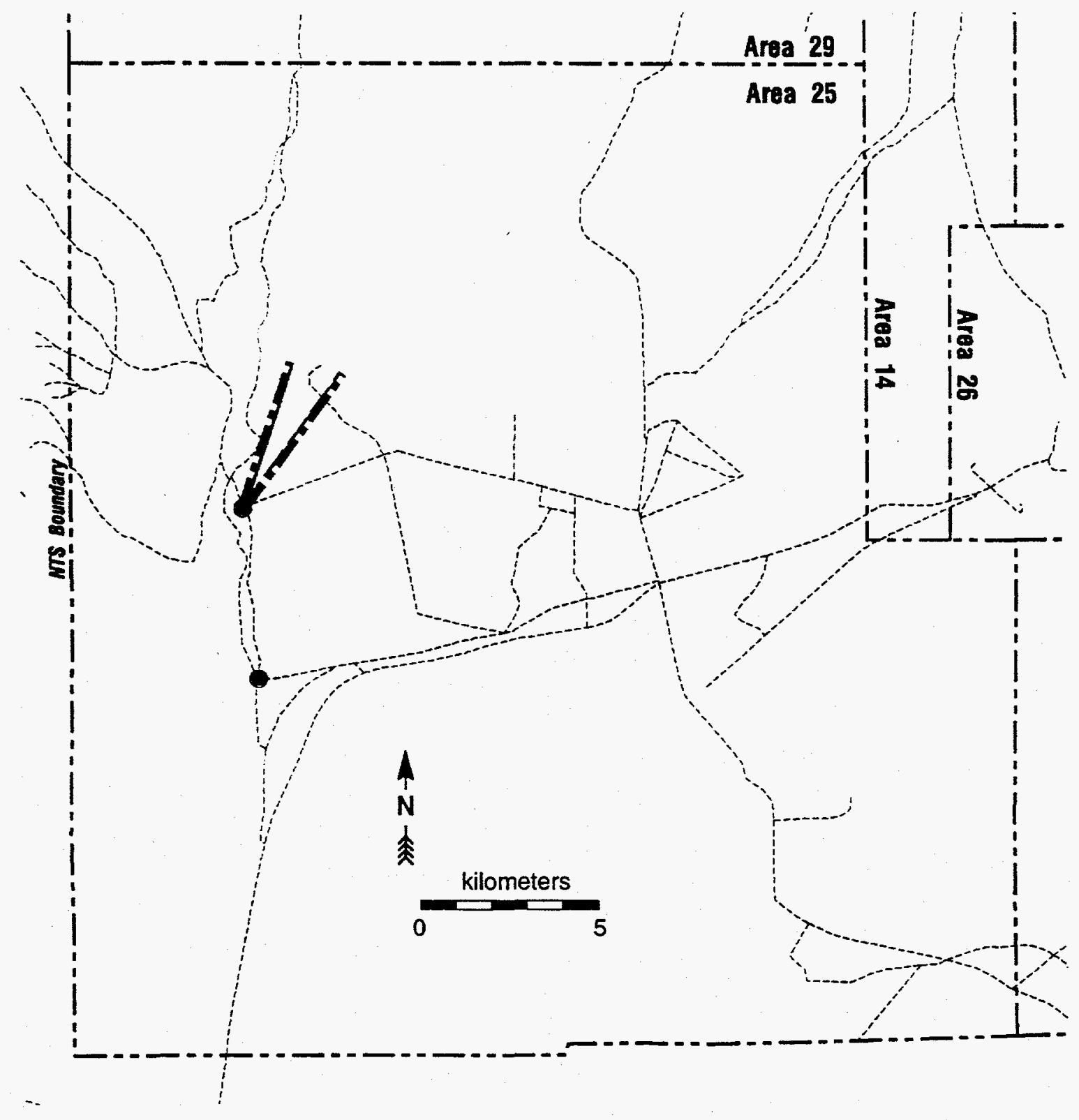

Figure 8b. Ultimate capture zones for the $95 \%$ reliability level for Well $\mathrm{J}-13$. Heavy dashed line is outer envelope for the two curves. Filled circle indicates a well. Standard deviation on the angle is $4.7^{\circ}$. 


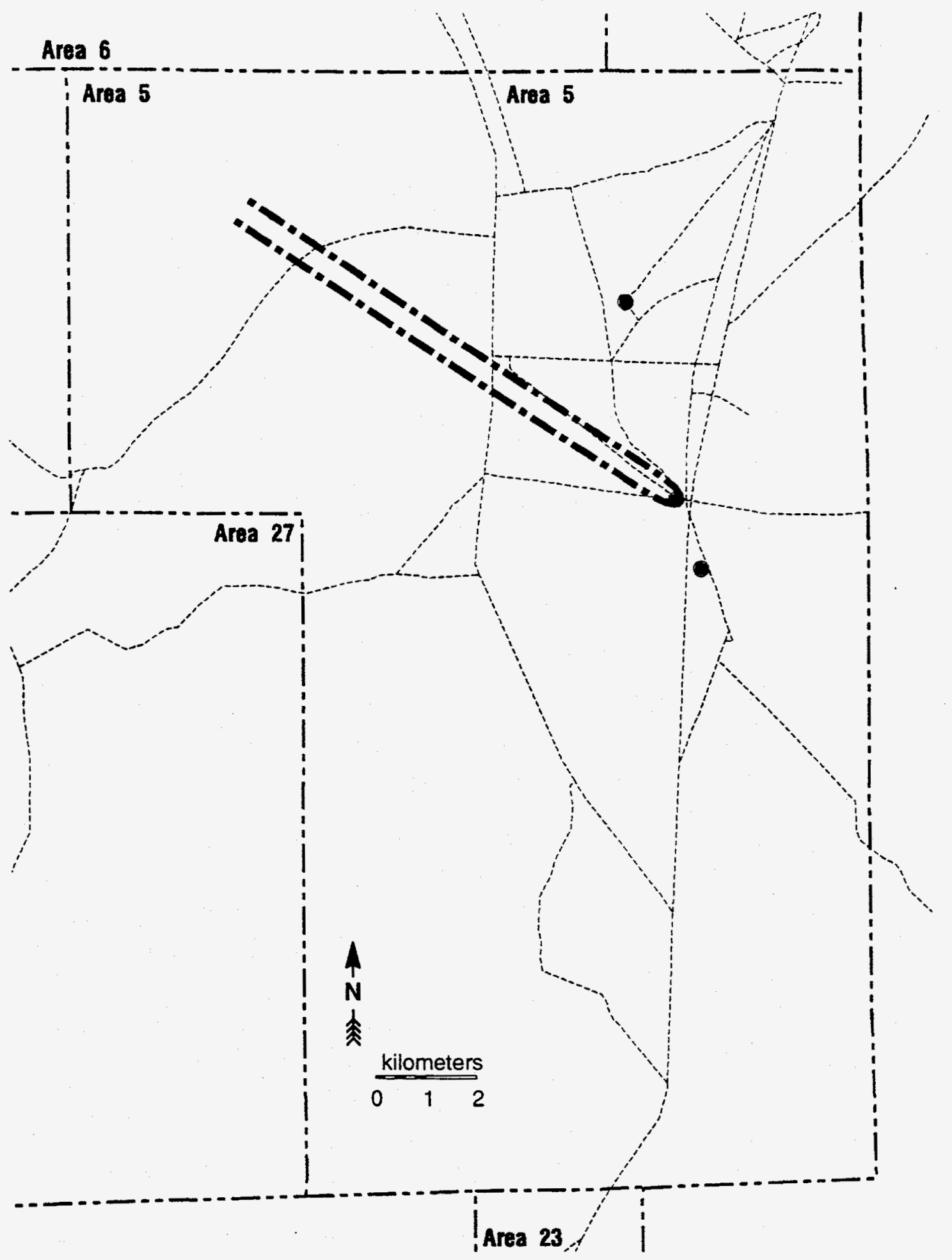

Figure 9a. Ultimate capture zone for the 50\% reliability level for Well 5B. Filled circle indicates a well. 


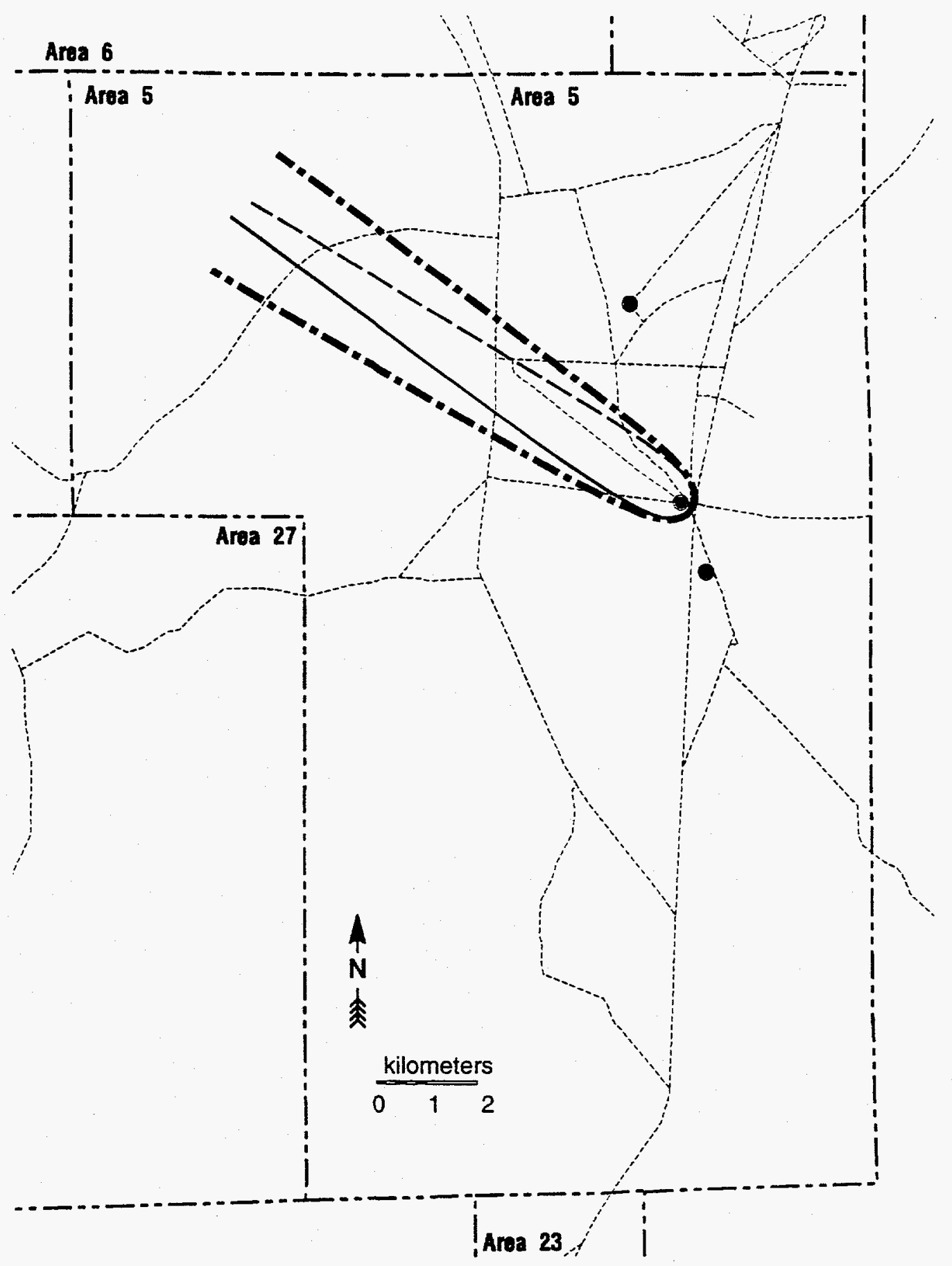

Figure $9 \mathrm{~b}$. Ultimate capture zones for the $95 \%$ reliability level for Well 5B. Heavy dashed line is outer envelope for the two curves. Filled circle indicates a well. Standard deviation on the angle is $1.5^{\circ}$. 


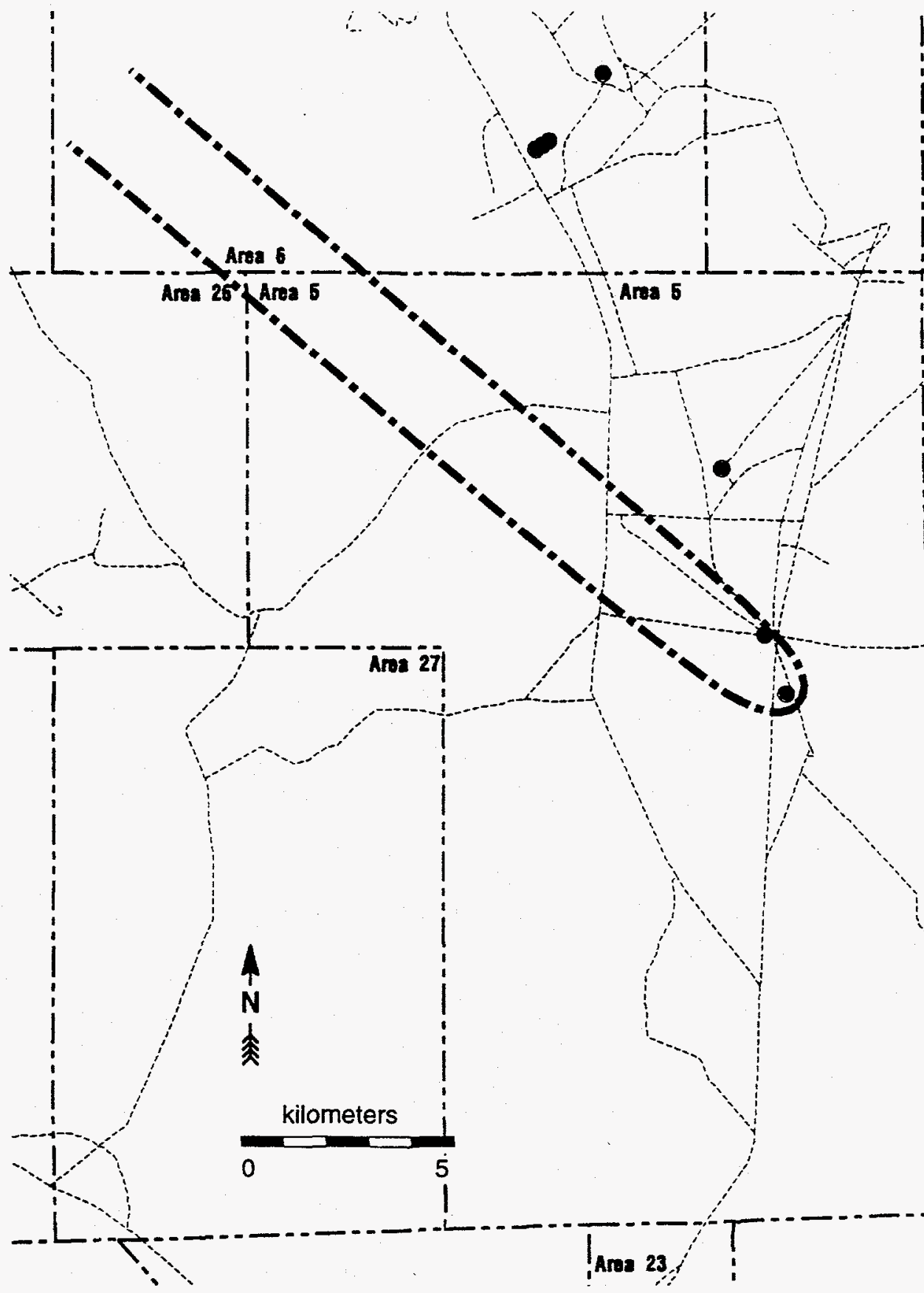

Figure 10a. Ultimate capture zone for the $50 \%$ reliability level for Well 5C. Filled circle indicates a well. 


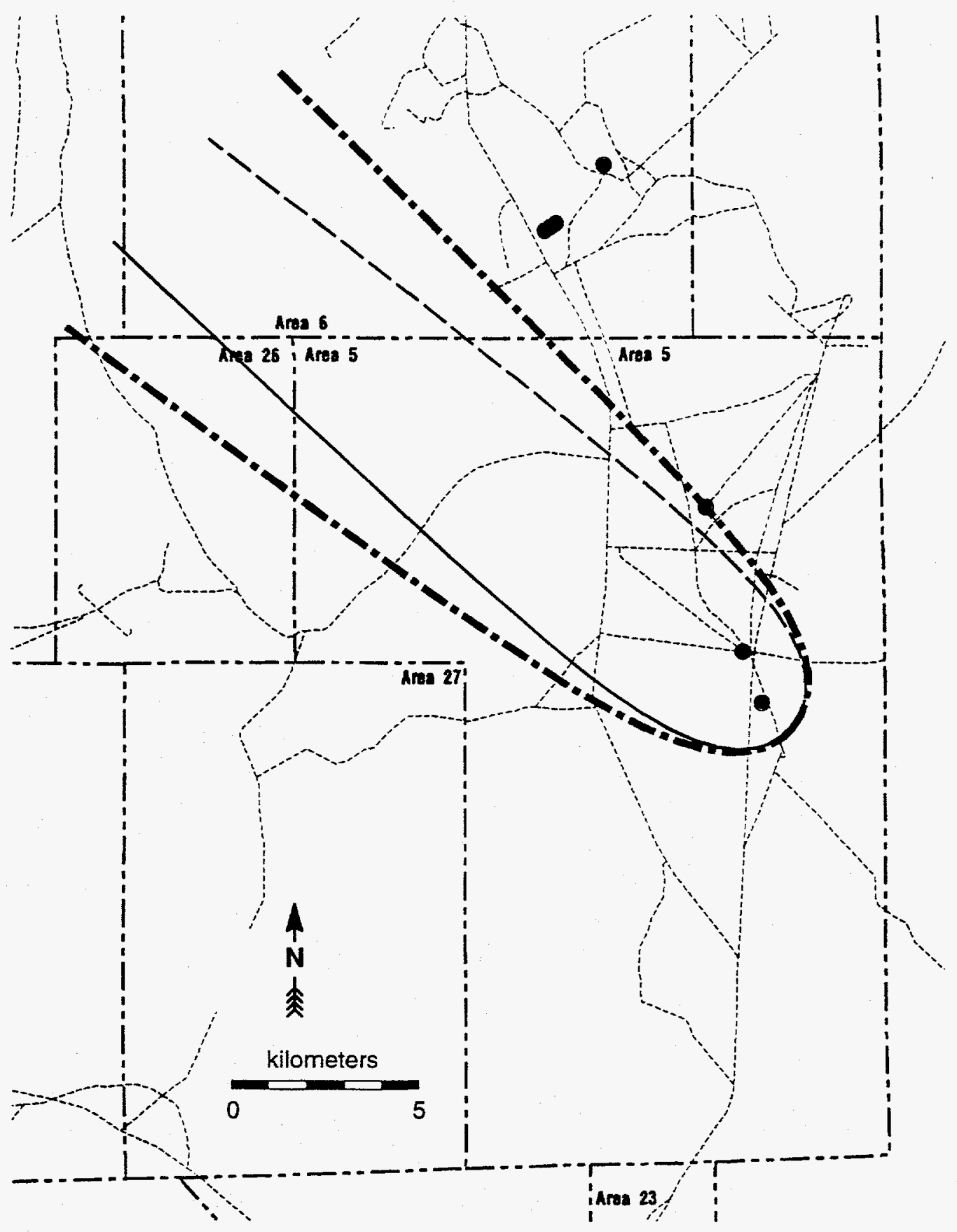

Figure 10b. Ultimate capture zones for the $95 \%$ reliability level for Well 5C. Heavy dashed line is outer envelope for the two curves. Filled circle indicates a well. Standard deviation on the angle is $1.8^{\circ}$. 


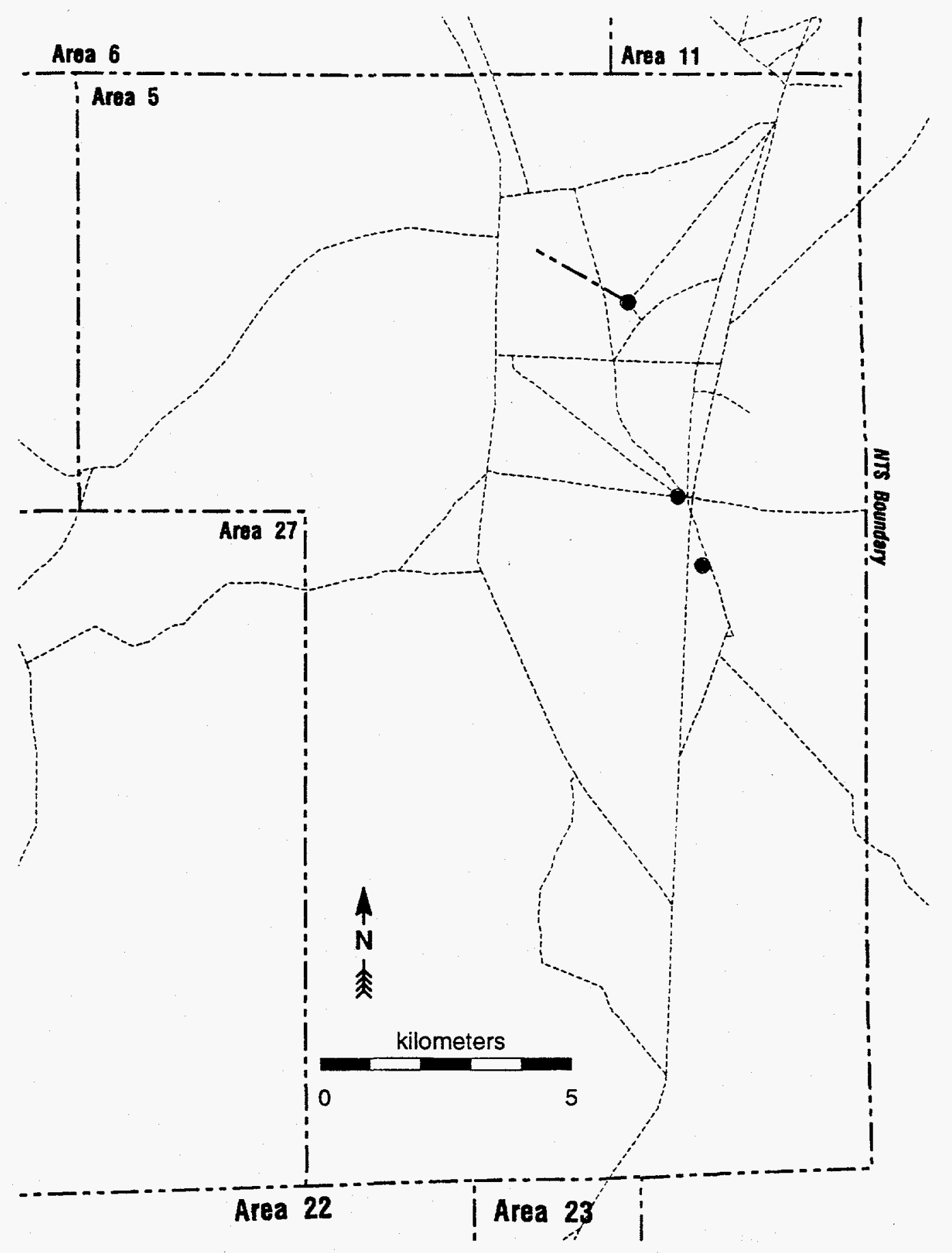

Figure 11a. Ultimate capture zone for the 50\% reliability level for Well UE-5C. Filled circle indicates a well. 


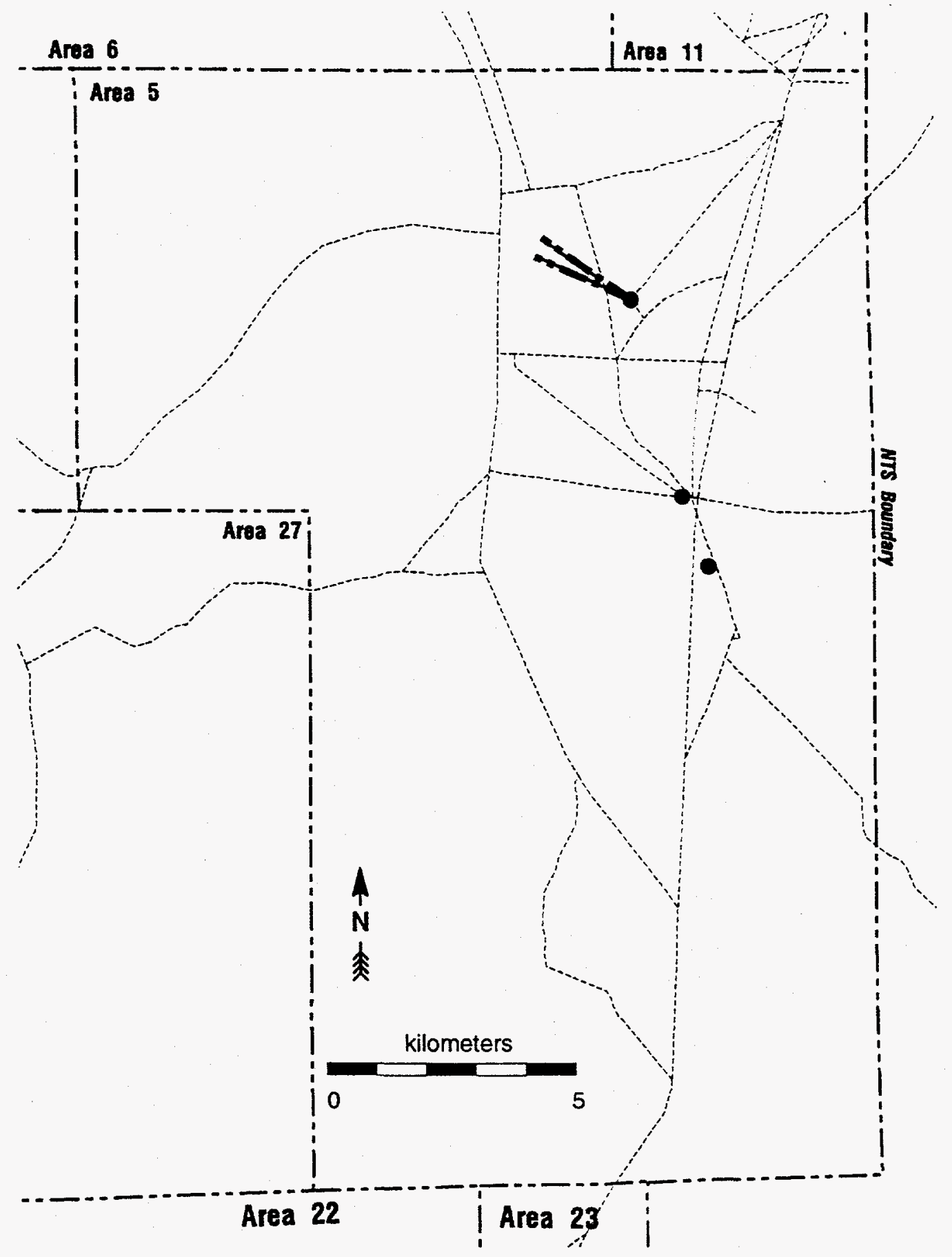

Figure 11b. Ultimate capture zones for the $95 \%$ reliability level for Well UE-5C. Heavy dashed line is outer envelope for the two curves. Filled circle indicates a well. Standard deviation on the angle is $2.5^{\circ}$. 


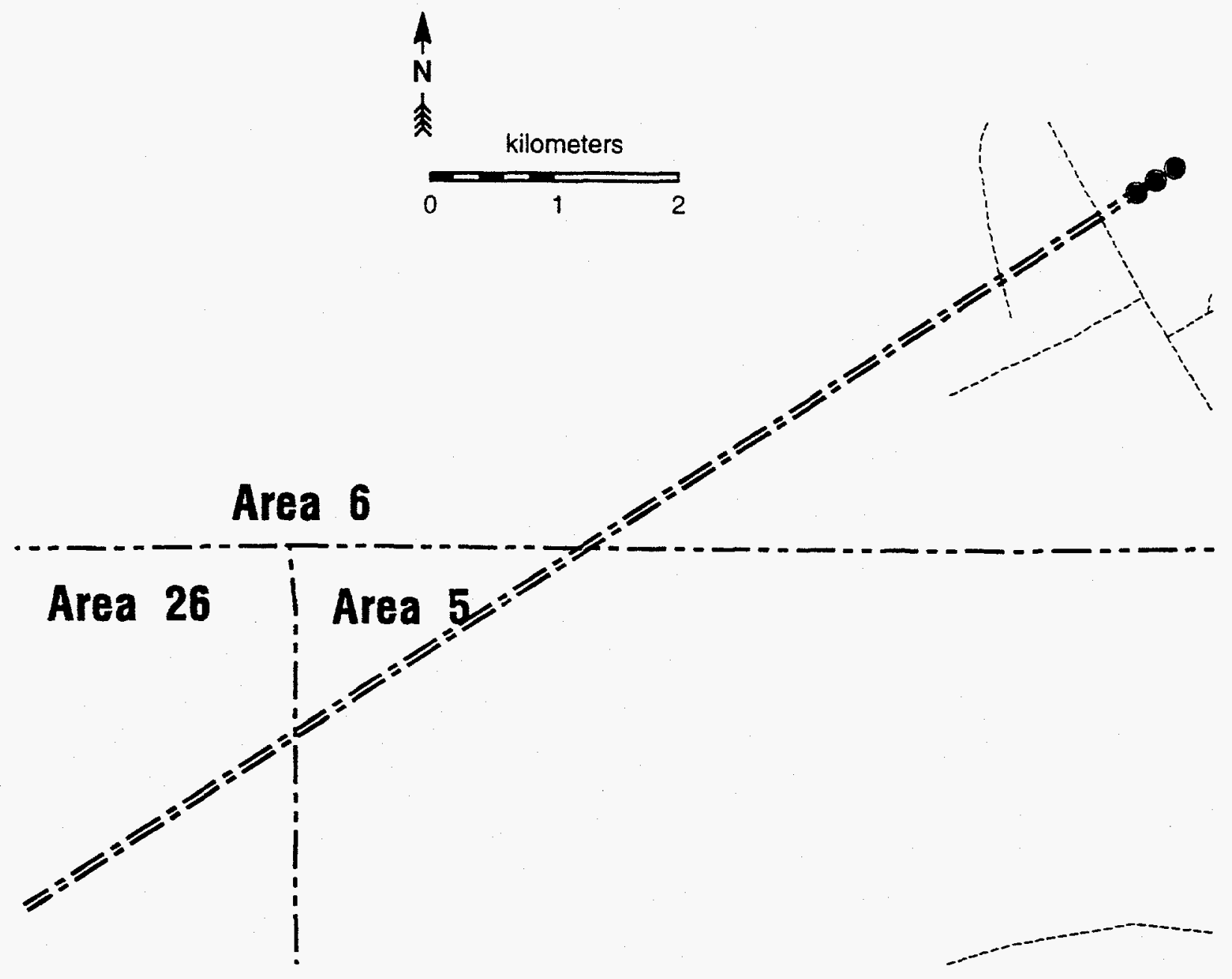

Figure 12a. Ultimate capture zone for the 50\% reliability level for Wells 4 and $4 \mathrm{~A}$. Filled circle indicates a well. 


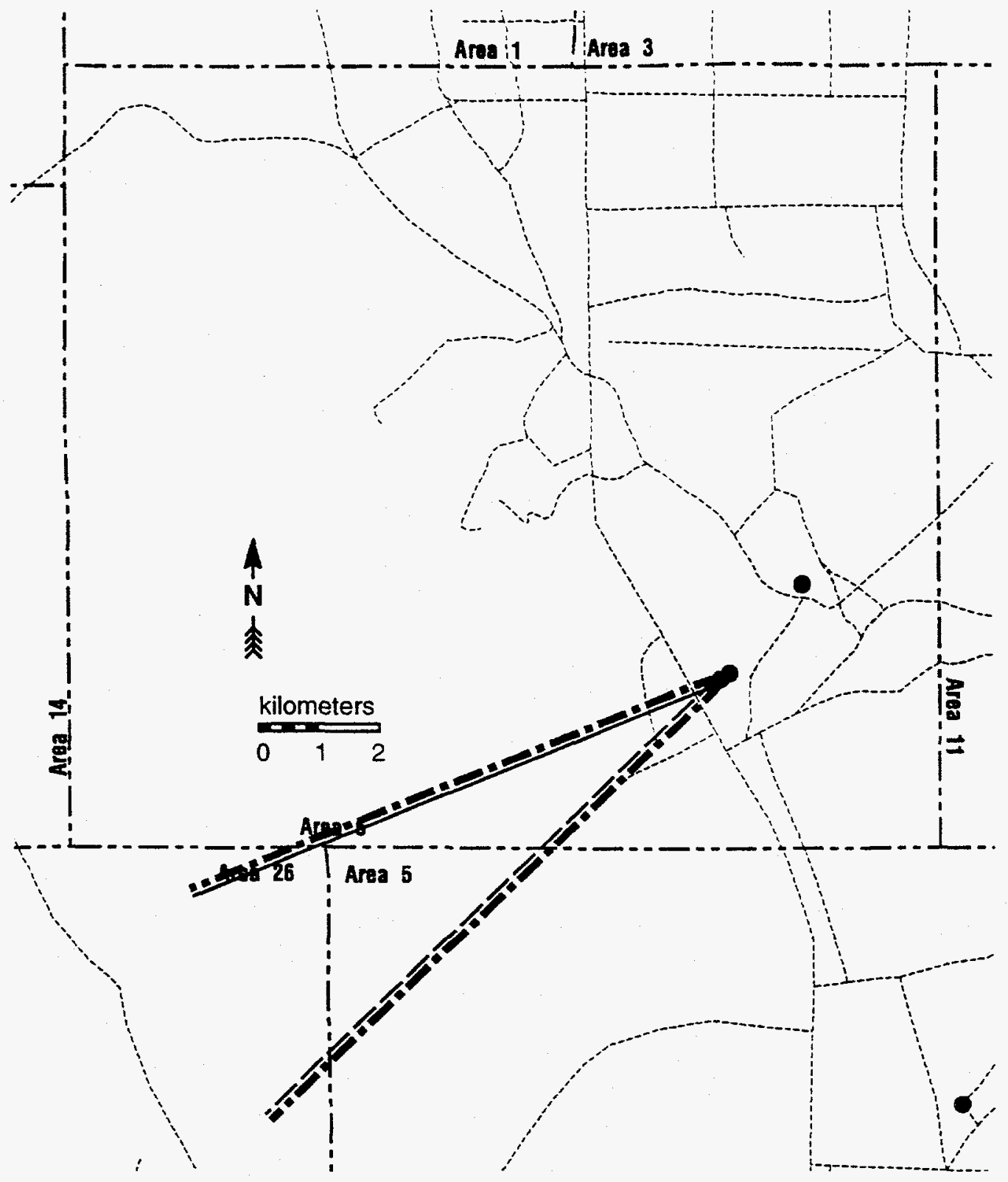

Figure $12 \mathrm{~b}$. Ultimate capture zones for the $95 \%$ reliability level for Wells 4 and $4 \mathrm{~A}$. Heavy dashed line is outer envelope for the two curves. Filled circle indicates a well. Standard deviation on the angle is $5.7^{\circ}$. 


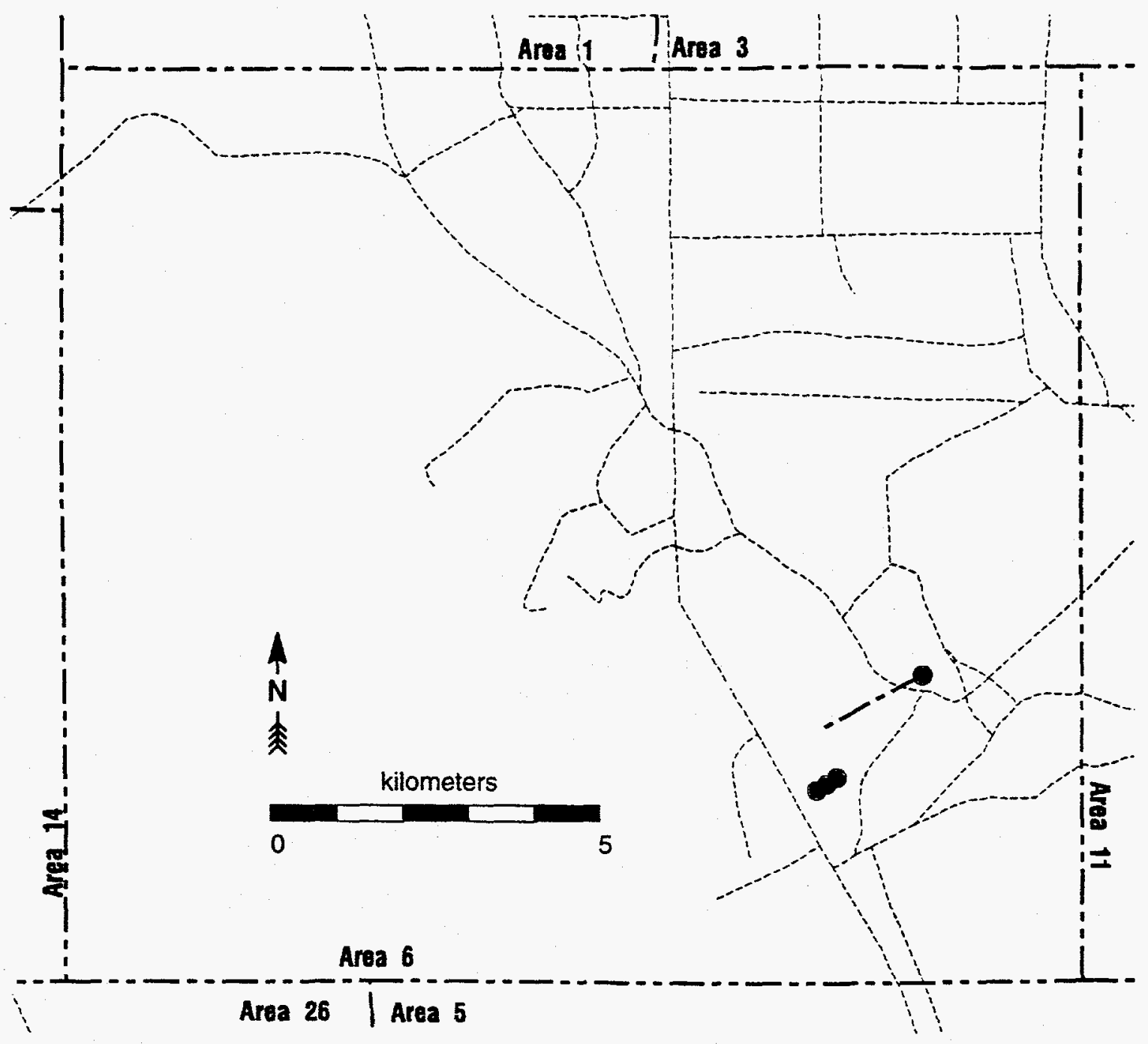

Figure 13a. Ultimate capture zone for the 50\% reliability level for Wells $\mathrm{C}$ and $\mathrm{C}-1$. Filled circle indicates a well. 


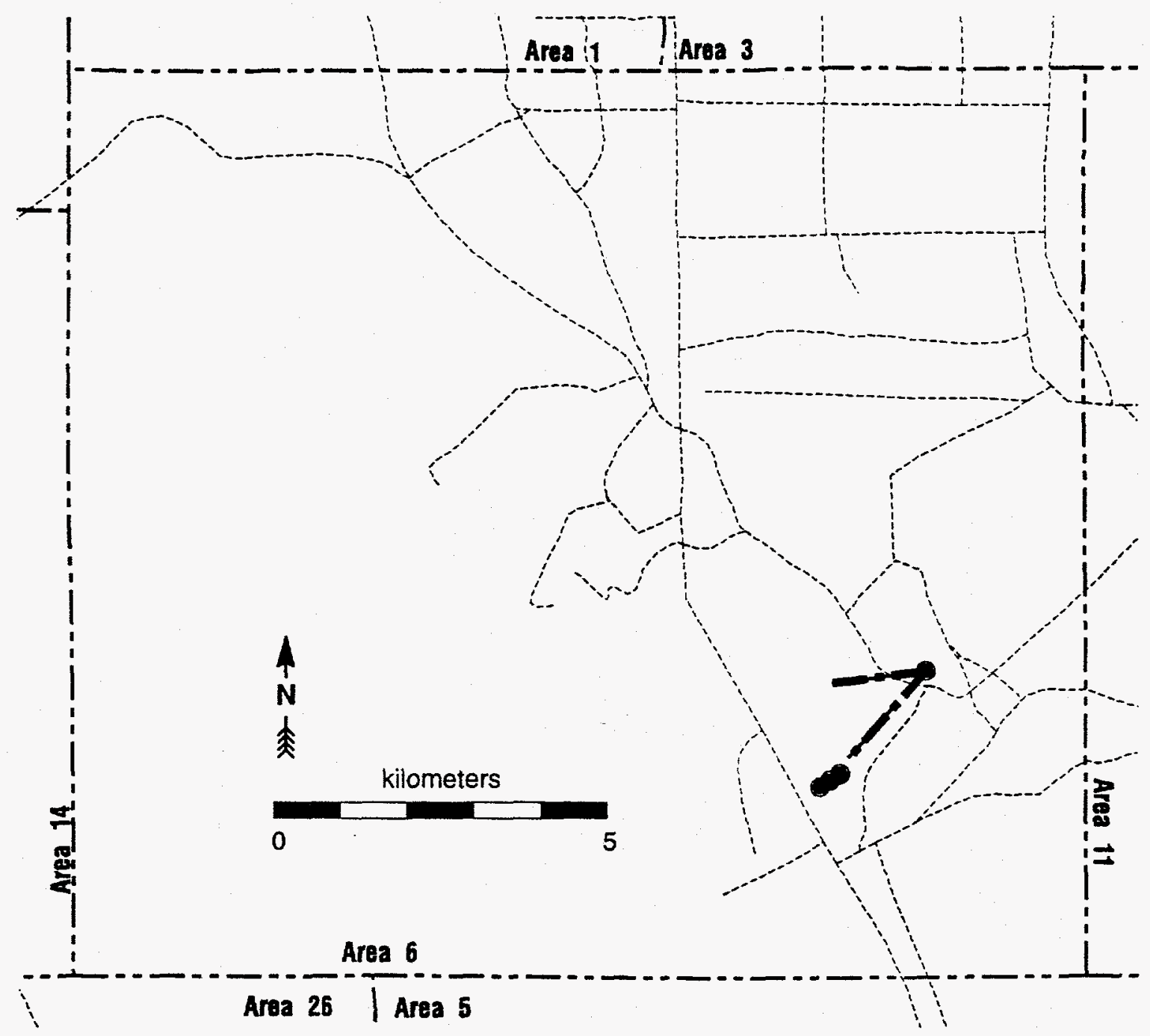

Figure 13b. Ultimate capture zones for the $95 \%$ reliability level for Wells $C$ and $C-1$. Heavy dashed line is outer envelope for the two curves. Filled circle indicates a well. Standard deviation on the angle is $10.5^{\circ}$. 


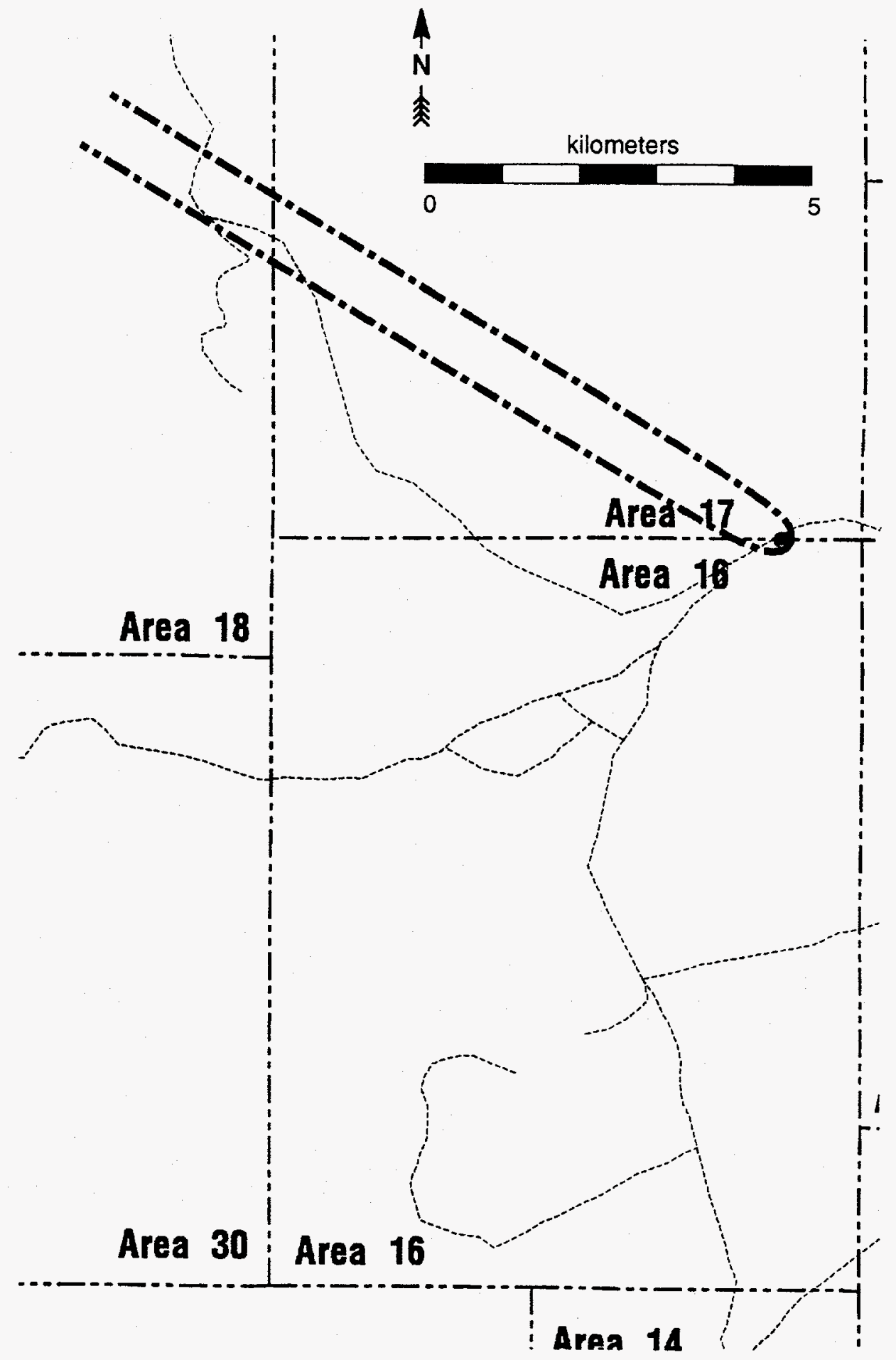

Figure 14a. Ultimate capture zone for the 50\% reliability level for Well UE-16d. Filled circle indicates a well. 


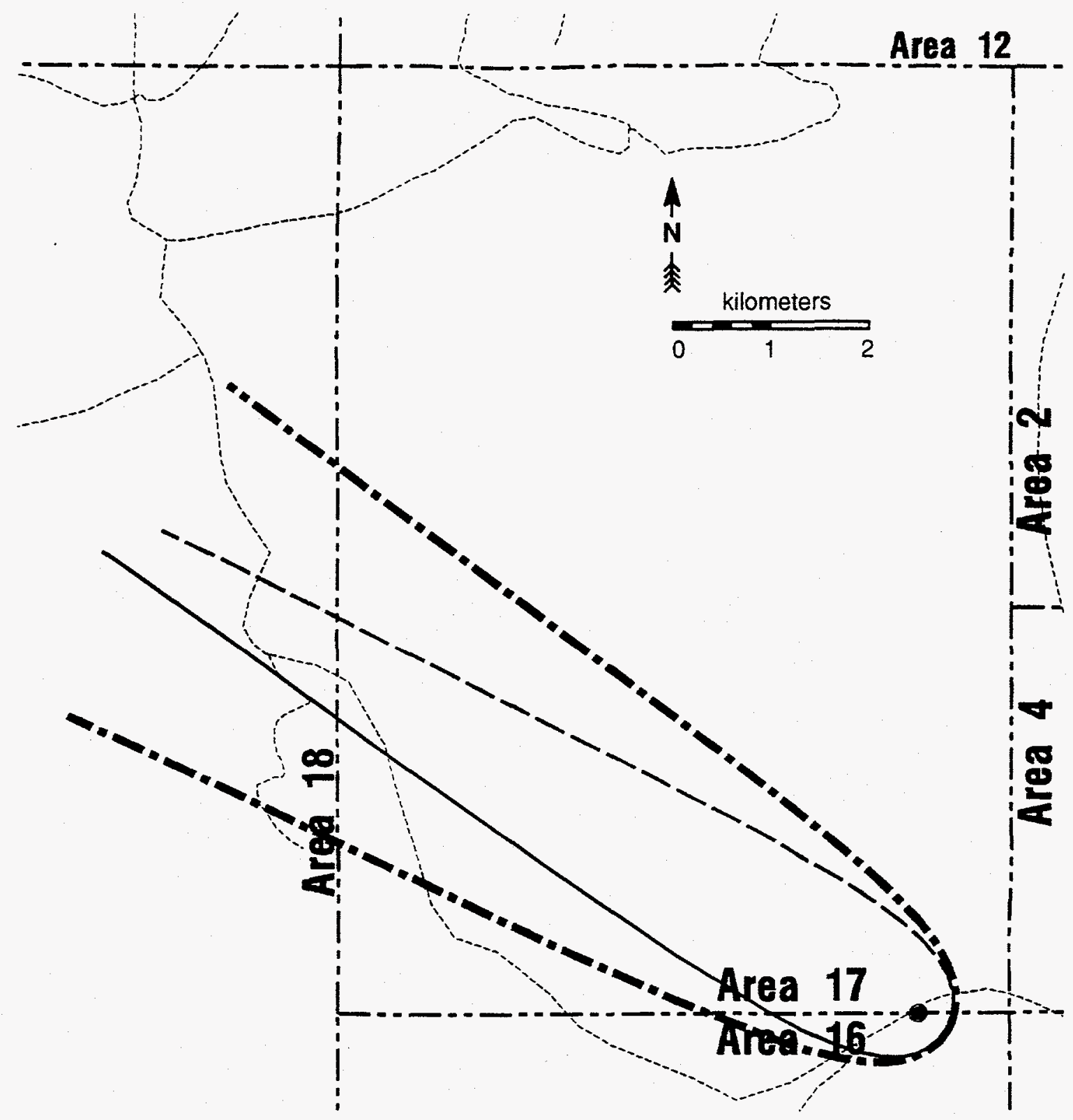

Figure 14b. Ultimate capture zones for the $95 \%$ reliability level for Well UE-16d. Heavy dashed line is outer envelope for the two curves. Filled circle indicates a well. Standard deviation on the angle is $2.7^{\circ}$. 


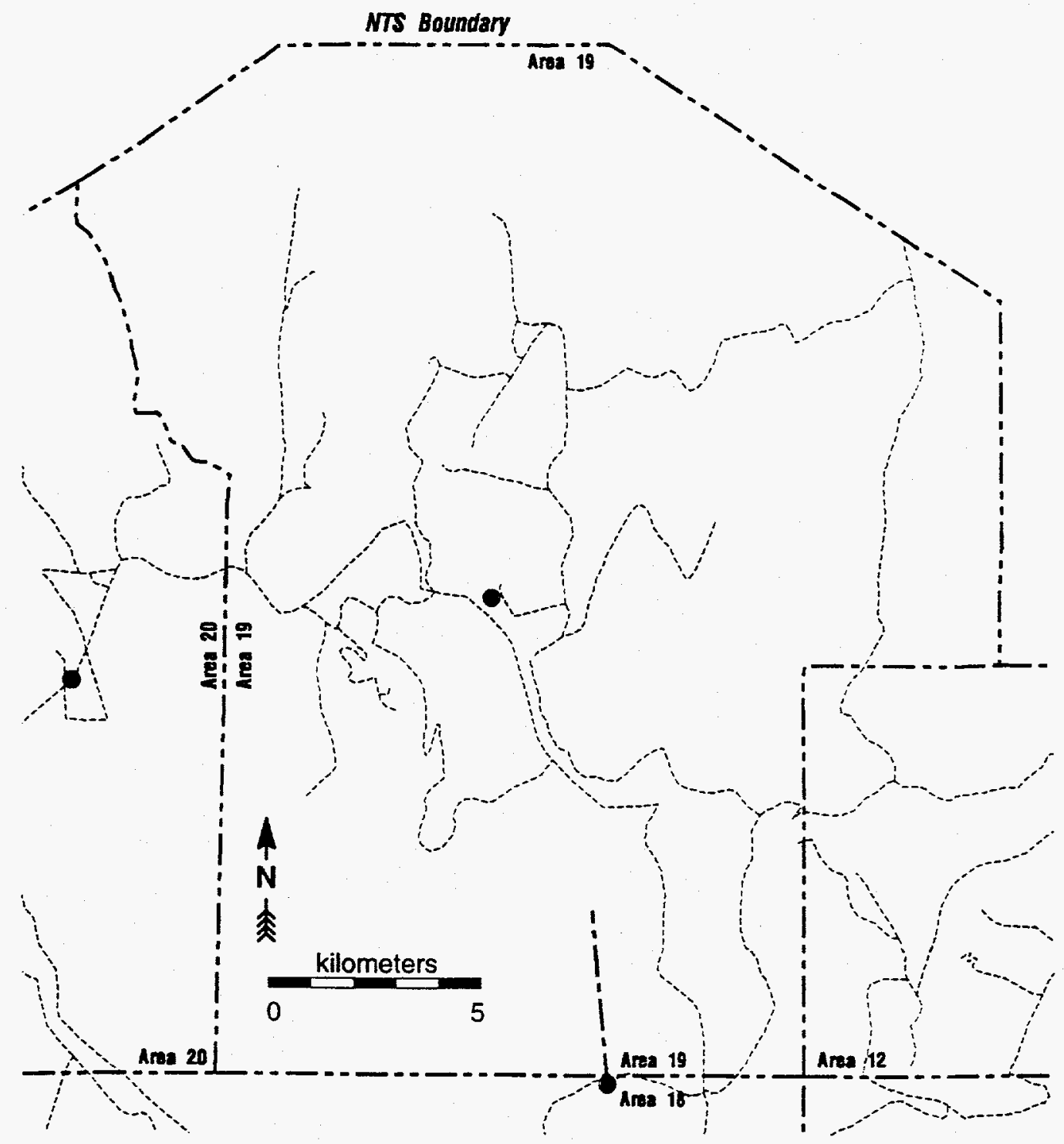

Figure 15a. Ultimate capture zone for the $50 \%$ reliability level for Well 8 . Filled circle indicates a well. 


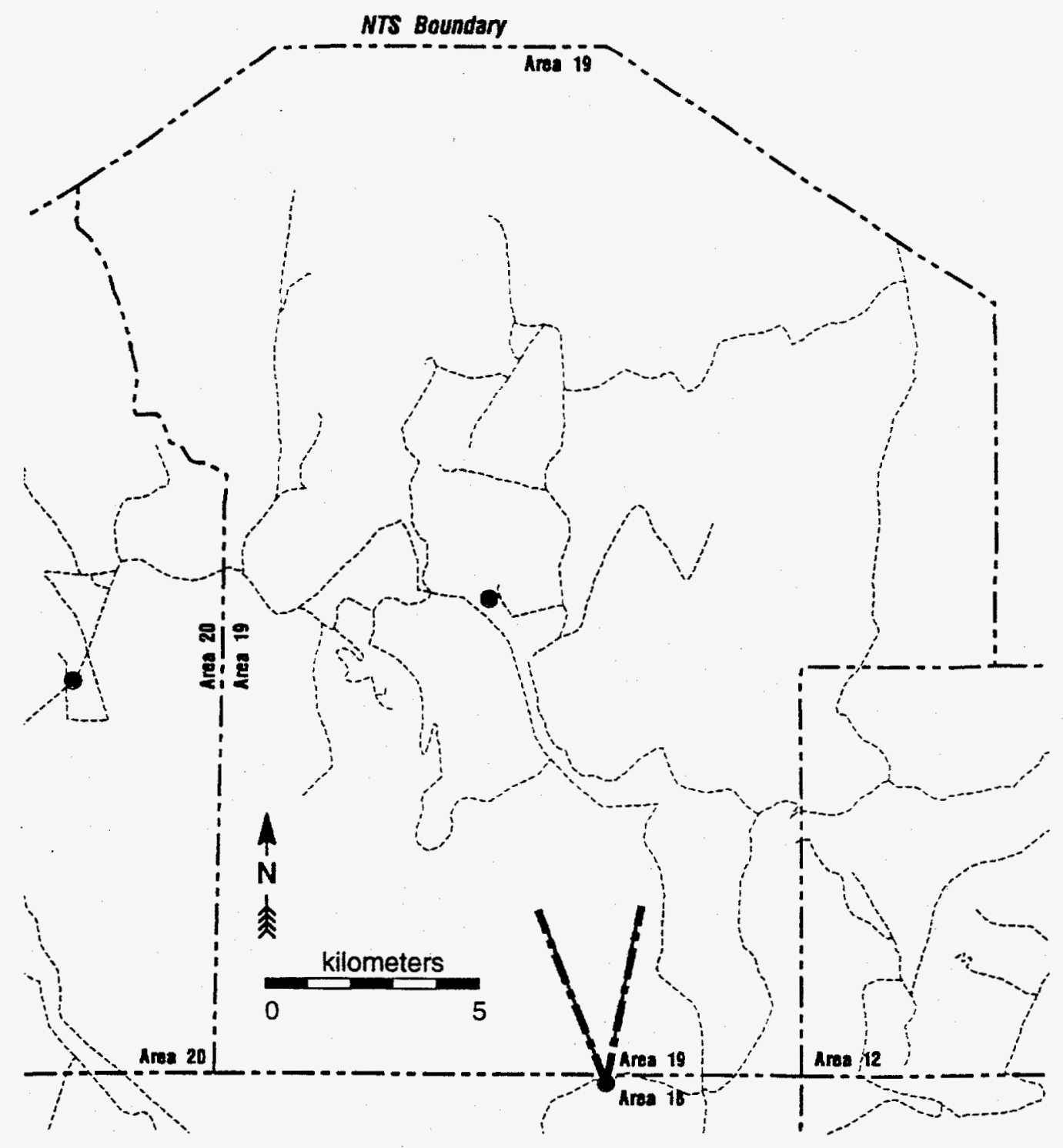

Figure $15 \mathrm{~b}$. Ultimate capture zones for the $95 \%$ reliability level for Well 8 . Heavy dashed line is outer envelope for the two curves. Filled circle indicates a well. Standard deviation on the angle is $8.3^{\circ}$. 


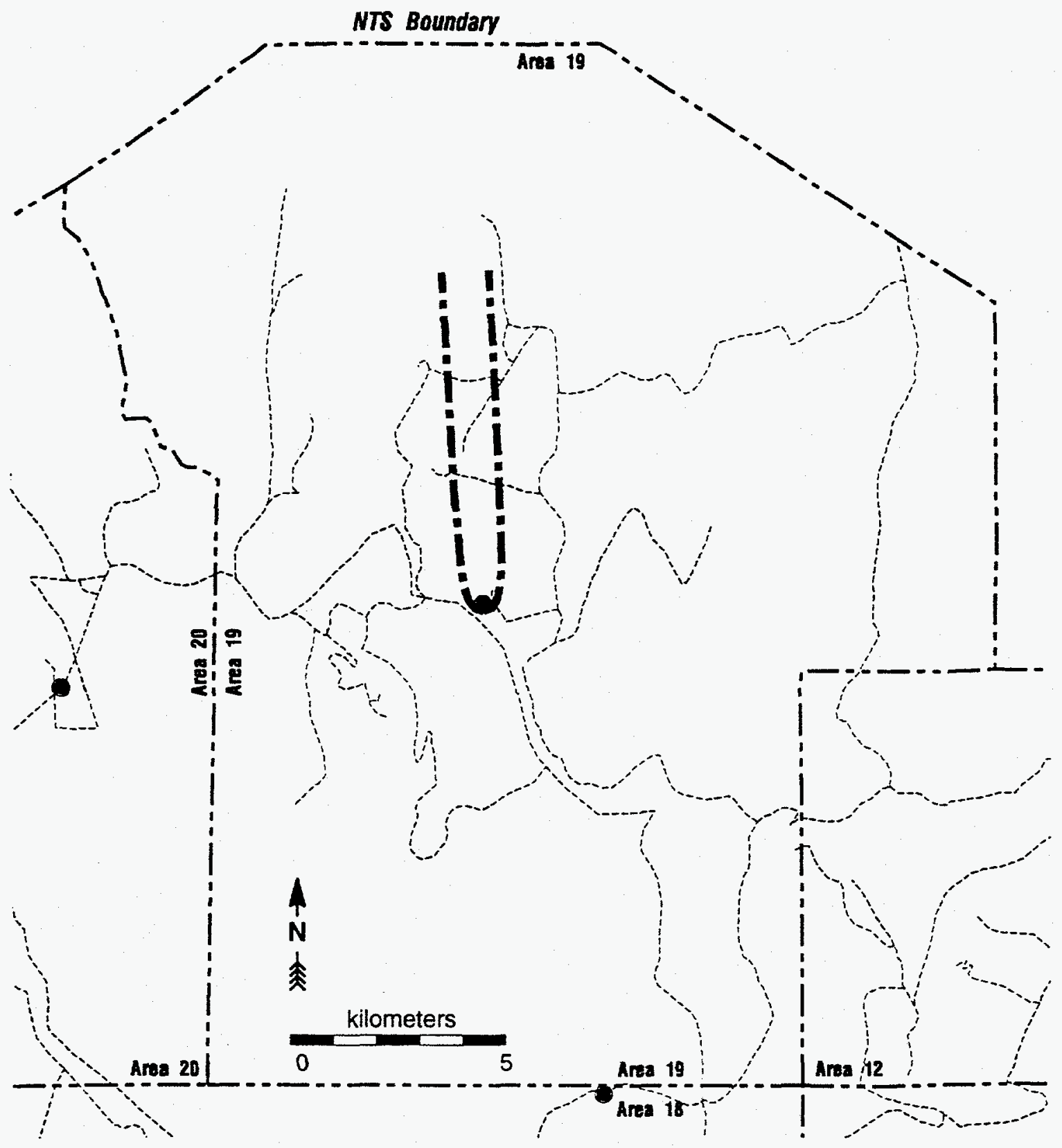

Figure 16a. Ultimate capture zone for the 50\% reliability level for Well UE-19c. Filled circle indicates a well. 


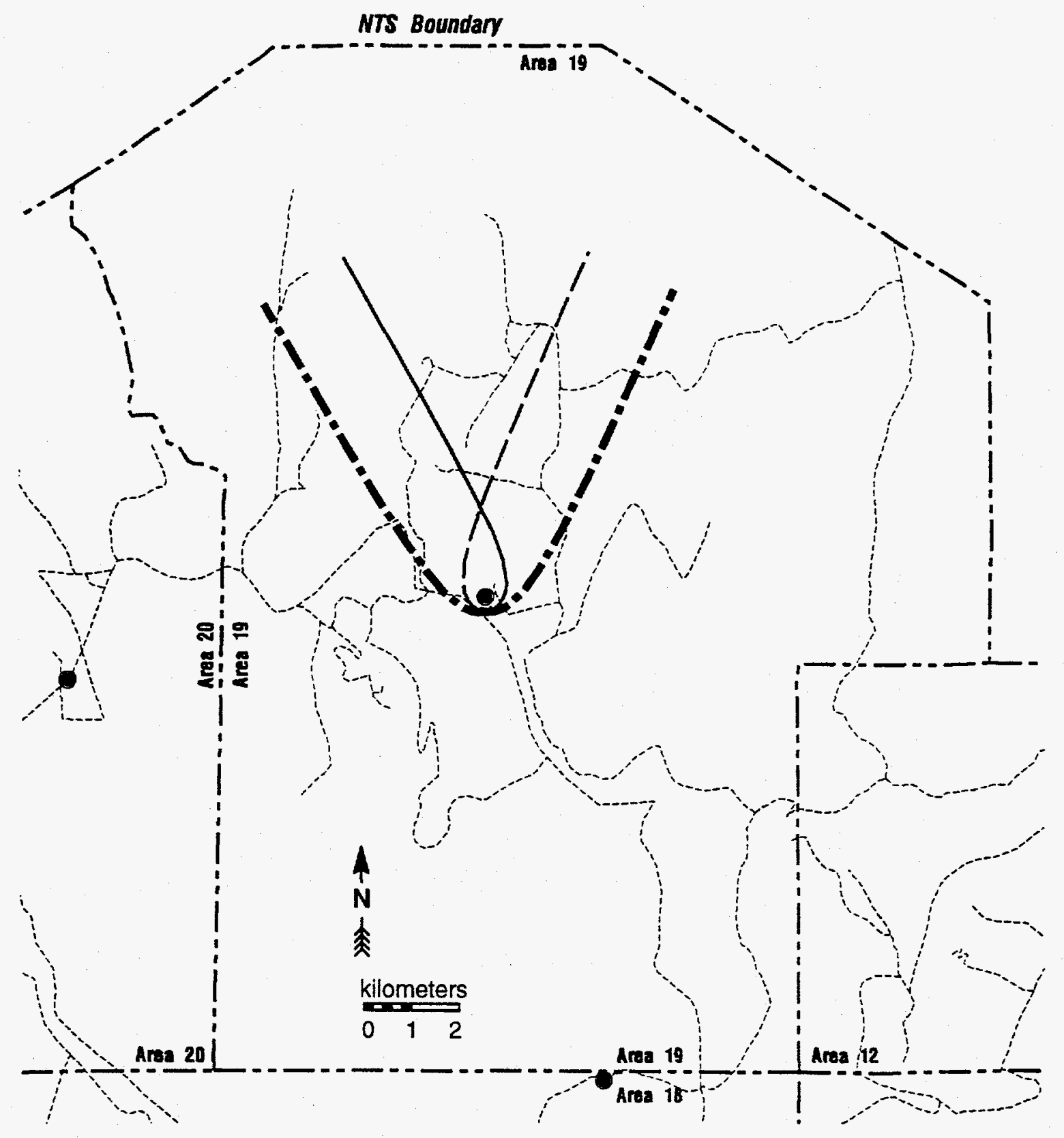

Figure 16b. Ultimate capture zones for the $95 \%$ reliability level for Well UE-19c. Heavy dashed line is outer envelope for the two curves. Filled circle indicates a well. Standard deviation on the angle is $14^{\circ}$. 


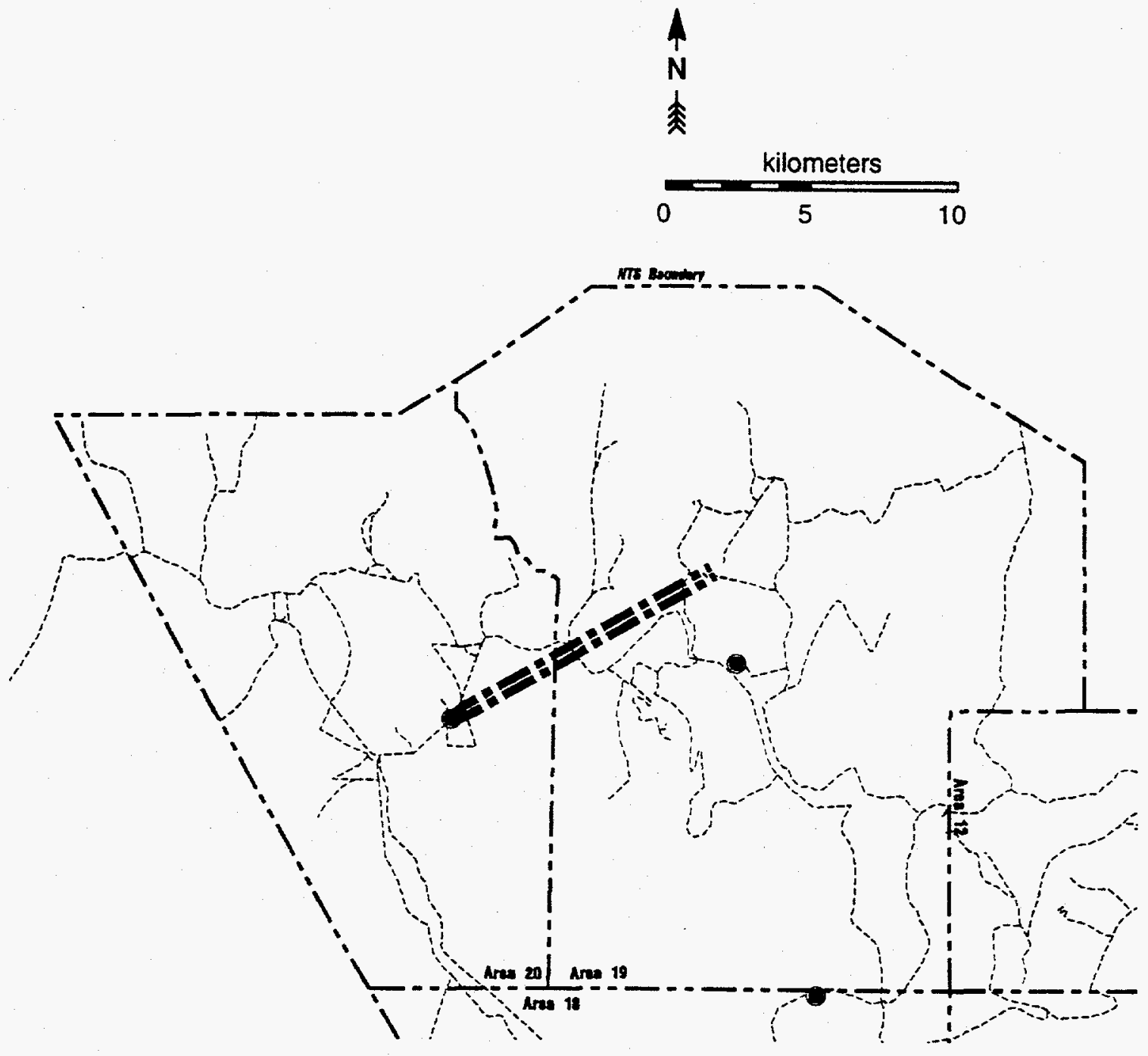

Figure 17a. Ultimate capture zone for the $50 \%$ reliability level for Well U-20. Filled circle indicates a well. 


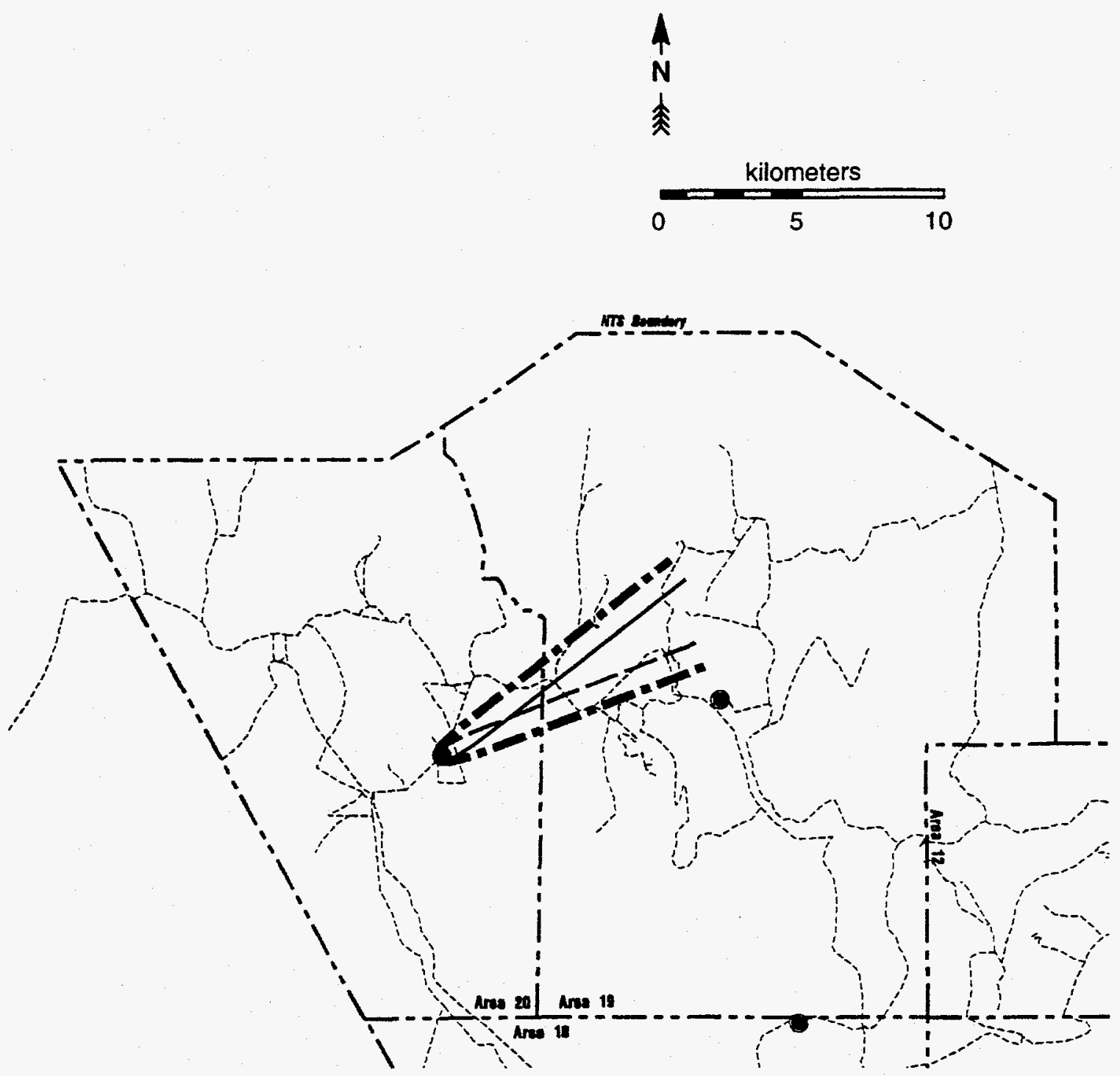

Figure $17 \mathrm{~b}$. Ultimate capture zones for the $95 \%$ reliability level for Well U-20. Heavy dashed line is outer envelope for the two curves. Filled circle indicates a well. Standard deviation on the angle is $4.3^{\circ}$. 

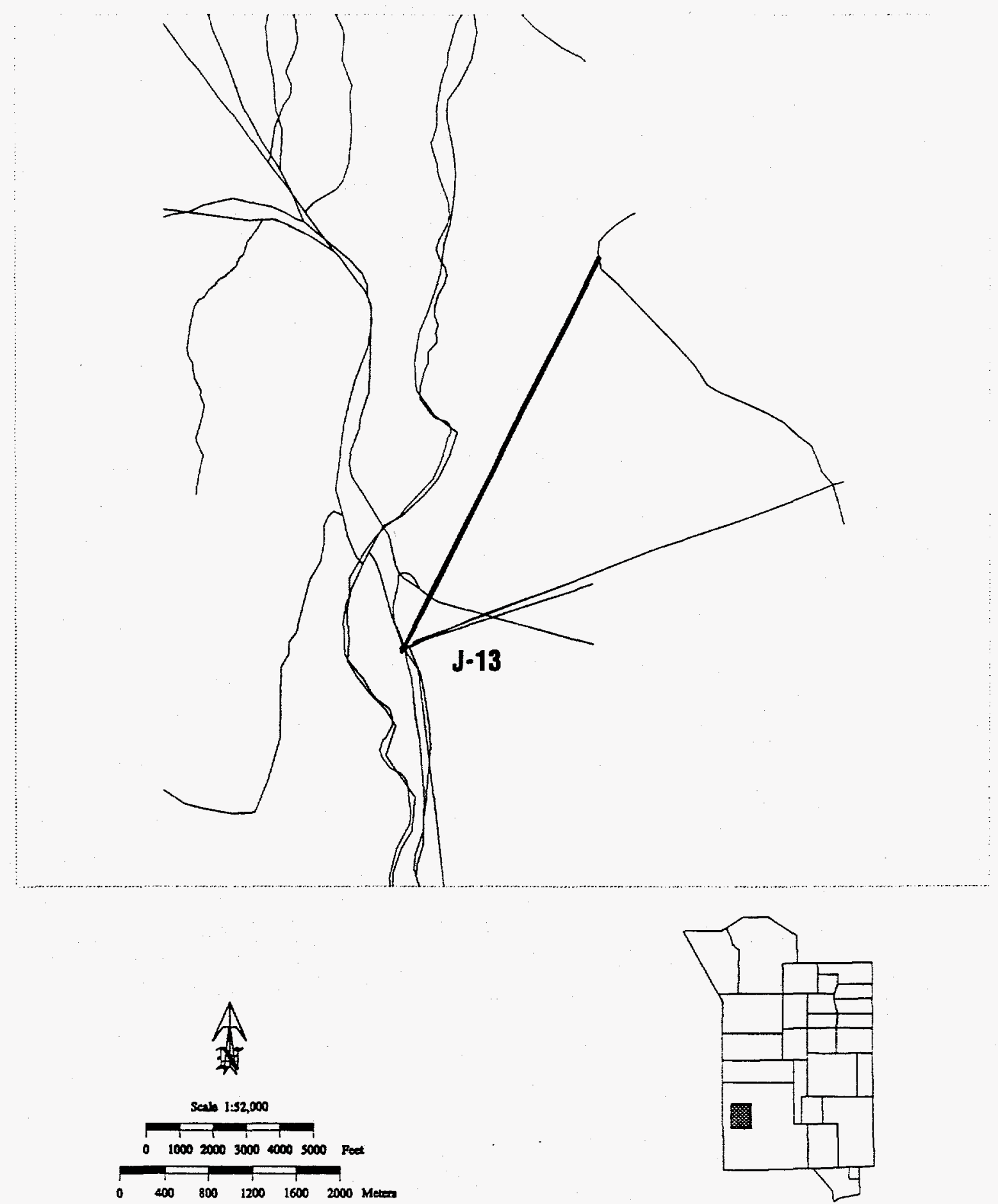

Figure 18a. Five-, 10-and 15-year time dependent capture zones for the $50 \%$ reliability level for Well J-13. Filled circle indicates a well. 

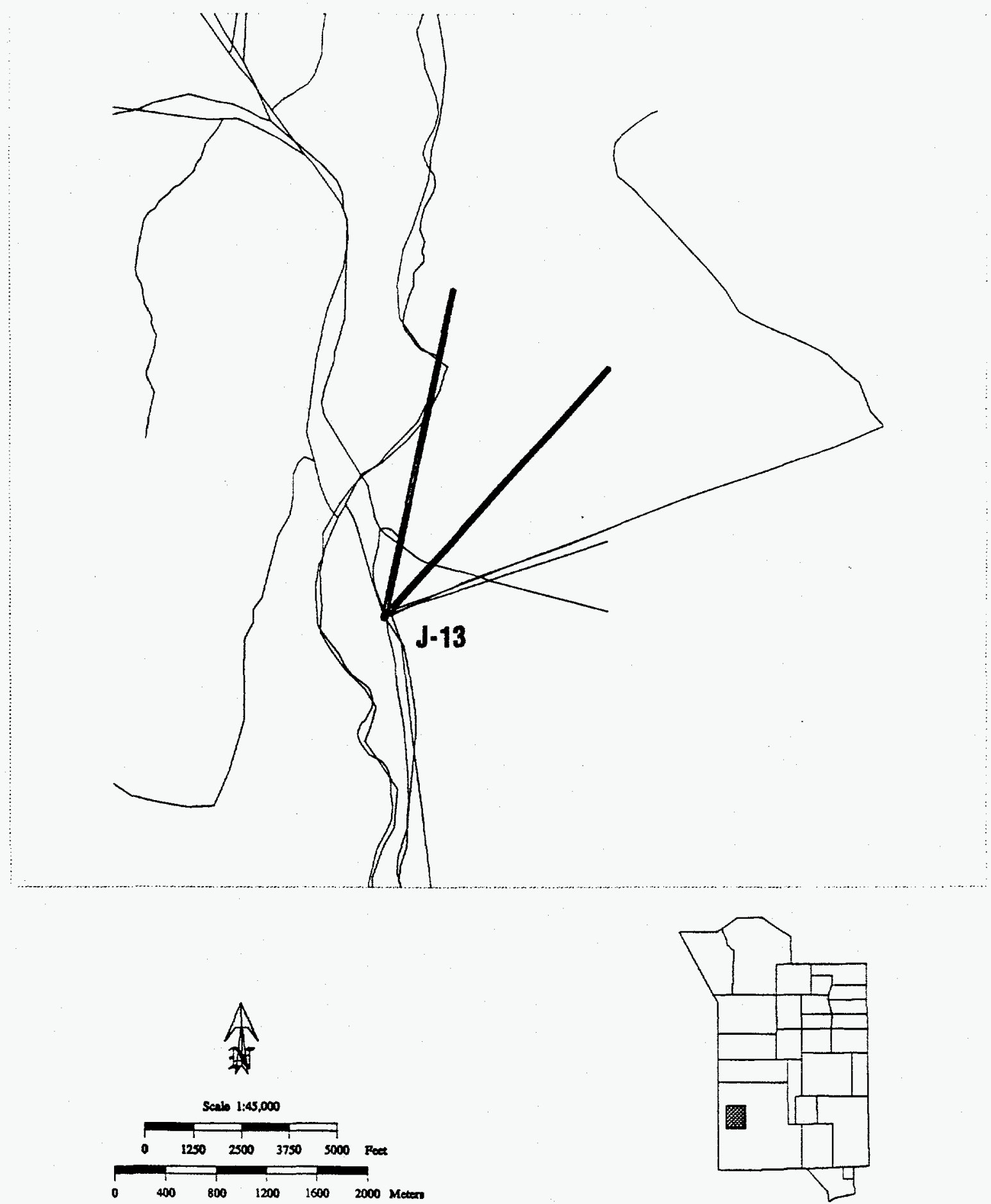

Figure $18 \mathrm{~b}$. Five-, 10-and 15-year time dependent capture zones for the $67 \%$ reliability level for Well J-13. Filled circle indicates a well. 


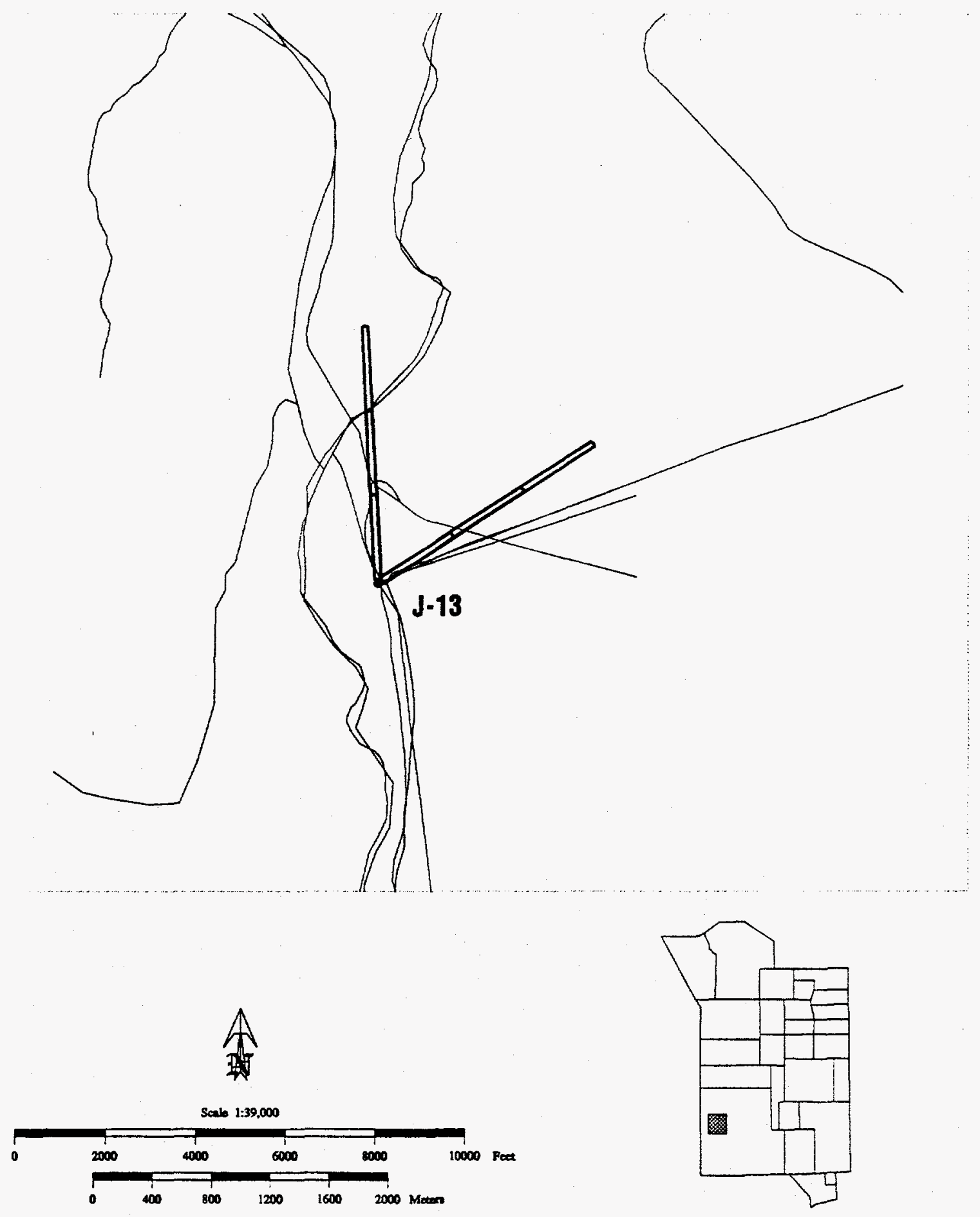

Figure 18c. Five-, 10-and 15-year time dependent capture zones for the $95 \%$ reliability level for Well J-13. Filled circle indicates a well. 

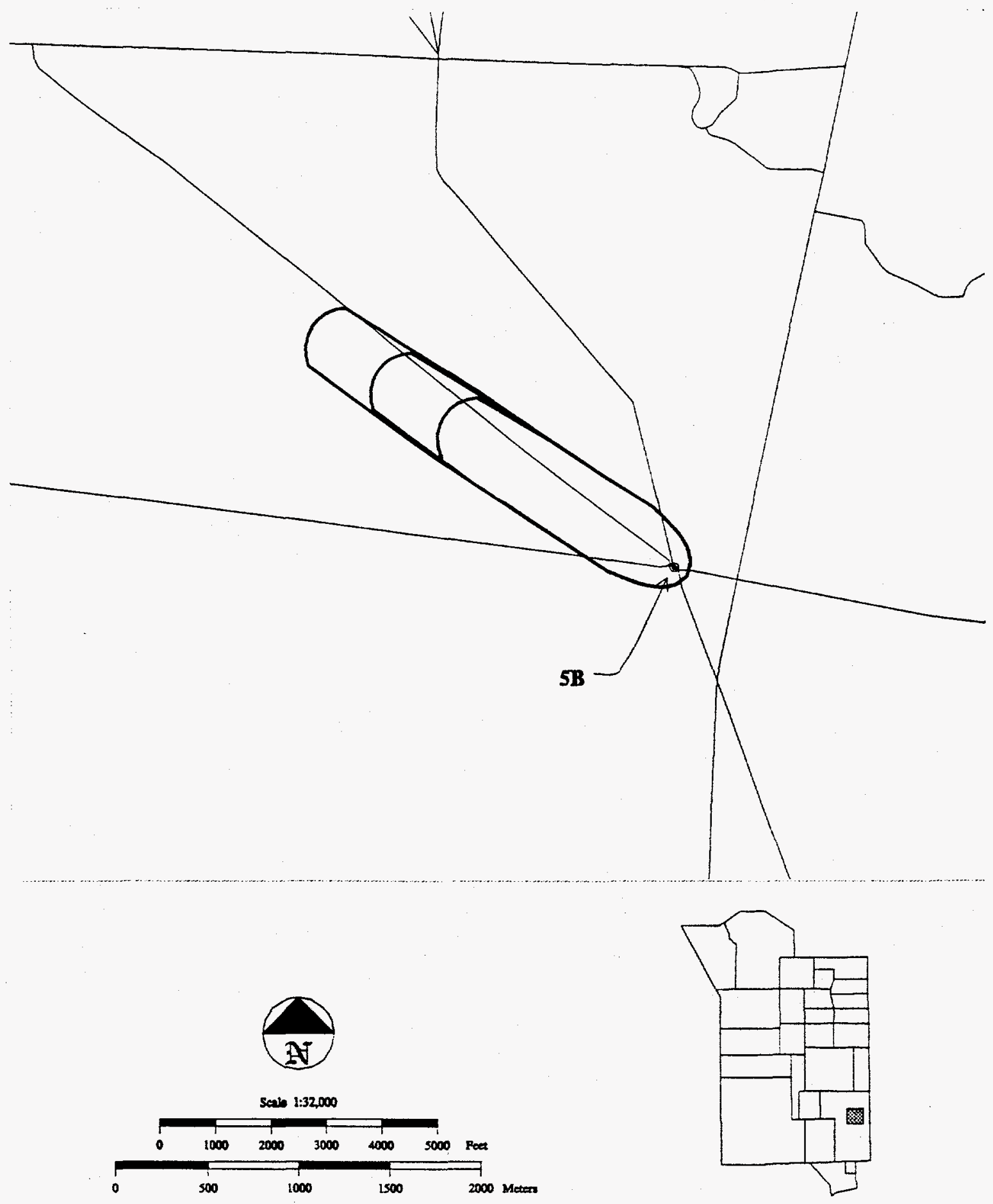

Figure 19a. Thirty-, 40- and 50-year time dependent capture zones for the 50\% reliability level for Well 5B. Filled circle indicates a well. 


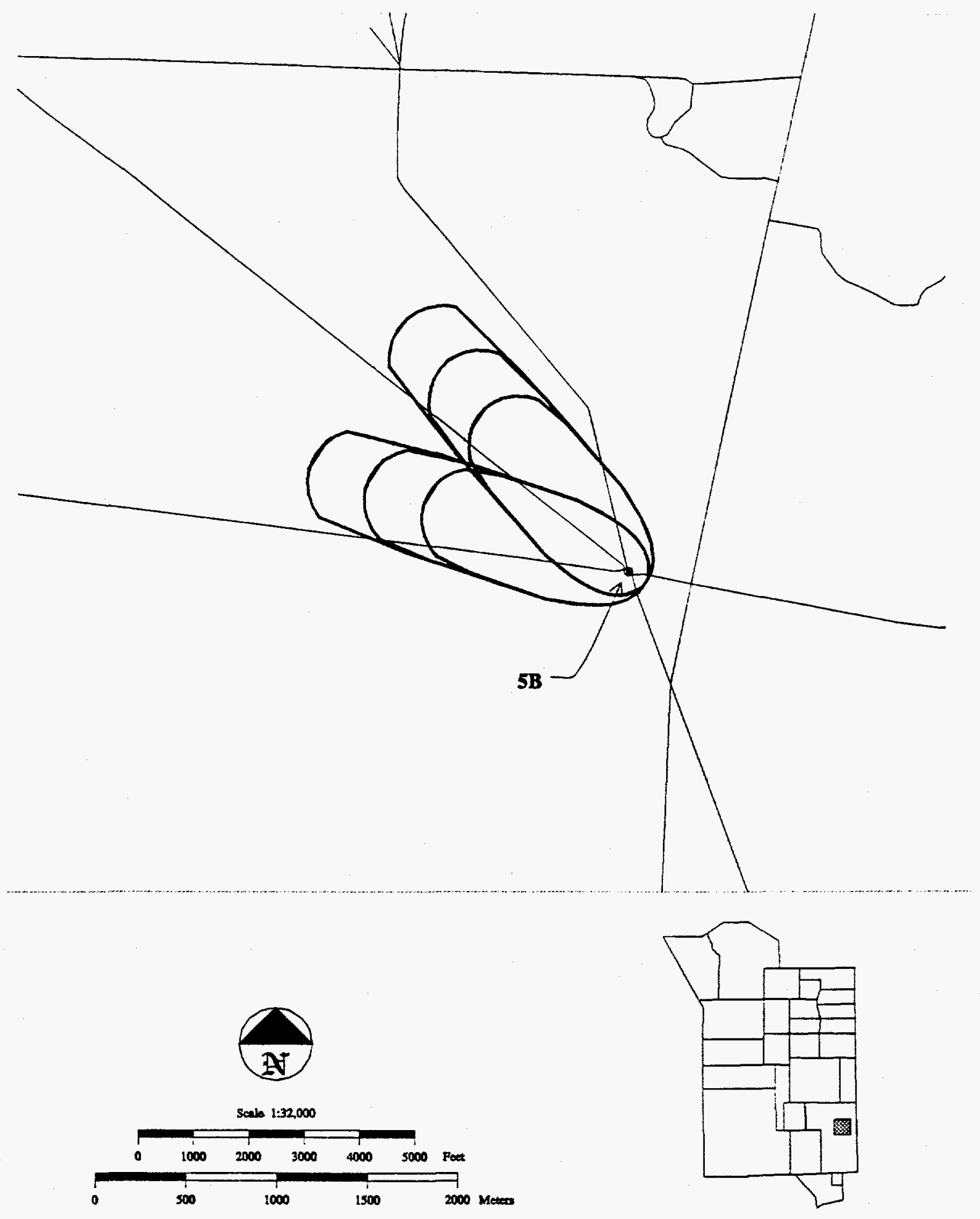

Figure 19b. Thirty-, 40- and 50-year time dependent capture zones for the $67 \%$ reliability level for Well 5B. Filled circle indicates a well. 

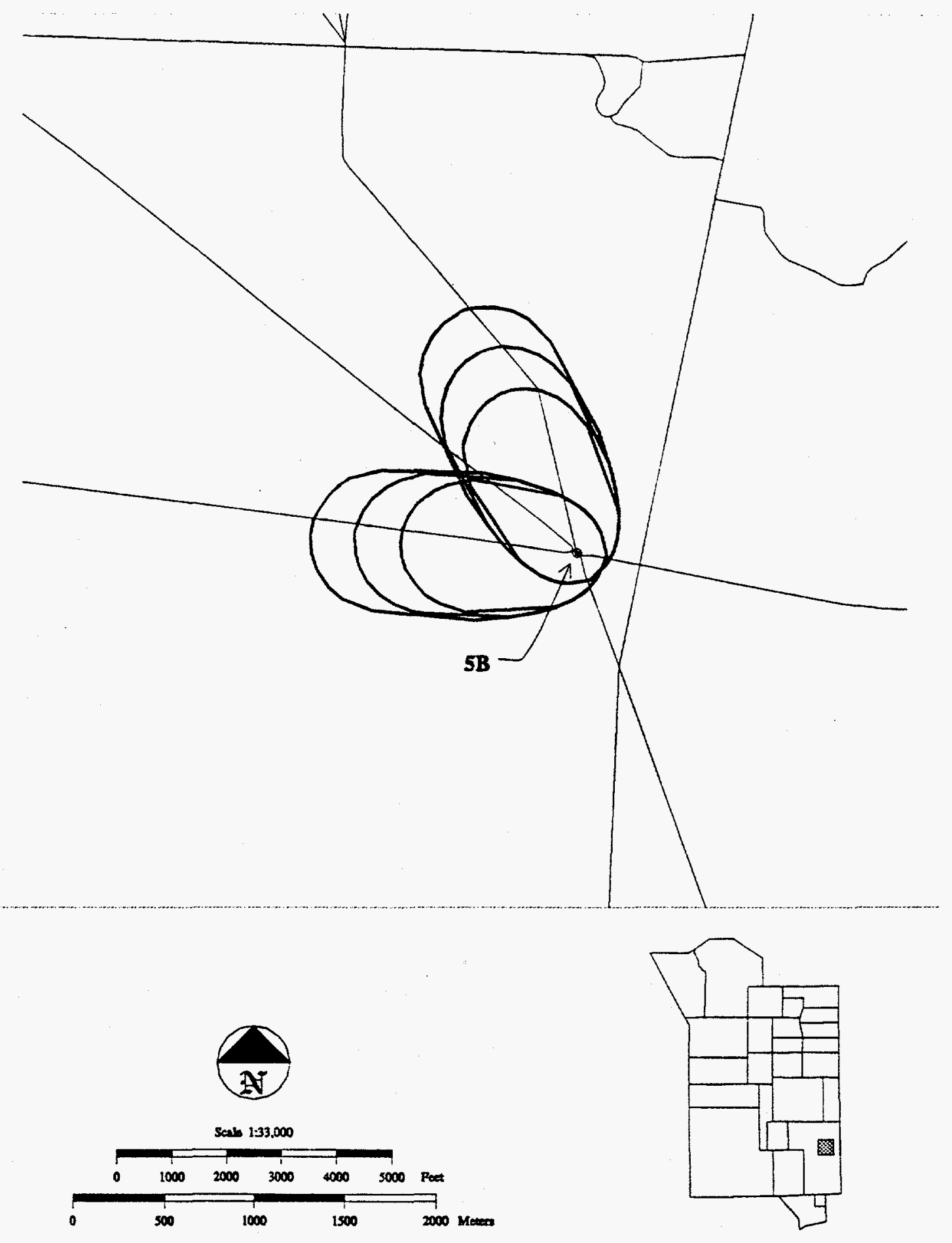

Figure 19c. Thirty-, 40- and 50-year time dependent capture zones for the $95 \%$ reliability level for Well 5B. Filled circle indicates a well. 

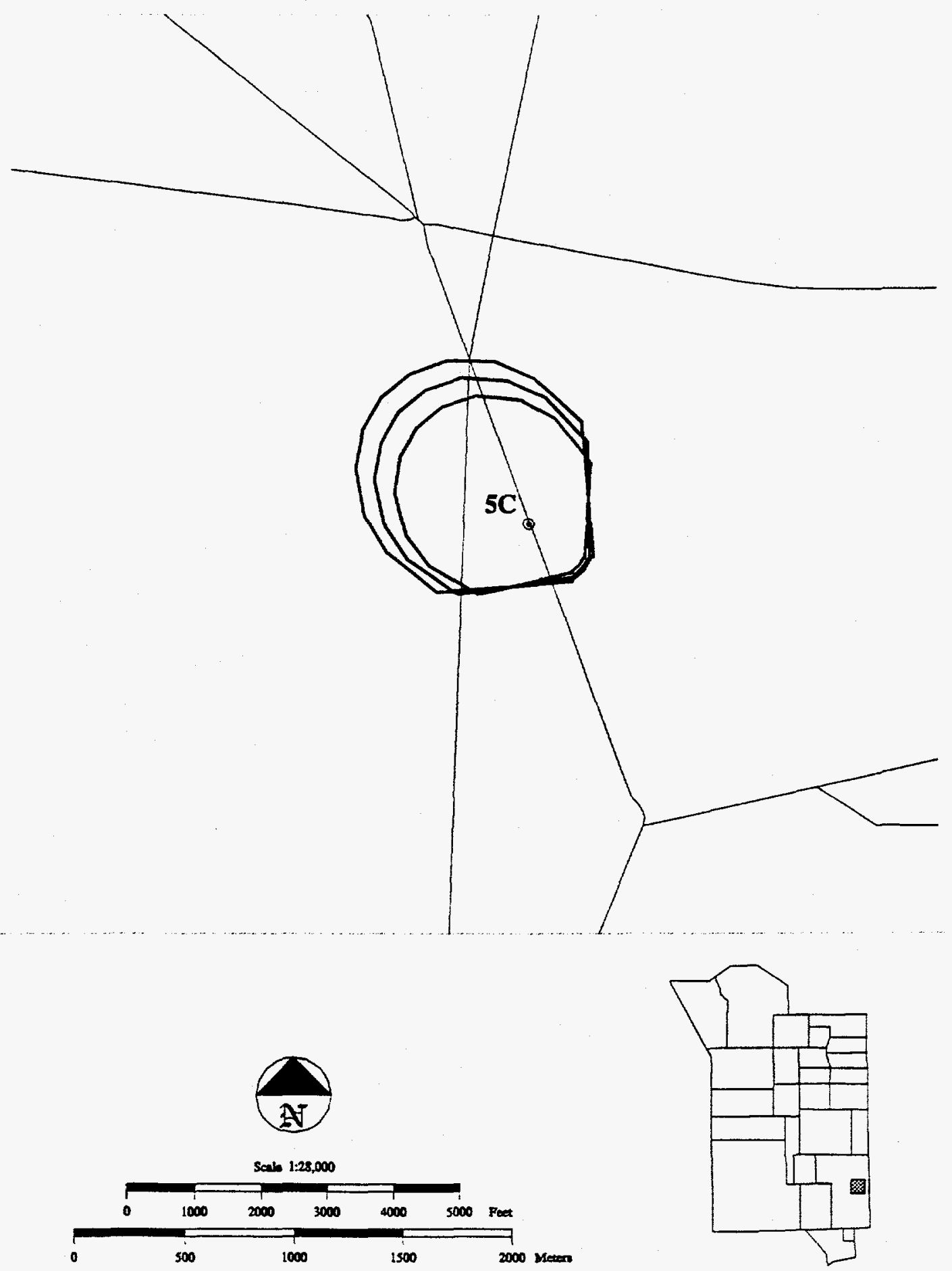

Figure 20a. Forty-, 50-and 60-year time dependent capture zones for the 50\% reliability level for Well 5C. Filled circle indicates a well. 


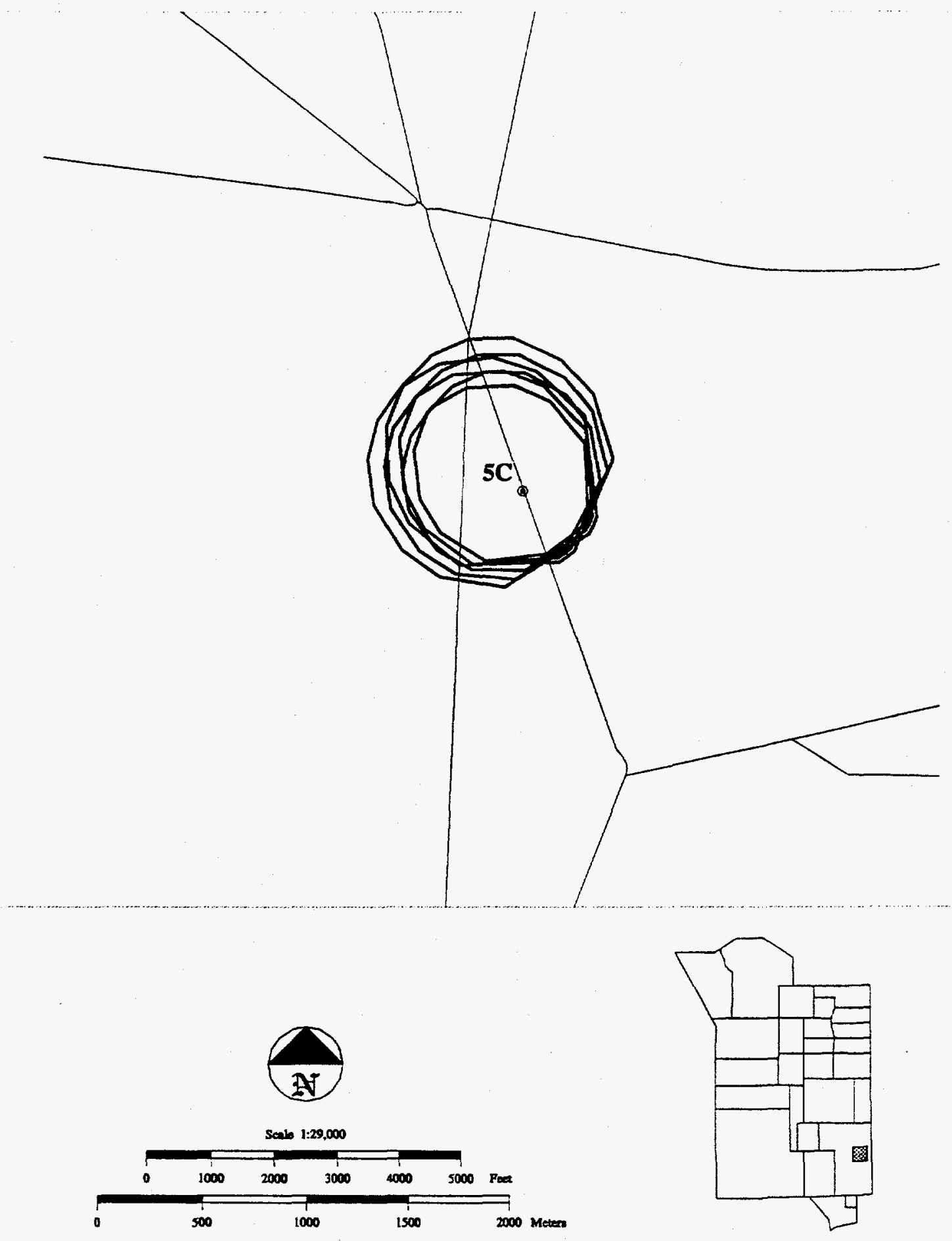

Figure 20b. Forty-, 50-and 60-year time dependent capture zones for the $67 \%$ reliability level for Well 5C. Filled circle indicates a well. 

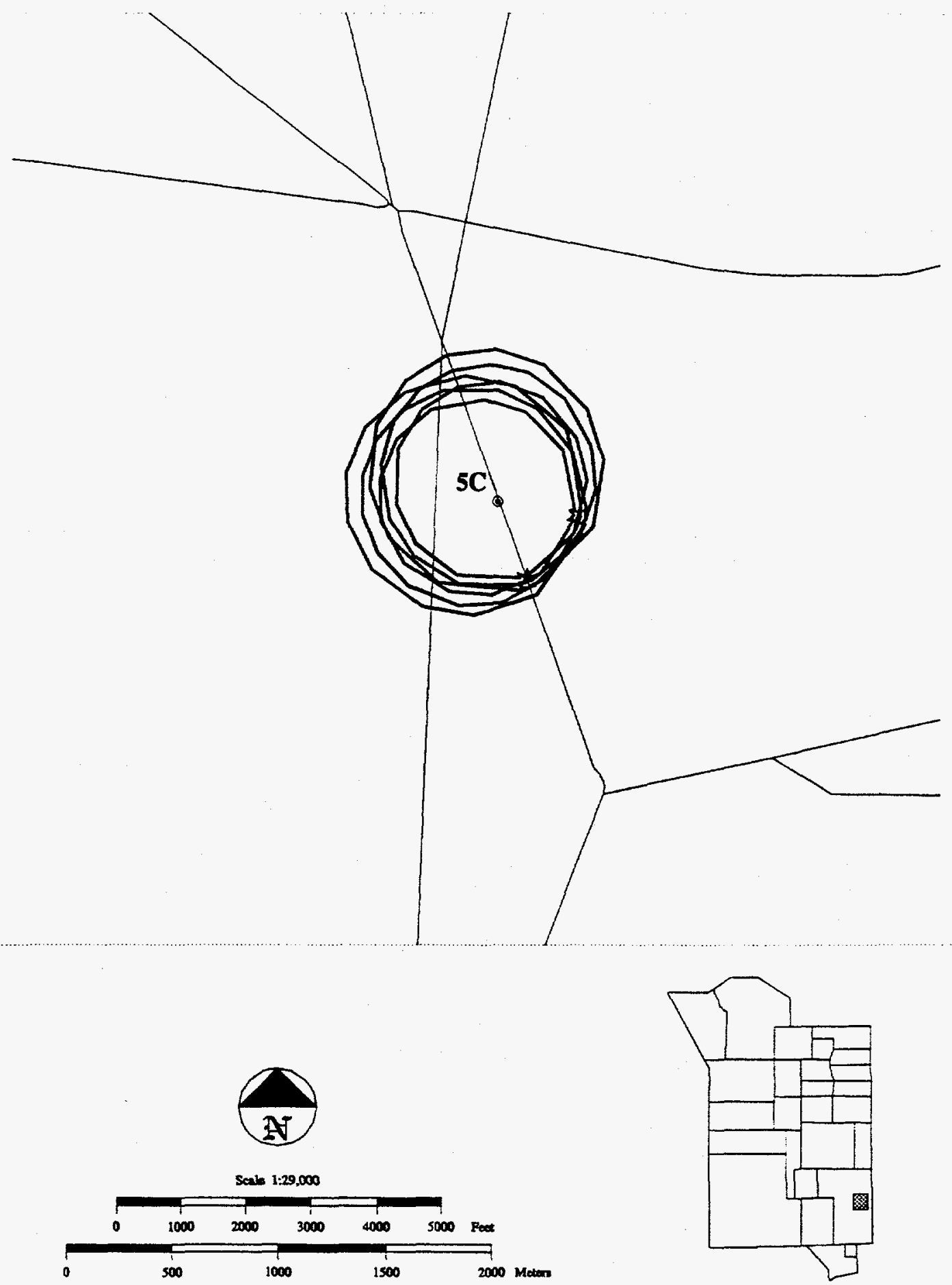

Figure 20c. Forty-, 50- and 60-year time dependent capture zones for the $95 \%$ reliability level for Well 5C. Filled circle indicates a well. 

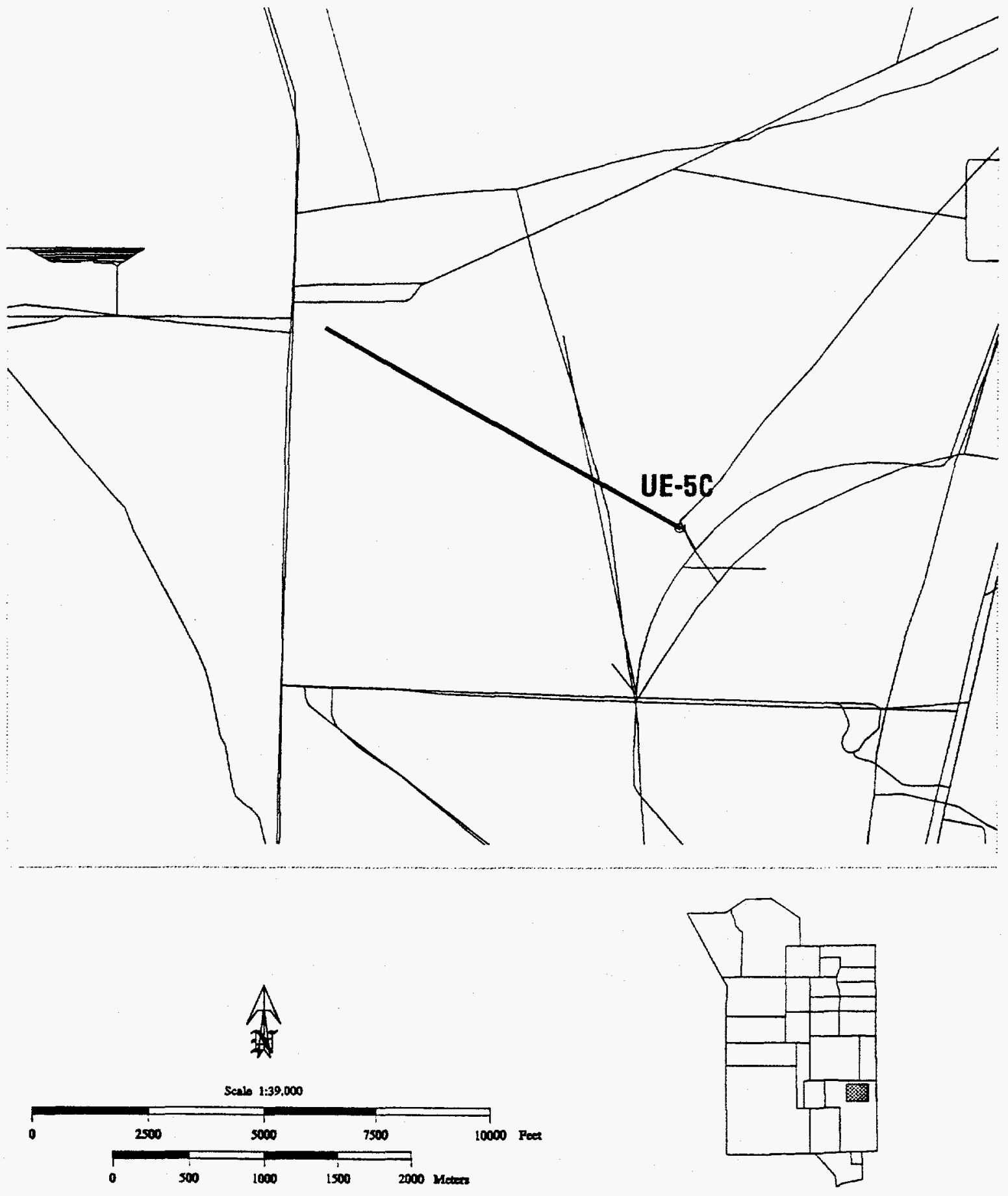

Figure 21a. Thirty-, 40- and 50-year time dependent capture zones for the 50\% reliability level for Well UE-5C. Filled circle indicates a well. 


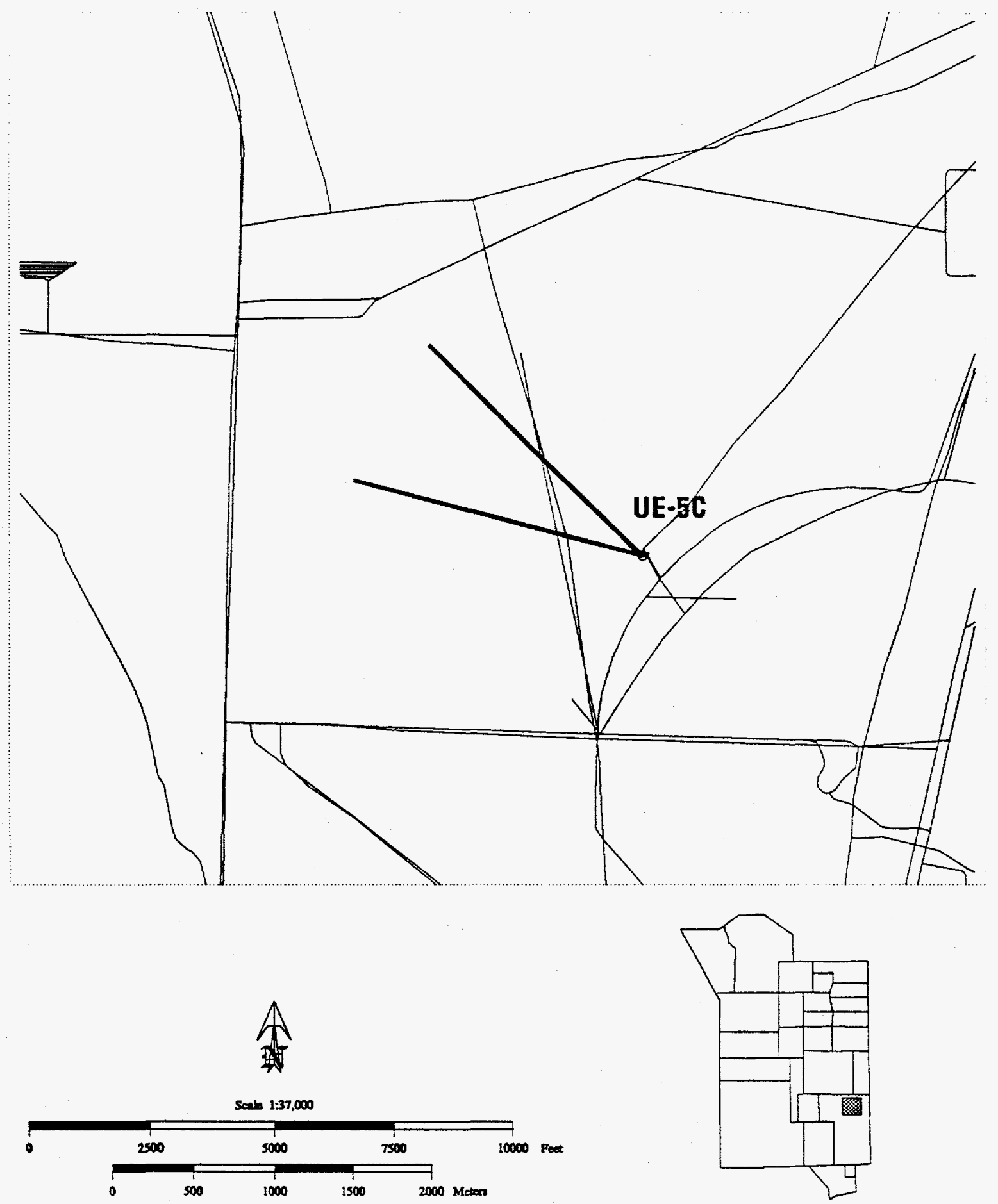

Figure 21b. Thirty-, 40- and 50-year time dependent capture zones for the $67 \%$ reliability level for Well UE-5C. Filled circle indicates a well. 


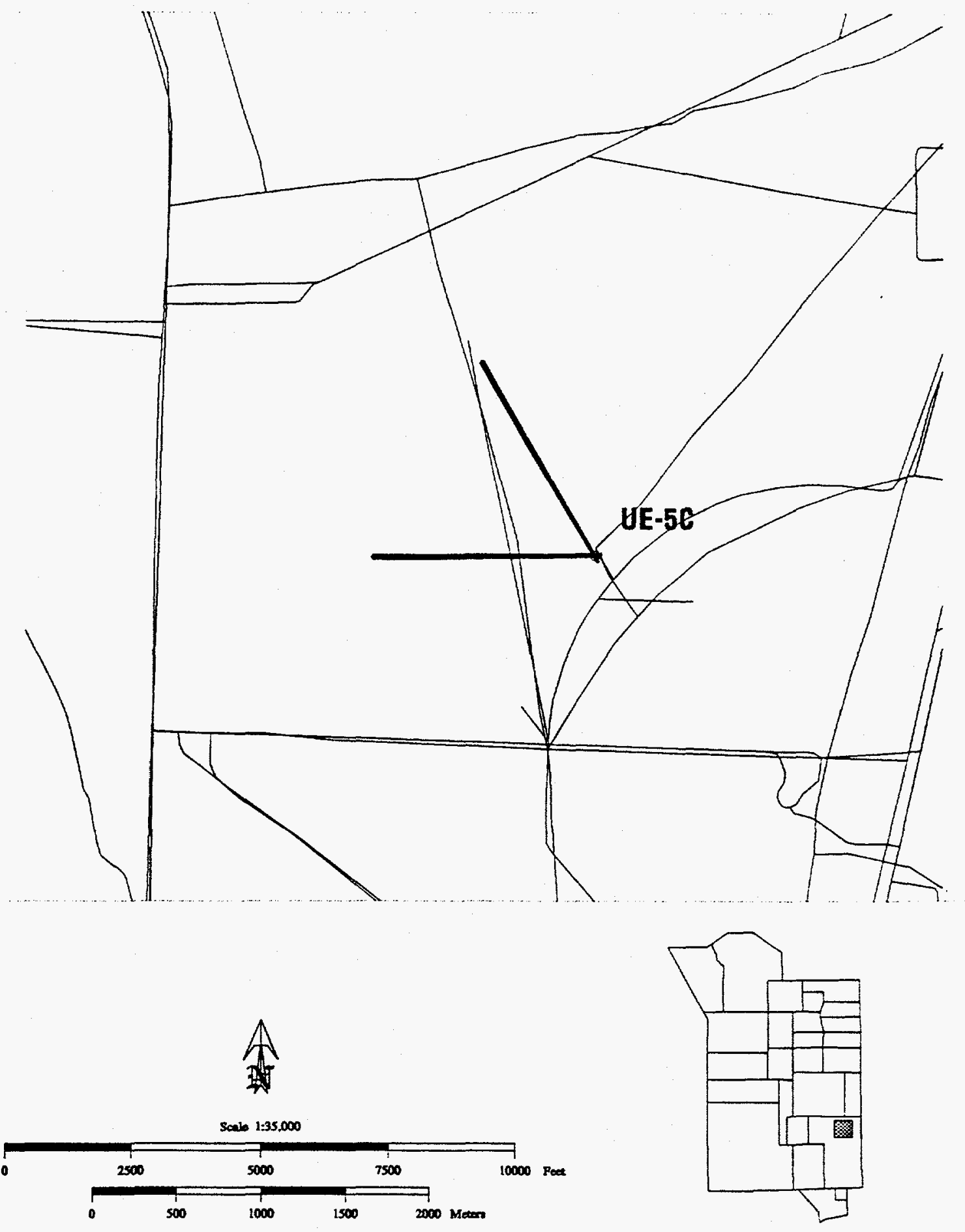

Figure 21c. Thirty-, 40- and 50-year time dependent capture zones for the $95 \%$ reliability level for Well UE-5C. Filled circle indicates a well. 


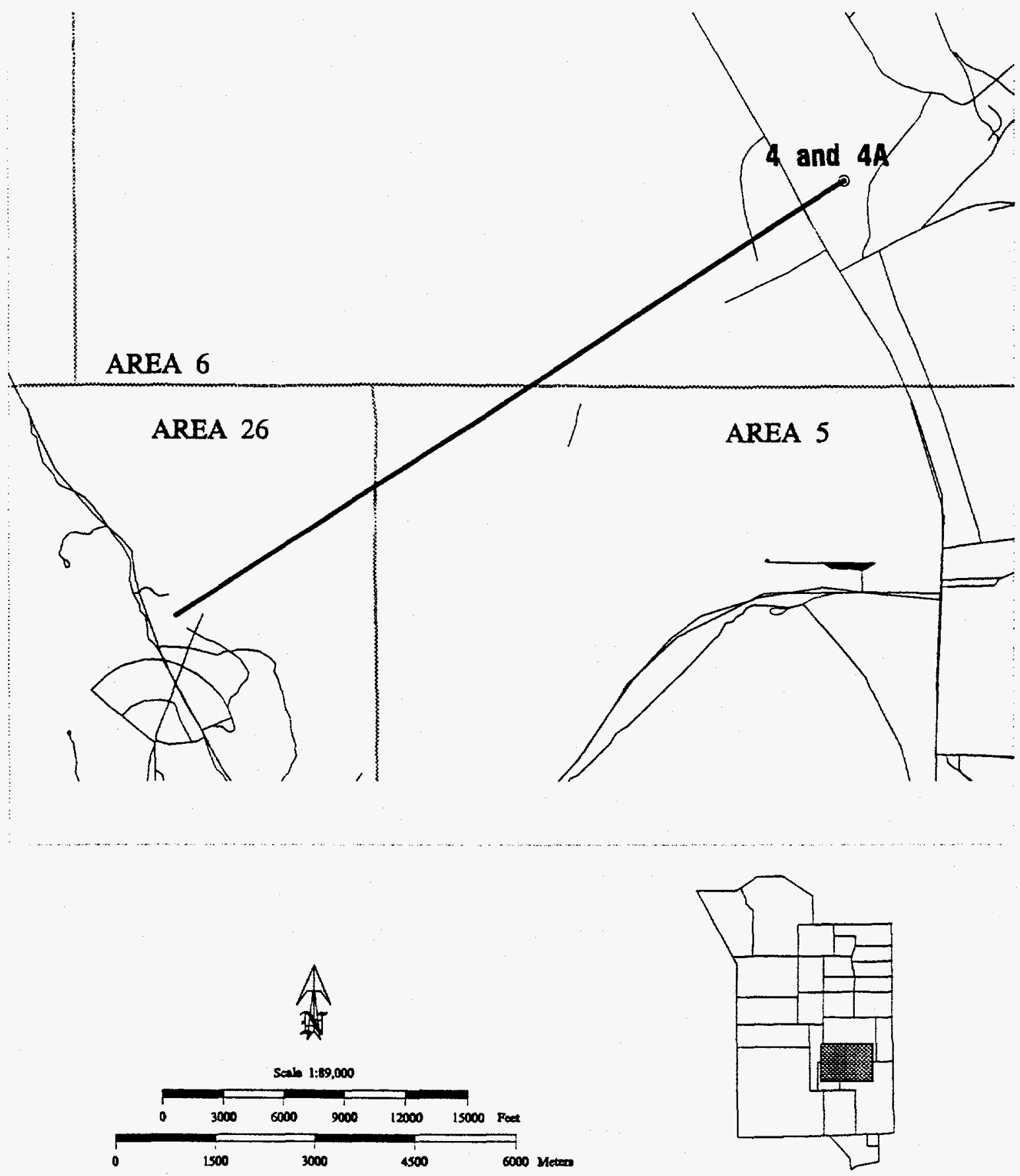

Figure 22a. Three-, four-and five-year time dependent capture zones for the $50 \%$ reliability level for Wells 4 and 4A. Filled circle indicates a well. 

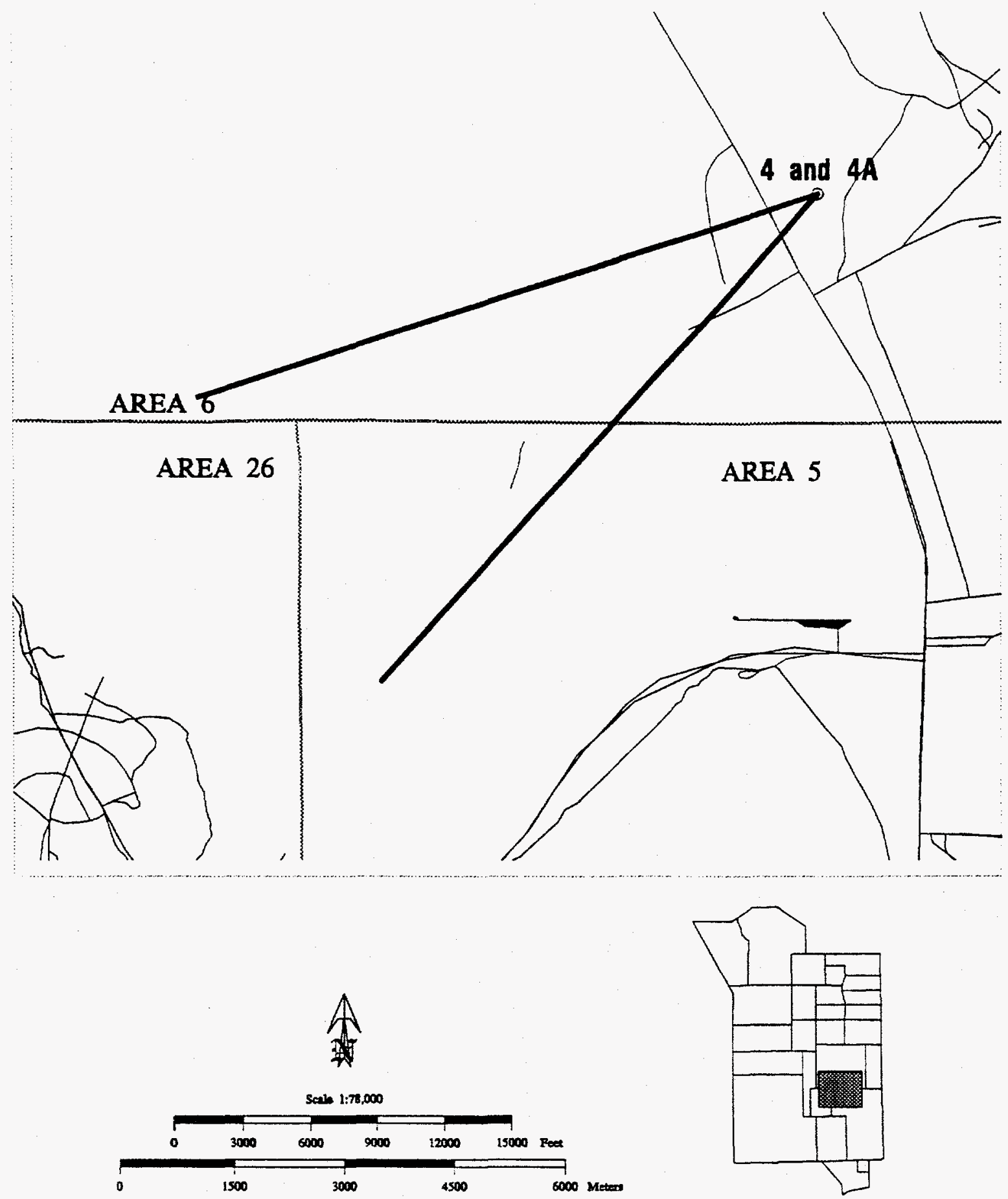

Figure $22 \mathrm{~b}$. Three-, four- and five-year time dependent capture zones for the $67 \%$ reliability level for Wells 4 and 4A. Filled circle indicates a well. 


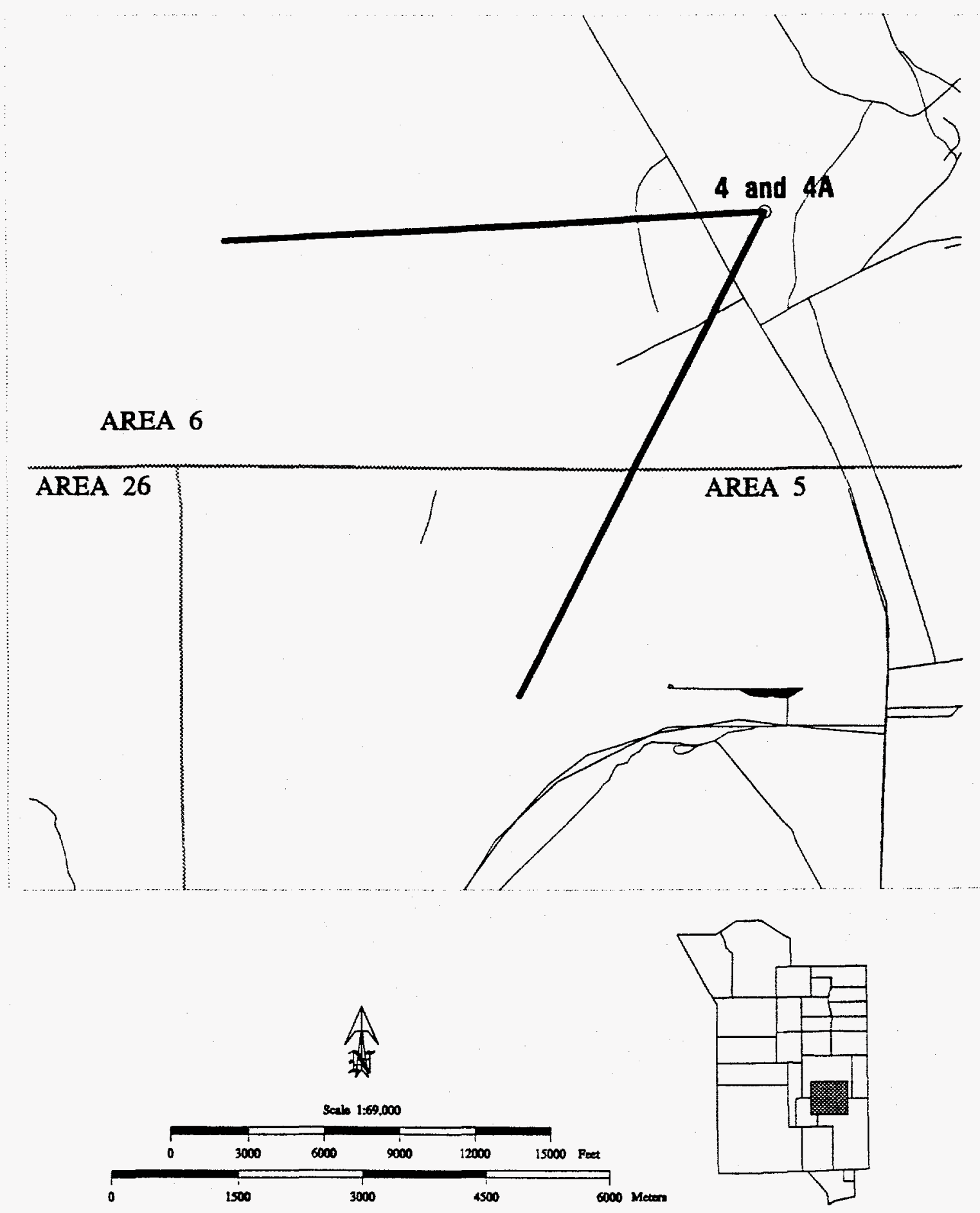

Figure 22c. Three-, four-and five-year time dependent capture zones for the $95 \%$ reliability level for Wells 4 and $4 \mathrm{~A}$. Filled circle indicates a well. 


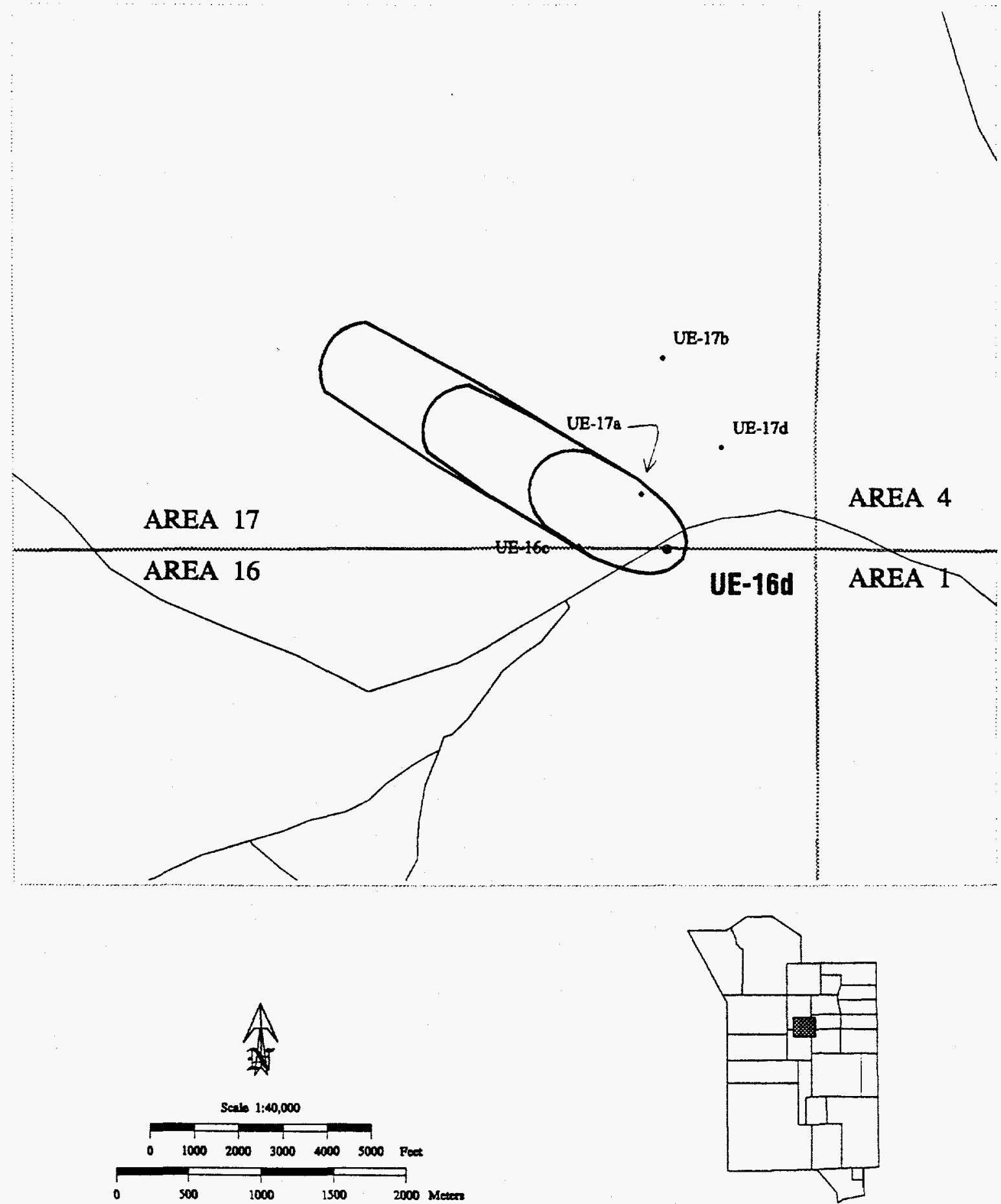

Figure 23a. Five-, 10-and 15-year time dependent capture zones for the $50 \%$ reliability level for Well UE-16d. Filled circle indicates a well. 


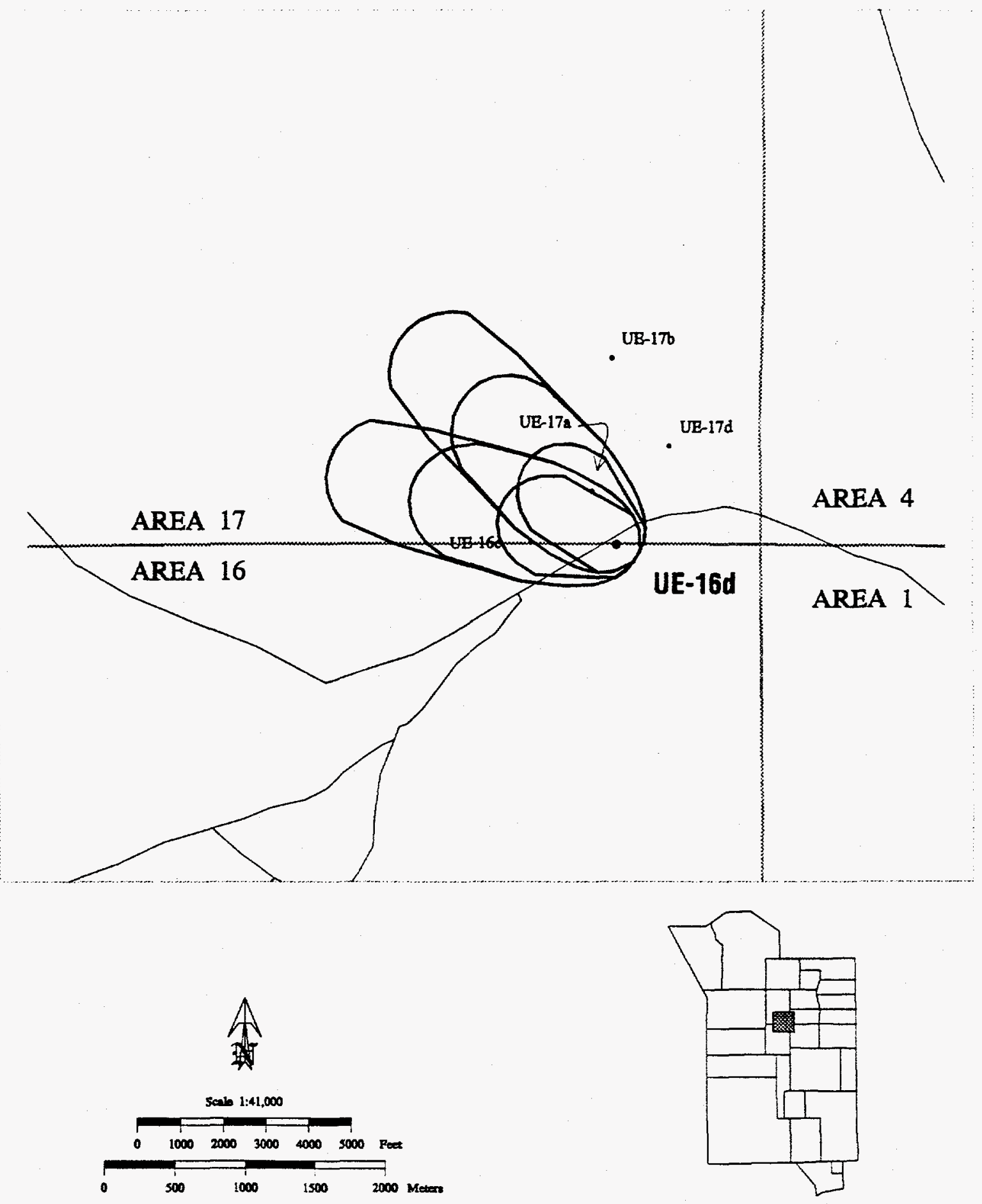

Figure $23 \mathrm{~b}$. Five-, 10 -and 15-year time dependent capture zones for the $67 \%$ reliability level for Well UE-16d. Filled circle indicates a well. 


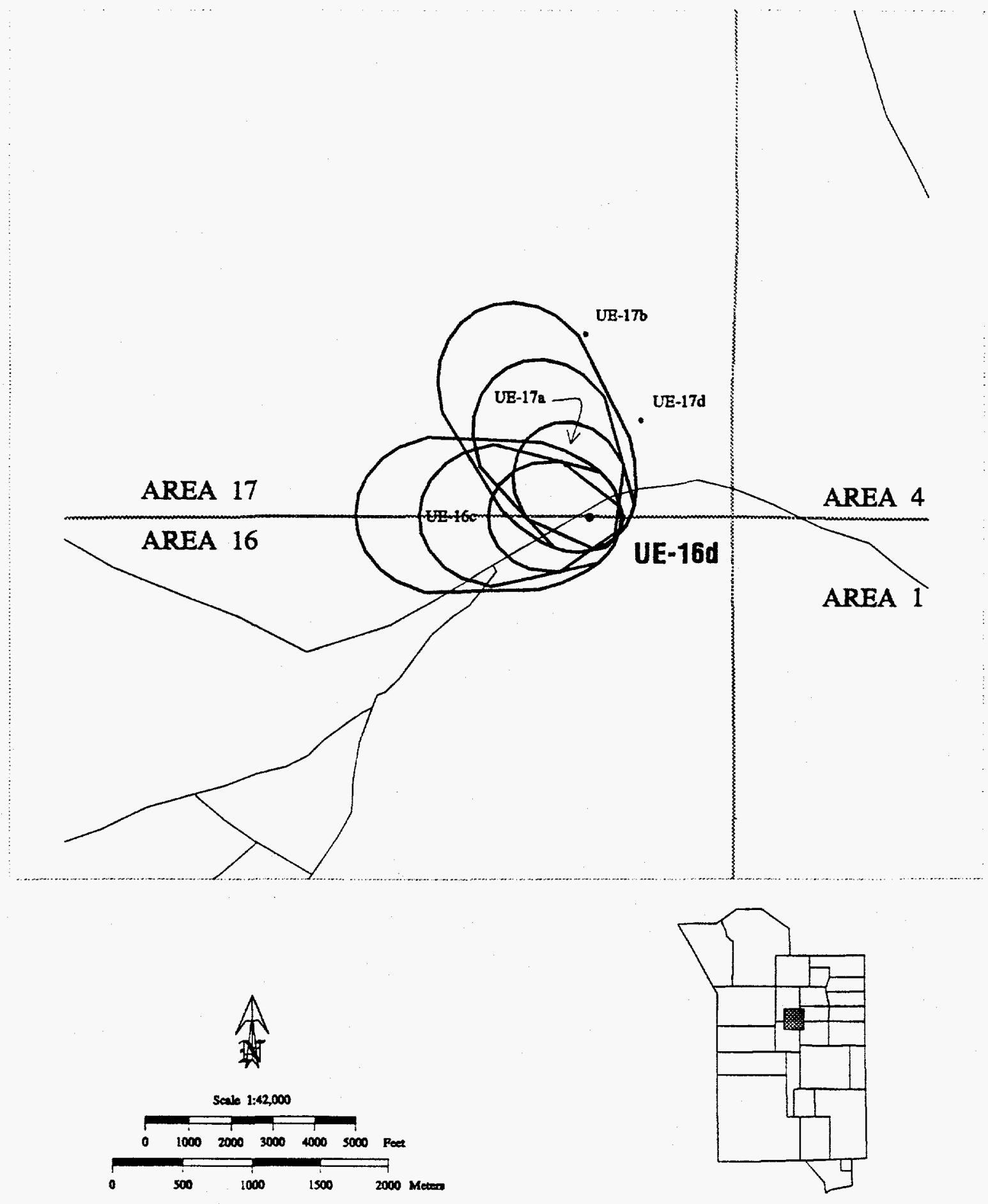

Figure 23c. Five-, 10-and 15-year time dependent capture zones for the $95 \%$ reliability level for Well UE-16d. Filled circle indicates a well. 

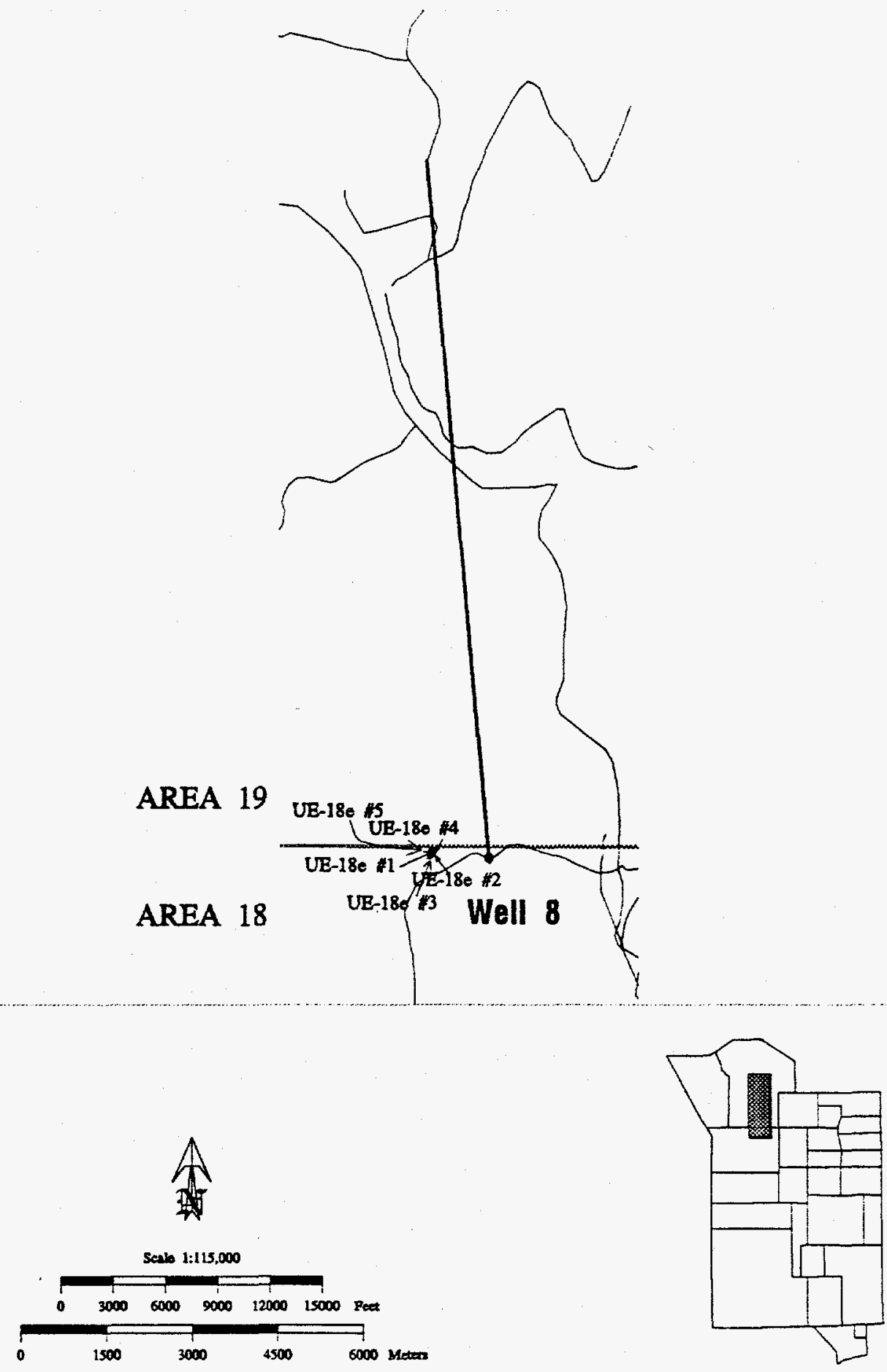

Figure 24a. Five-, 10-and 15-year time dependent capture zones for the $50 \%$ reliability level for Well 8. Filled circle indicates a well. 

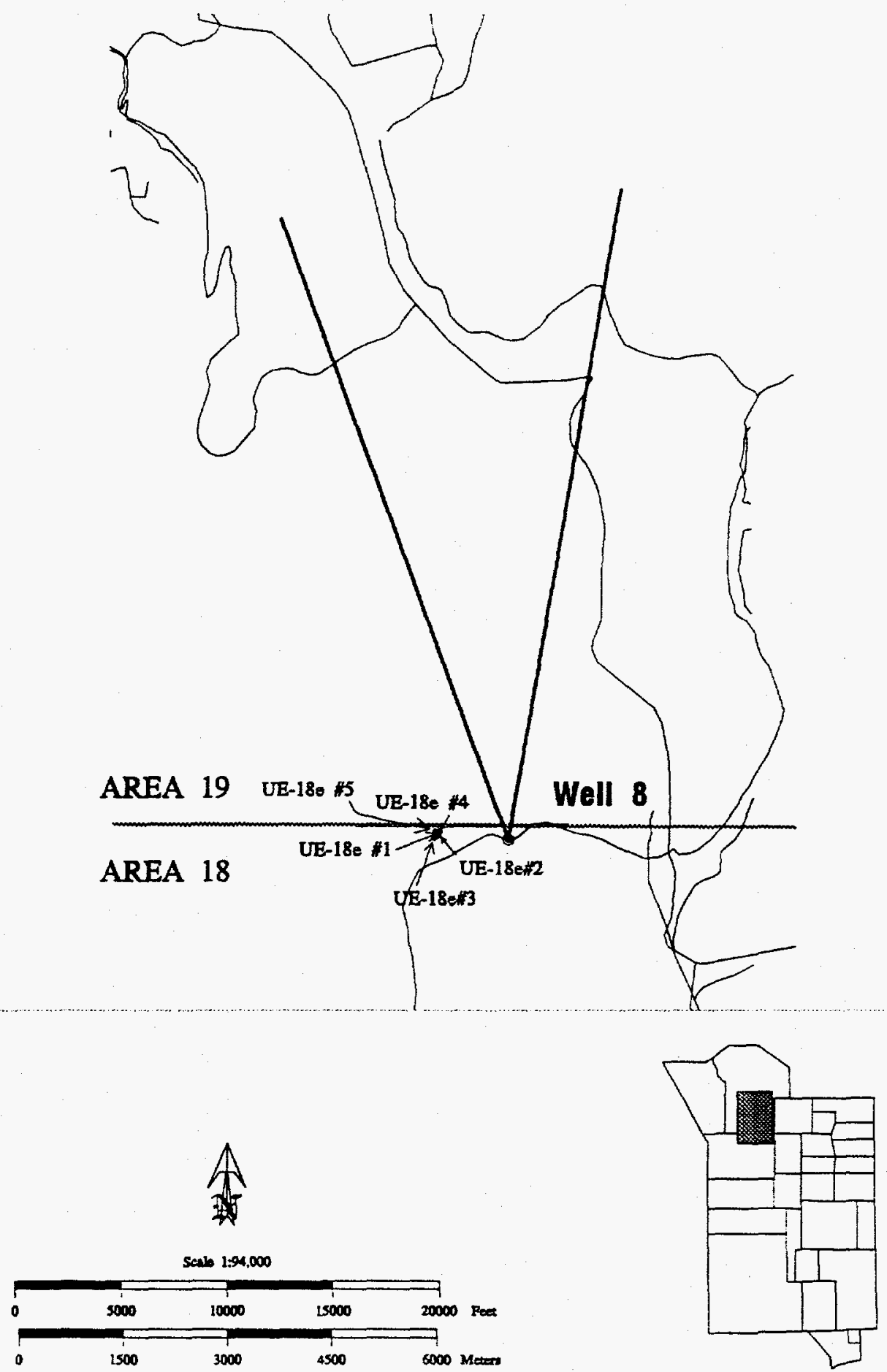

Figure 24b. Five-, 10-and 15-year time dependent capture zones for the $67 \%$ reliability level for Well 8. Filled circle indicates a well. 


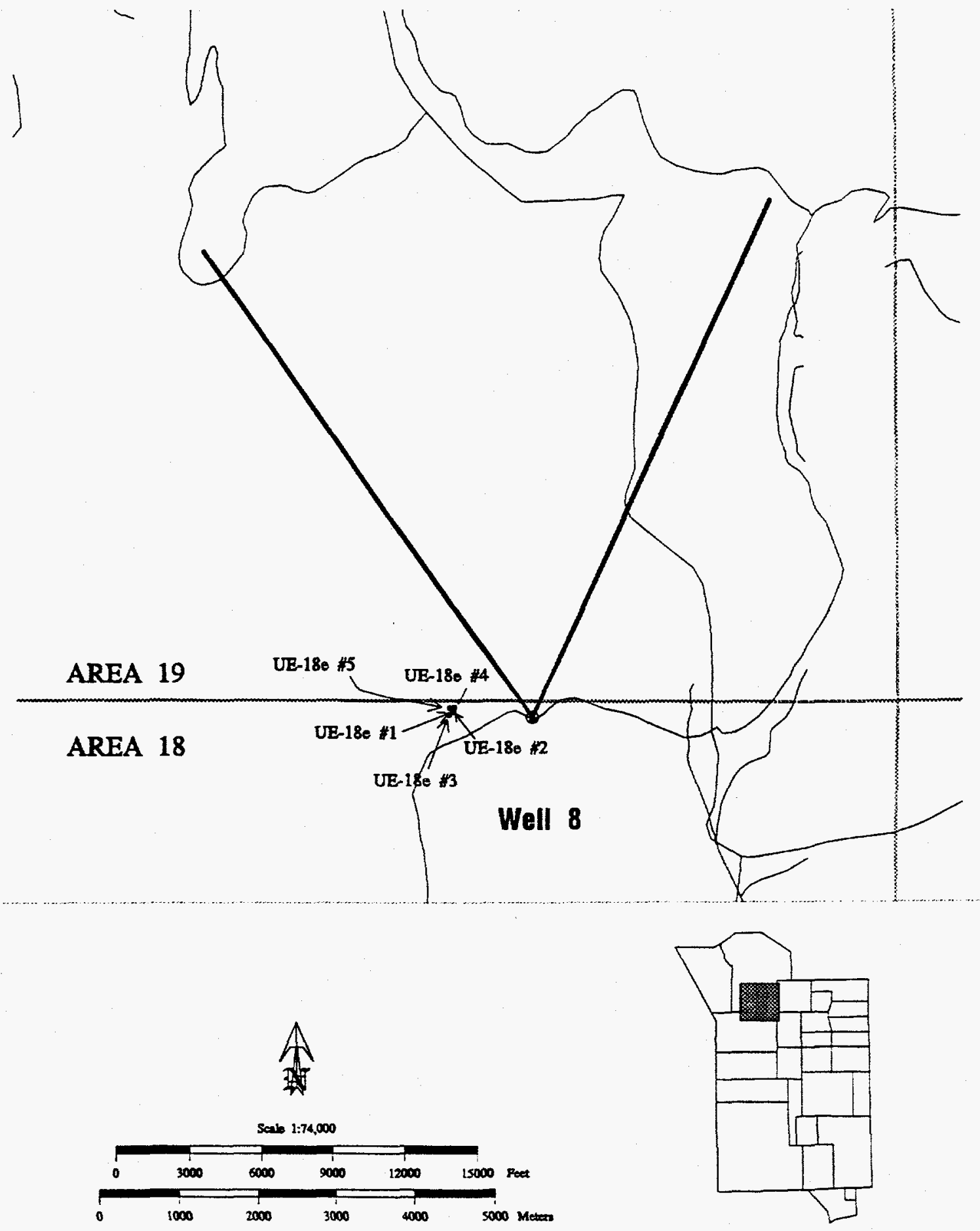

Figure 24c. Five-, 10-and 15-year time dependent capture zones for the $95 \%$ reliability level for Well 8. Filled circle indicates a well. 
AREA 19
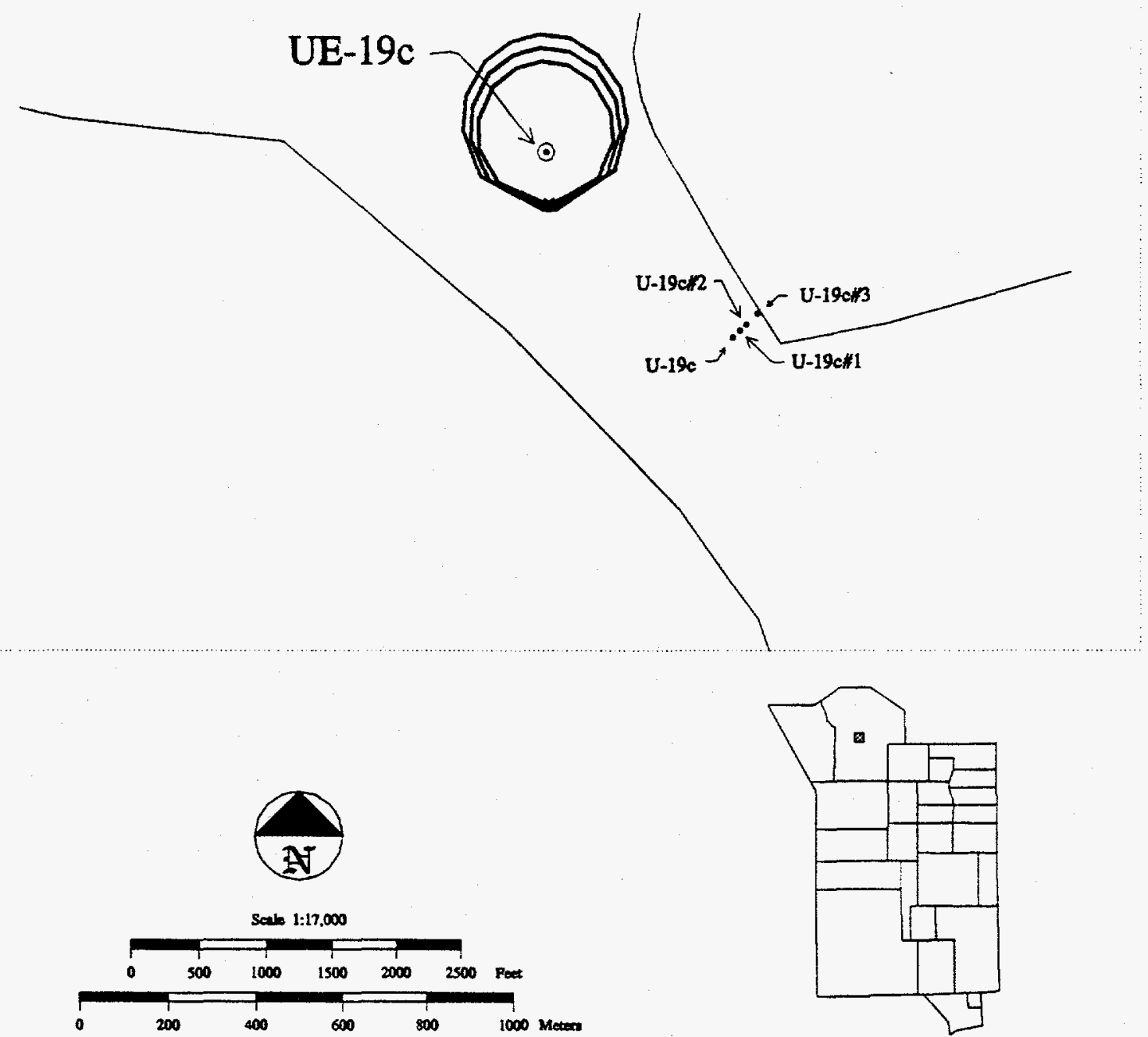

Figure 25a. Forty-, 50-and 60-year time dependent capture zones for the 50\% reliability level for UE-19c. Filled circle indicates a well. 

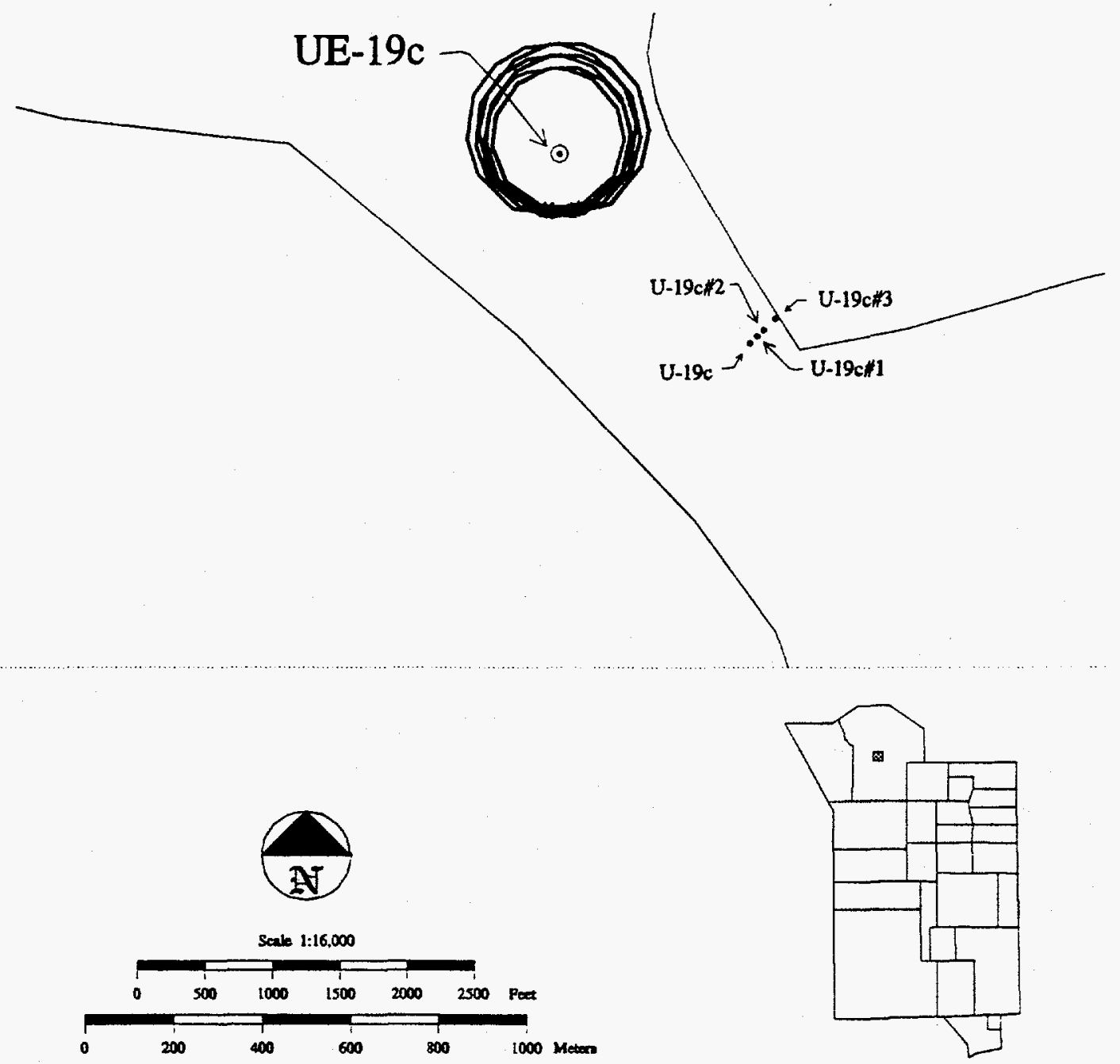

Figure 25b. Forty-, 50-and 60-year time dependent capture zones for the $67 \%$ reliability level for UE-19c. Filled circle indicates a well. 

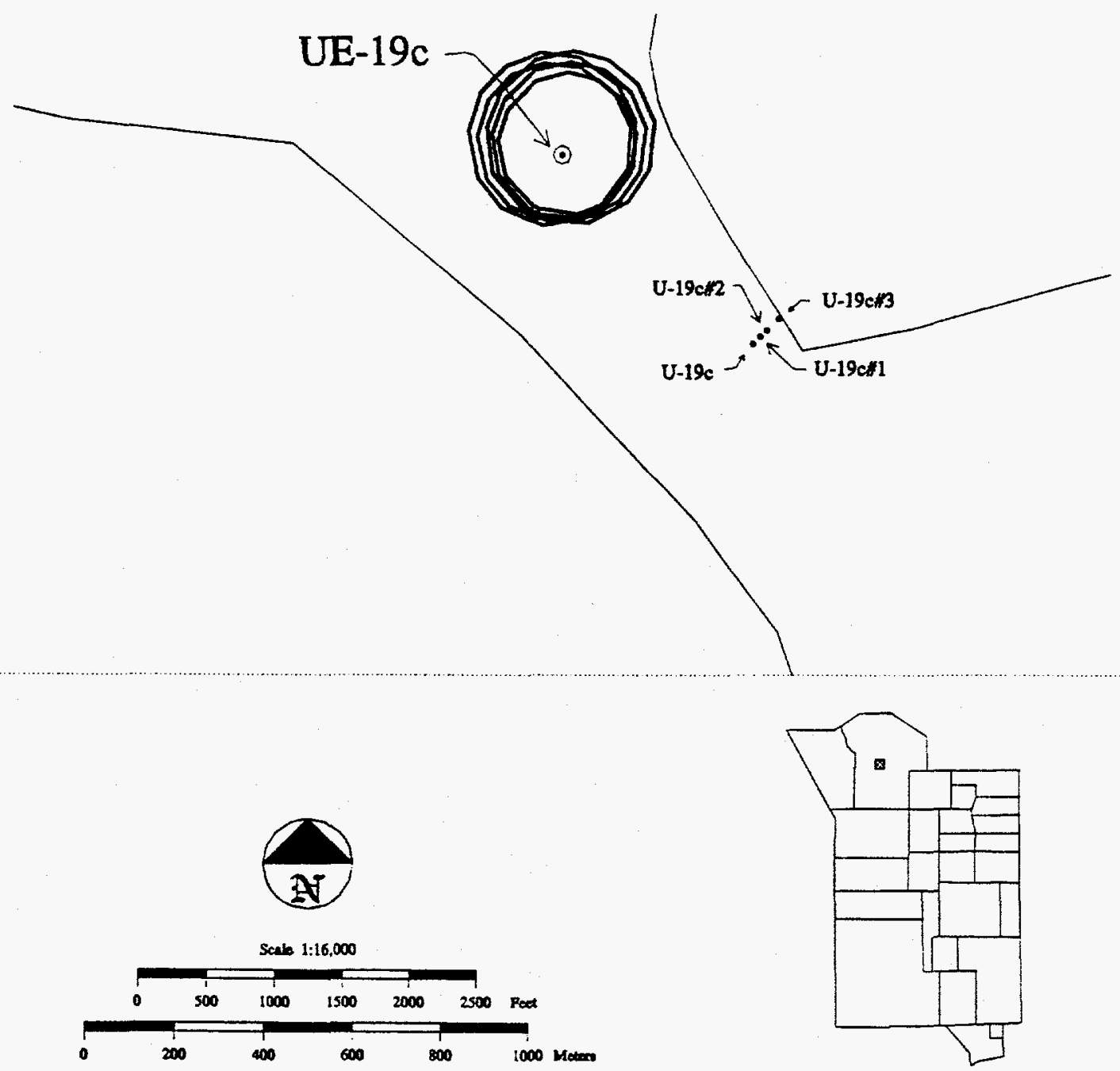

Figure 25c. Forty-, 50- and 60-year time dependent capture zones for the $95 \%$ reliability level for UE-19c. Filled circle indicates a well. 

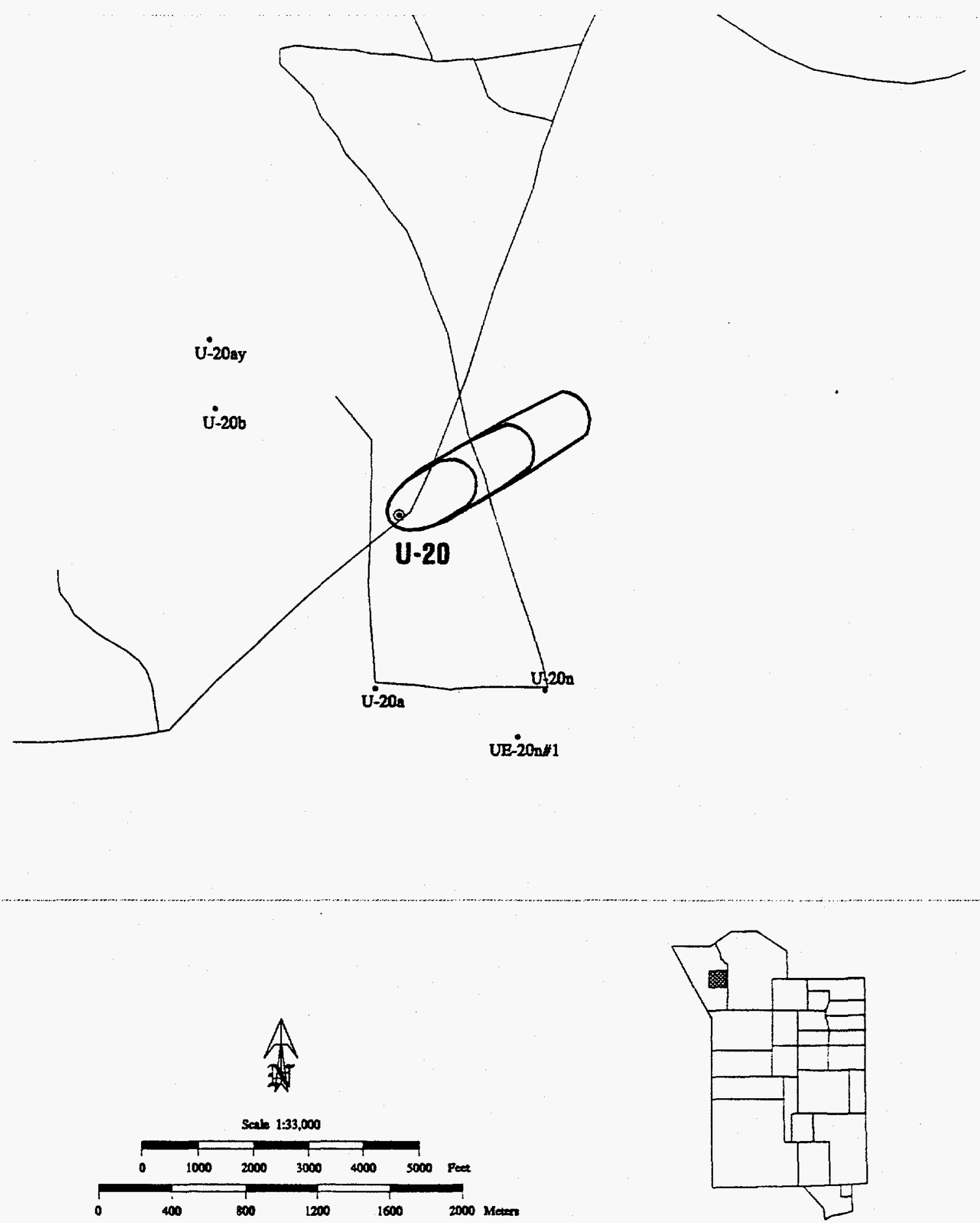

Figure 26a. Five-, 10-and 15-year time dependent capture zones for the $50 \%$ reliability level for U-20. Filled circle indicates a well. 

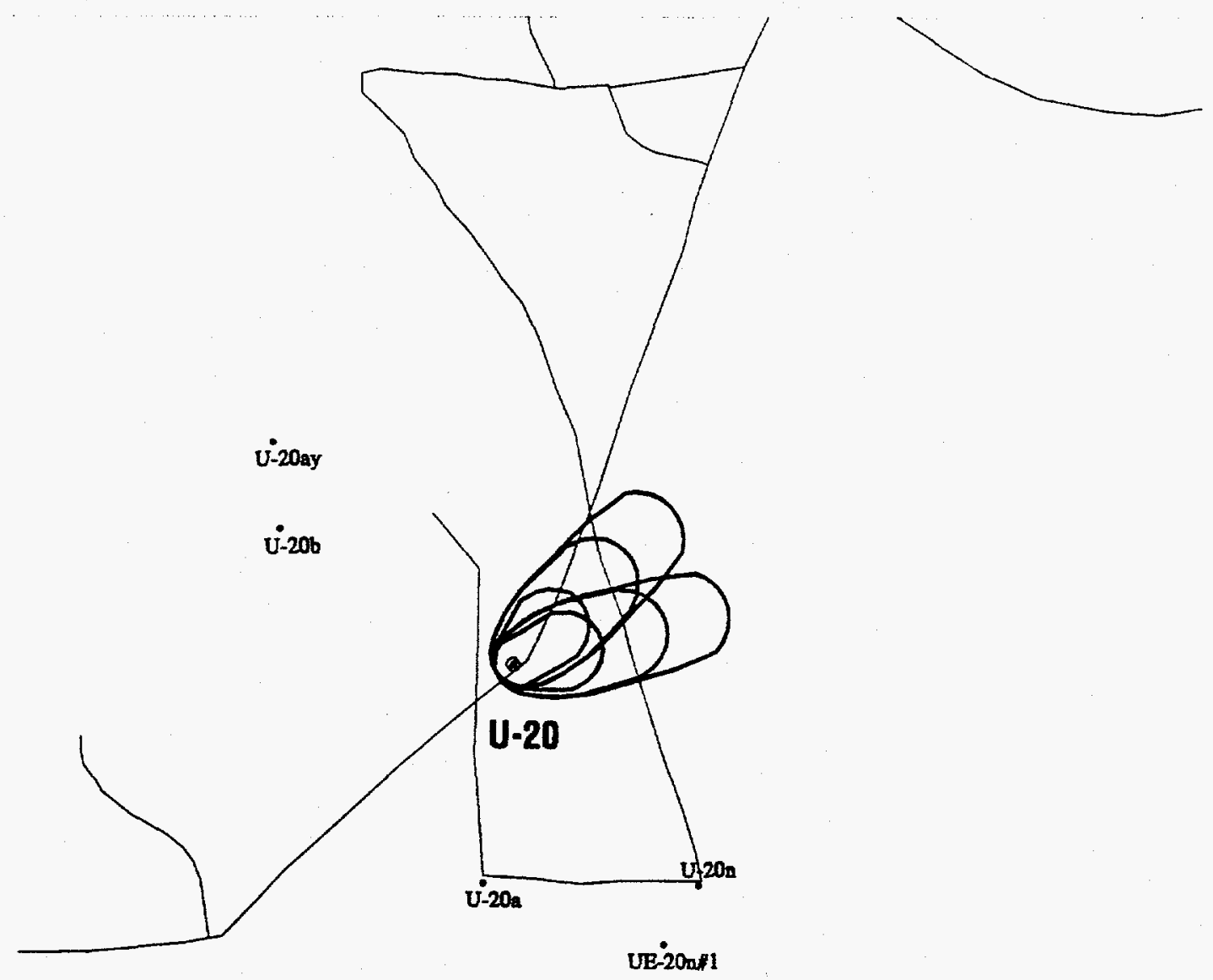

UE-200
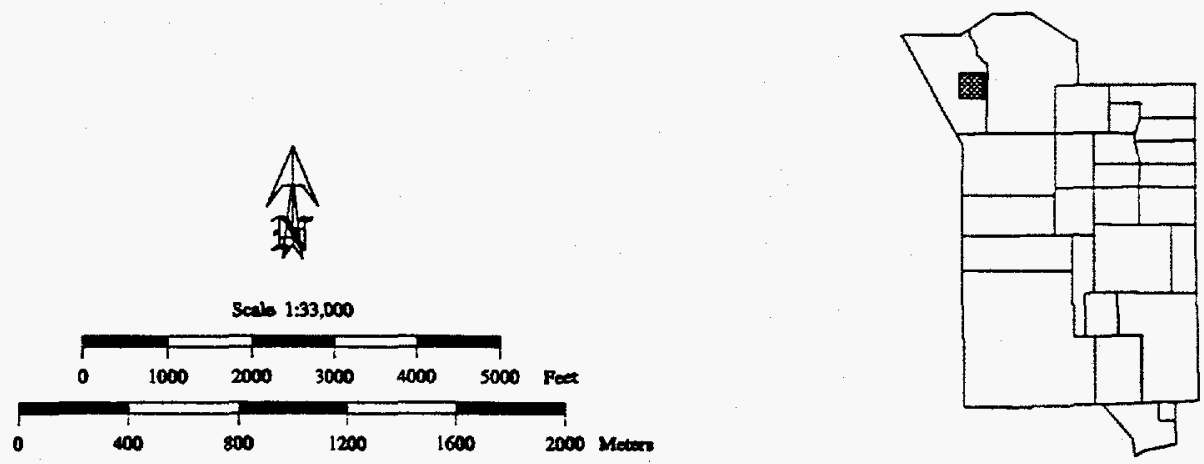

Figure 26b. Five-, 10- and 15-year time dependent capture zones for the $67 \%$ reliability level for U-20. Filled circle indicates a well. 

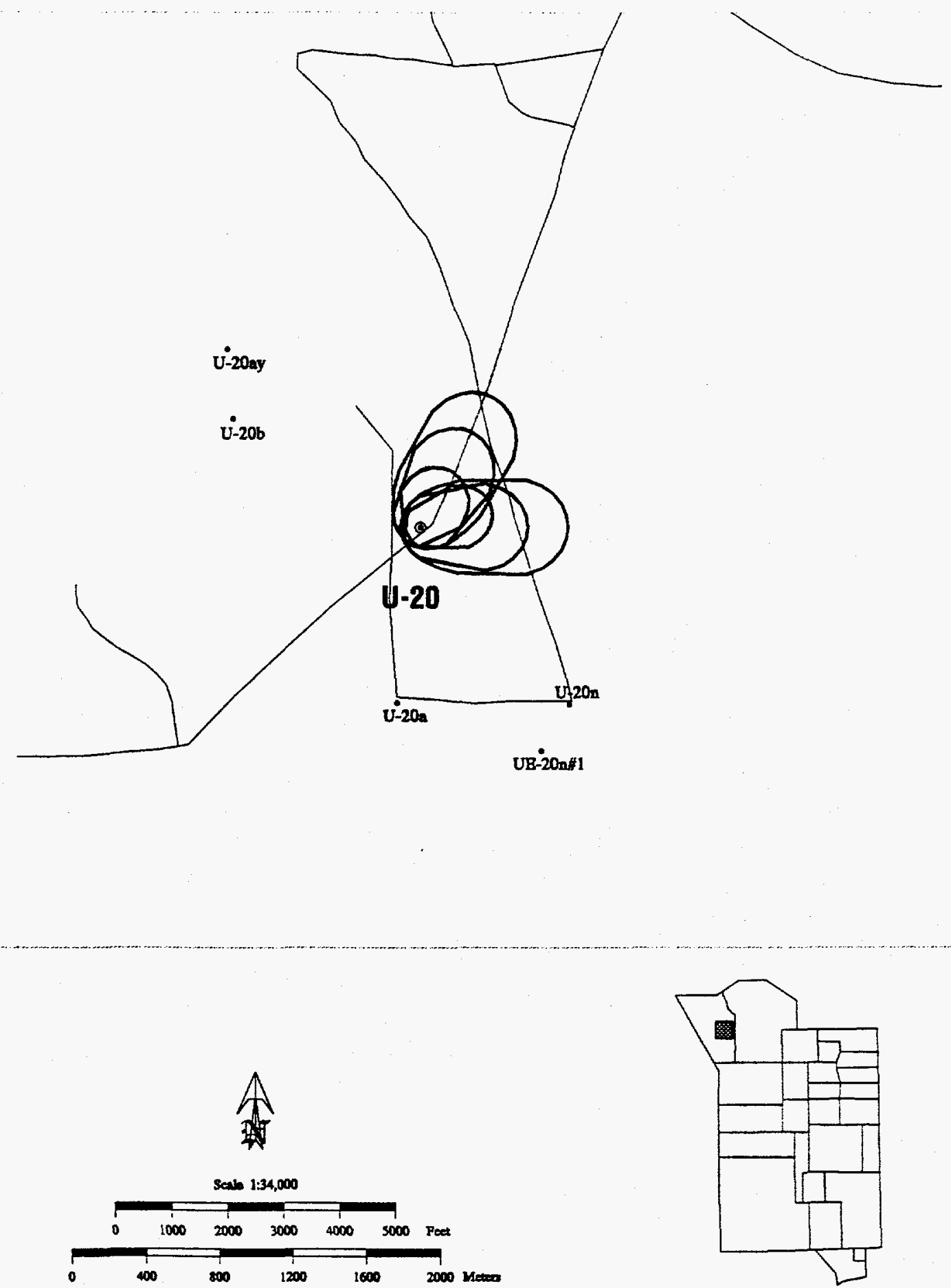

Figure 26c. Five-, 10-and 15-year time dependent capture zones for the $95 \%$ reliability level for U-20. Filled circle indicates a well. 


\section{REFERENCES}

Arteaga, F.E.. C.S. Savard, M.E. Johnson and J.C. Stone, 1991. Hydrogeologic Data from Selected Wells and Test Holes In and Adjacent to the Nevada Test Site. Nye County, Nevada, through 1986, U.S. Geol. Survey Open-File Report 87-536, 23 p.

Bear, J. and M. Jacobs. 1965. On the Movement of Water Bodies Injected into Aquifers, Journal of Hydrology, 3, p. 37-57.

Benjamin, J.R. and C.A. Cornell, 1970. Probability, Statistics, and Decision for Civil Engineers. McGraw-Hill, New York, 684 p.

Blandford, T.N., 1991. U.S. EPA WHPA Model, A Modular Semi-Analytical Model for the Delineation of Wellhead Protection Areas, Version 2.0, American Institute of Hydrology, Minneapolis, $\mathrm{MN}$.

Blankennagel, R.K. and J.E. Weir, Jr., 1973. Geohydrology of the Eastern Part of Pahute Mesa, Nevada Test Site, Nye County, Nevada. U.S. Geol. Survey Prof. Paper 712-B, 35 p.

Boughon, C., 1986. Integrated Geochemical and Hydraulic Analyses of Nevada Test Site Ground Water Systems. Master's thesis, University of Nevada, Reno, 135 p.

McElwee, C.D., 1991. Capture Zones for Simple Aquifers, Ground Water, 29(4), p. 587-590.

Raytheon Services Nevada, 1990. Hole History Data, Water Well \#4A. Draft, 9 p.

Raytheon Services Nevada, Technical Support Division, 1991. Nevada Test Site Drilling and Mining Summary "Red Book," Raytheon Services Nevada.

Sadler, W.R., 1990. A Deuterium-Calibrated, Discrete-State Compartment Model of Regional Groundwater Flow, Nevada Test Site and Vicinity. Master's thesis, University of Nevada, Reno, $249 \mathrm{p}$.

Todd, D.K., 1980. Groundwater Hydrology. John Wiley and Sons, New York, 535 p.

Winograd, I.J. and W. Thordarson, 1975. Hydrogeologic and Hydrochemical Framework, South-Central Great Basin, Nevada-California, with Special Reference to the Nevada Test Site. U.S. Geol. Survey Prof. Paper 712-C, 126 p.

Wood, D., 1993. U.S. Geological Survey, personal communication. 


\section{APPENDIX A}

\section{MATHEMATICAL DEVELOPMENT OF METHODOLOGY FOR WELLHEAD PROTECTION AREA DELINEATION UNDER UNCERTAINTY}




\section{CAPTURE ZONE DELINEATION}

Consider a hypothetical flow system consisting of a single. fully penetrating pumping well in an infinite flow domain with a component of uniform regional flow, schematically shown on Figure 1 in the text.

The complex potential $f(z)$ for the combined flow in the horizontal $(x, y)$ plane is obtained by superposition (Bear and Jacobs, 1965)

$$
f(z)=-q(\cos \alpha-i \sin \alpha) z+\frac{Q}{2 \pi} \ln z ; z=x+i y
$$

having the velocity potential

$$
\phi(x, y)=-q(x \cos \alpha+y \sin \alpha)+\frac{Q}{4 \pi} \ln \left(x^{2}+y^{2}\right)
$$

and the stream function

$$
\psi(x, y)=-q(-x \sin \alpha+y \cos \alpha)+\frac{Q}{2 \pi} \tan ^{-1}\left(\frac{y}{x}\right)
$$

where $q\left[L^{2} / T\right]$ is the mean regional flow integrated over the aquifer thickness, $Q\left[L^{3} / T\right]$ is the well pumping rate, and $\alpha$ denotes the angle between $x$-axis and the direction of uniform regional flow. The velocity components in $x$ and $y$ direction are $v_{x}=-(b n)^{-1} \partial \phi / \partial x, v_{y}=-(b n)^{-1} \partial \phi / \partial y$, where $n$ is the effective porosity and $b$ is the aquifer thickness.

Assuming that all parameters are known with certainty, the single capture zone can be easily derived by setting the stream function $\psi$ equal to zero and solving for

$$
\left(\frac{y}{x}\right)=\tan \left[\frac{+2 \pi q \theta}{Q}\right] \quad y>0 \quad ; \quad\left(\frac{y}{x}\right)=-\tan \left[\frac{+2 \pi q \theta}{Q}\right] y<0
$$

where $\theta=(-x \sin \alpha+y \cos \alpha)$. The above expression is the solution for the ultimate (steady state) capture zone which implies an unlimited pumping and infinite time. Equation (4) is widely used today (Blandford, 1991) to delineate the pumping well capture zone using the parameters estimated from the available field data. For the purpose of deriving the time-dependent capture zones, Bear and Jacobs (1965) followed the equation of pathlines (in the steady flow, pathlines coincide with streamlines) in the flow field given with $d x / v_{x}=d y / v_{y}=d t$. The solution of this equation defines at time $t$ the position of a particle with respect to originating point. The solution is obtained in the dimensionless form as

$$
\exp (\bar{x}-\bar{t})=\cos \bar{y}+\frac{\bar{x}}{\bar{y}} \sin \bar{y}
$$

where $\bar{x}=2 \pi q x / Q, \bar{y}=2 \pi q y / Q$, and $\bar{t}=2 \pi q^{2} t /(n b Q)$. This transcendental equation for time-dependent capture zones is usually solved using some kind of iterative procedure (e.g., 
McElwee, 1991). Both solutions, (4) and (5), are conditioned on the set of parameters which are assumed to be perfectly known. A deterministic solution is based on these representative values for the various model parameters. They usually represent a mean or average value of the system. Since perfect knowledge in model parameters is seldom the case, the influence of the uncertainty becomes a major factor.

Modeling capture zones around pumping wells and understanding the physical nature of its development is fundamental for decision making. The associated risk involved and uncertainty in its evaluation represent an important component of the modeling effort. Risk analysis based on the deterministic solution, which results in single representations of the capture zone, may be insufficient for making decisions about protective areas, and particularly for monitoring measures to be taken to prevent contamination from reaching the water-supply wells.

In other words, the regional flow $q$ is to be considered a random variable instead of a random field which requires the identification of the appropriate spatial structure.

\section{METHODOLOGY TO INCLUDE UNCERTAINTY}

The ability to obtain the capture zones conditioned on the uncertainty in the mean regional flow is a first step in delineating WHPA under uncertainty. In the following, the methodology for analyzing the ultimate capture zone under uncertainty is demonstrated.

Consider the steady state flow condition for the stream function given in (3). Under the uncertainty in the regional flow $q$ and parameter $\theta$, the stream function $\psi(x, y \mid q, \theta)$ is also an uncertain function that is conditioned on the values that $q$ and $\theta$ may obtain. The corresponding unconditional stream function $\psi(x, y, q, \theta)$, i.e., the stream function for all possible values of $q$ and $\theta$, is obtained by using the basic relationship between the conditional and unconditional probabilities, i.e., $\psi(x, y \mid q, \theta)=\psi(x, y, q, \theta) / f(q, \theta)$, where $f(q, \theta)$ is the joint probability distribution function (pdf) of $q$ and $\theta$, obtained in the process of inference of parameter estimates from available field data. Assuming $q$ and $\theta$ are independent, the joint probability distribution function of $q$ and $\theta$ becomes $f(q, \theta)=f(q) f(\theta)$. Including the uncertainties in $q$ and $\theta$ simultaneously to obtain an estimate of the uncertainty in the stream function would lead to an unmanageable solution, thus the uncertainties in $q$ and $\theta$ will be treated separately. First, consider the uncertainty in $q$ with $\theta$ fixed at its mean value $\langle\theta\rangle$. The first two moments of the stream function are now given by

$$
\begin{gathered}
\langle\psi(x, y, q, \theta)\rangle=-\int q \theta f(q) d q+\frac{Q}{2 \pi} \tan ^{-1}\left(\frac{y}{x}\right)=-\langle q\rangle\langle\theta\rangle+\frac{Q}{2 \pi} \tan ^{-1}\left(\frac{y}{x}\right) \\
\sigma_{\psi}^{2}=\int[\psi(x, y, q, \theta)]^{2} f(q) d q-\langle\psi(x, y, q, \theta)\rangle^{2}=\sigma_{q}^{2}(\theta\rangle^{2}
\end{gathered}
$$

where $\langle q\rangle$ and $\langle\theta\rangle$ are means, respectively, of the regional flow $q$ and parameter $\theta$, and $\sigma_{q}^{2}$ is the variance of the flow. 
In general, the mean flow is not measured, but rather estimated indirectly using a form of Darcy's law, $q=T J$. where $T$ is the aquifer transmissivity and $J$ is the hydraulic head gradient. These parameters are estimated from the scarce field data, thus they are subject to an estimation error which produces the total uncertainty in the regional flow estimate. If both $T$ and $J$ are lognormally distributed, then so is $q$, such that the first two moments of the regional flow are $\langle\ln q\rangle=\langle\ln T\rangle^{+}$ $\langle\ln J\rangle$ and $\sigma_{l n q}^{2}=\sigma_{\ln T}^{2}+\sigma_{\ln J}^{2}+2 \varrho \sigma_{\ln T} \sigma_{l n J}$, respectively, where $\varrho$ is the correlation coefficient between $\ln T$ and $\ln J$. The first two moments of $q$ are then readily obtained by converting the moments into

$$
\langle q\rangle=\exp \left(\langle\ln q\rangle+\sigma_{\ln q}^{2} / 2\right)
$$

for the mean and

$$
\sigma_{q}^{2}=\exp \left(2\langle\ln q\rangle+\sigma_{\ln q}^{2}\right)\left[\exp \left(\sigma_{\ln q}^{2}\right)-1\right]
$$

for the variance of $q$. In the case of the parameter $\theta$, which contains the regional flow direction angle $a$, the mean, $\langle\theta\rangle$, is calculated based on the mean $\langle\alpha\rangle$ by

$$
\langle\theta\rangle=-x \sin \langle\alpha\rangle+y \cos \langle\alpha\rangle
$$

The expected value capture zone is obtained by replacing all uncertain parameters with their mean values and in this case, the streamline function maintains the same form as the deterministic solution and is labeled with the probability of 0.5 , as shown on Figure 2a in the text. The other probabilities are produced by evaluating the following expression of the stream function

$$
\langle\psi(x, y, q, \theta)\rangle \pm m \sigma_{\psi}=-\langle q\rangle\langle\theta\rangle+\frac{Q}{2 \pi} \tan ^{-1}\left(\frac{y}{x}\right) \pm m \sigma_{q}\langle\theta\rangle
$$

where $m$ is a real valued number indicating the magnitude of departure from the mean streamline. Setting the left-hand side of (11) to zero, the probabilistic ultimate capture zone solution can be written in the following form

$$
\left(\frac{y}{x}\right)= \pm \tan \left[\frac{-2 \pi\left(\langle q\rangle \pm m \sigma_{q}\right)\langle\theta\rangle}{Q}\right]
$$

An interpretation of the probabilistic ultimate capture zone solution given above can be made by looking at the reliability issue which corresponds to a level of confidence. For a normally distributed variable as seen in Figure $2 \mathrm{~b}$ in the text, the 67 percent level of confidence corresponds to the values of \pm 1 . In equation (12), using $m=-1$ would yield a wider ultimate capture zone than using $m=+1$. Thus, the ultimate capture zone for the 67 percent reliability level would be generated using $m=-1$. For the 95 percent reliability level ultimate capture zone, $m$ would be set equal to -2 . 
The uncertainty in the capture zone caused by the uncertainty in $\alpha$ can be estimated in the same manner based on the reliability level. Assuming $\alpha$ is normally distributed, the chosen reliability level will lead to an $m$ value that is used in equation (12) to obtain the dimensions of the capture zone and is also used in the following equation

$$
\langle a\rangle \pm m \sigma_{a}
$$

to obtain the two angles corresponding to the same reliability level. The envelope of the capture zone is obtained by plotting the capture zone determined from equation (12) about the two angles obtained in equation (13), as shown in Figure 3 in the text. This envelope represents the area of the capture zone given the uncertainties in $q$ and $\alpha$ at a certain reliability level. 


\section{DISTRIBUTION}

Desert Research Institute

Roger Jacobson

Desert Research Institute

Water Resources Center

P.O. Box 19040

Las Vegas, NV 89132-0040

Marjory Jones

Desert Research Institute

Water Resources Center

P.O. Box 60220

Reno, NV 89506-0220

International Technology Corp.

Rick Waddell

Geotrans, c/o IT

4330 Valley View

Suite 112, MS-439

Las Vegas, NV 89103

Joe Yeasted

International Technology Corporation

4330 S. Valley View

Suite 114

Las Vegas, NV 89103

\section{Lawrence Livermore National Laboratory}

Lee Davisson

Nuclear Chemistry Division

Lawrence Livermore National Laboratory

P.O. Box 808

L-237

Livermore, CA 94550

Greg Nimz

Lawrence Livermore National Laboratory

P.O. Box 808

MS L233

Livermore, CA 94550
Los Alamos National Laboratory

Joe Thompson

Los Alamos National Laboratory

INC-11, MS J514

P.O. Box 1663

Los Alamos, NM 87545

Raytheon Services Nevada

Stuart E. Rawlinson

Raytheon Services Nevada

P.O. Box 95487, M/S 580

Las Vegas, NV 89193-5487

Reynolds Electrical \& Engineering Co.

Martha DeMarre

Chief, Document Research Section

Health Protection Dept.

Reynolds Electrical \& Engineering Co.

P.O. Box 98521

Las Vegas, NV 89193-8521

Brian Dozier

Reynolds Electrical \& Engineering Co.

2501 Wyandotte

Mercury, NV 89102

\section{State of Nevada}

Larry Franks

Nevada State Health Department

Radiological Health Section

620 Belrose Avenue

Las Vegas, NV 89158

\section{U.S. Department of Defense}

David Bedsun

Defense Nuclear Agency

Field Command

Nevada Operations Office

P.O. Box 208

Mercury, NV 89023-0208 


\section{U.S. Department of Energy}

Gylan Allen, Director

Test Operations Division

Nevada Operations Office

U.S. Department of Energy

P.O. Box 98518

Las Vegas, NV 89193-8518

Bob Bangerter

Environmental Restoration Division

Nevada Operations Office

U.S. Department of Energy

P.O. Box 98518

Las Vegas, NV 89193-8518

Joanne M. Bradbery, Director

Contracts Division

Nevada Operations Office

U.S. Department of Energy

P.O. Box 98518

Las Vegas, NV 89193-8518

Doug Duncan

Hydrology Program Manager

Office of Environmental Restoration

and Waste Management

Nevada Operations Office

U.S. Department of Energy

P.O. Box 98518

Las Vegas, NV 89193-8518

Donald Elle, Director

Environmental Protection Division

Nevada Operations Office

U.S. Department of Energy

P.O. Box 98518

Las Vegas, NV 89193-8518

Joseph N. Fiore, Acting Assistant Manager Office of Environmental Restoration

and Waste Management

Nevada Operations Office

U.S. Department of Energy

P.O. Box 98518

Las Vegas, NV 89193-8518
Joseph M. Ginanni

Waste Management Division

Nevada Operations Office

U.S. Department of Energy

P.O. Box 98518

Las Vegas, NV 89193-8518

Joseph H. Kitchen

Project Control and Technology

Development Division

Nevada Operations Office

U.S. Department of Energy

P.O. Box 98518

Las Vegas, NV 89193-8518

Steve Lawrence

Environmental Restoration Division

Nevada Operations Office

U.S. Department of Energy

P.O. Box 98518

Las Vegas, NV 89193-8518

Steve Leedom

Test Operations Division

Nevada Operations Office

U.S. Department of Energy

P.O. Box 98518

Las Vegas, NV 89193-8518

Steve Mellington, Director

Environmental Restoration Division

Nevada Operations Office

U.S. Department of Energy

P.O. Box 98518

Las Vegas, NV 89193-8518

Richard Pearl

Environmental Protection Division

Nevada Operations Office

U.S. Department of Energy

P.O. Box 98518

Las Vegas, NV 89193-8518

\section{U.S. Geological Survey}

Virginia Glanzman

U.S. Geological Survey

Box 2506, MS 913

Denver Federal Center

Denver, CO 80225 
Randy Laczniak

U.S. Geological Survey

Water Resources Division

6770 S. Paradise Rd.

Las Vegas, NV 89119

Paul Orkild

U.S. Geological Survey

Box 2506, MS 913

Denver Federal Center

Denver, CO 80225

Doug Trudeau

U.S. Geological Survey

Water Resources Division

6770 S. Paradise Rd.

Las Vegas, NV 89119

\section{LIBRARIES}

Annie Kelley

State Documents Department

Nevada State Library

Capitol Complex

Carson City, NV 89710

Archives

Getchell Library

University of Nevada, Reno

Beverly Carter

MacKay School of Mines Library

University of Nevada, Reno

Document Section, Library

University of Nevada, Las Vegas

4505 Maryland Parkway

Las Vegas, NV 89154
Library (Stead)

Desert Research Institute

P.O. Box 60220

Reno, Nevada 89506-0220

Library

IT Corporation

4330 S. Valley View

Suite 114

Las Vegas, NV 89103

ATTN: Toni Miller

Library

Southern Nevada Science Center

Desert Research Institute

P.O. Box 19040

Las Vegas, NV 89132-0040

Technical Information Resource Center

Nevada Operations Office

U.S. Department of Energy

P.O. Box 98518

Las Vegas, NV 89193-8518

Librarian

Water Resources Center Archives

$4100^{\prime}$ Brien Hall

University of California

Berkeley, CA 94720-1718 